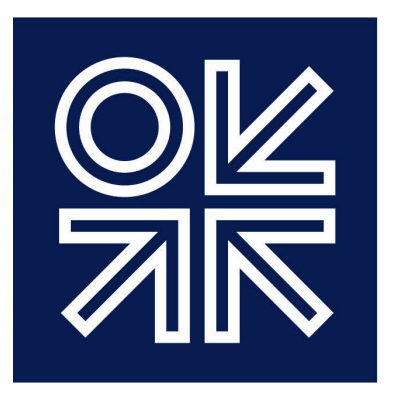

THE OXFORD

INSTITUTE

FOR ENERGY

STUDIES

September 2015

\title{
The cost of price de-linkages between European gas hubs
}



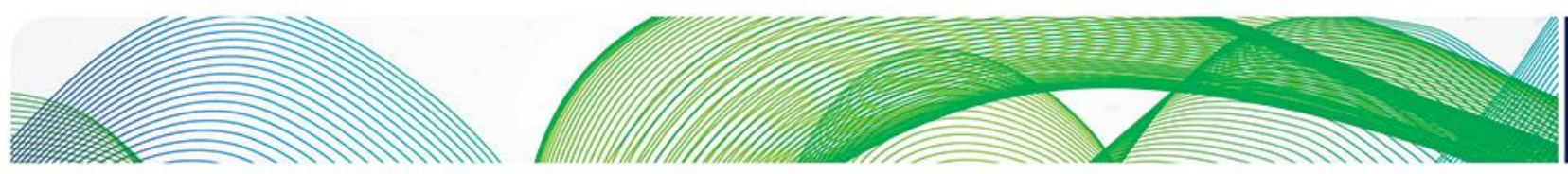

\section{O는}

The contents of this paper are the authors' sole responsibility. They do not necessarily represent the views of the Oxford Institute for Energy Studies or any of its members.

Copyright $\odot 2015$

Oxford Institute for Energy Studies

(Registered Charity, No. 286084)

This publication may be reproduced in part for educational or non-profit purposes without special permission from the copyright holder, provided acknowledgment of the source is made. No use of this publication may be made for resale or for any other commercial purpose whatsoever without prior permission in writing from the Oxford Institute for Energy Studies.

ISBN 978-1-78467-038-2 

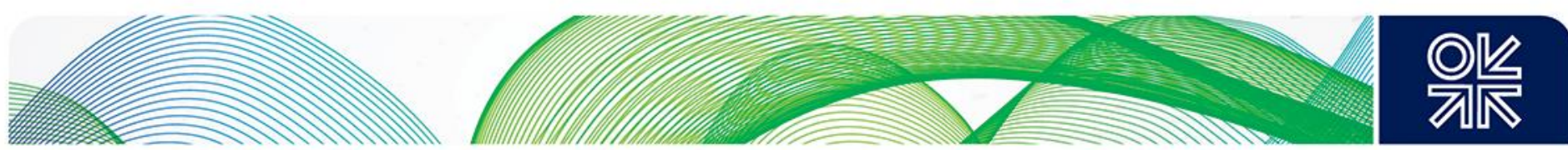

\section{Preface}

The growth of trading activity on Europe's gas hubs and access to anonymised OTC price data provides the OIES Gas Programme with the opportunity to analyse and draw conclusions on issues of direct relevance to policy makers and market participants. With 2014 data available, the objective of this paper is primarily to explore the extent to which conclusions reached in the Author's previous papers have changed.

As trading volumes and liquidity increase one would expect to see price correlations across market geography improve, and indeed this is the general trend observed in this paper. Of equal interest however are the anomalies to this trend which may be one-off or recurrent in nature. Beatrice identifies such 'de-linkages' and with reference to the work of market monitoring groups and using data on infrastructure capacities and flowrates which has recently become more widely available, applies a forensic approach to assessing the prime causes for such episodes - whether due to physical or contractual congestion.

With the IGU's annual price survey data available at a national market level, a measure of the financial impact on consumers of such price de-linkages is also estimated, helping to focus the minds of policy makers on appropriate actions to ensure the free flow of gas across interconnection points. As the future pattern of gas flows inevitably changes over time, due to LNG import level fluctuations, pipeline import patterns changing and a more diverse supply pattern from the European core to eastern Europe and indeed Ukraine, we should expect this to be a continuing and dynamic challenge.

The Oxford Institute for Energy Studies Natural Gas Research Programme undertakes research over a wide spectrum of supply and demand side developments, geo-political considerations and supply security issues as well as price formation evolution. The ability to reach timely and relevant conclusions through leading edge quantitative analysis such as that demonstrated in this paper is an extremely important capability. I am grateful to the Author for her commitment, diligence and application in this field of research.

Howard Rogers

Oxford 2015 

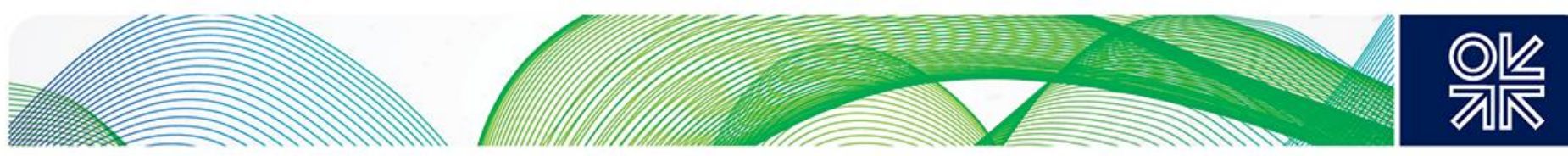

\section{Acknowledgements}

I am very grateful for the support I received from the Oxford Institute for Energy Studies. In particular, I am very grateful to Howard Rogers and Jonathan Stern, who shared with me helpful suggestions and precious inputs. I must also thank the Tankard Parties for providing data for this project. I am really grateful for the insightful comments received, especially during the Gas Programme Sponsors' Meetings, conferences and workshops where I presented preliminary findings from this work. My grateful thanks also go to all who found this research topic interesting and shared their comments and valuable insights with me.

I also would like to thank John Elkins for its excellent editing and Kate Teasdale.

I would like to thank the sponsors of the Natural Gas Research Programme (OIES) for their support and useful remarks.

Thank you to all who supported and encouraged me during this research project.

I am, however, fully responsible for any remaining shortcomings and errors. 

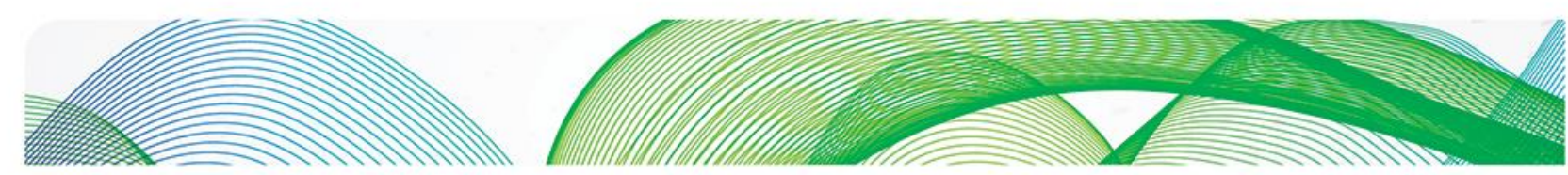

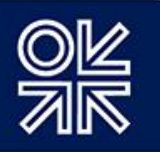

\section{Contents}

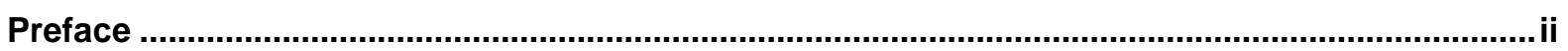

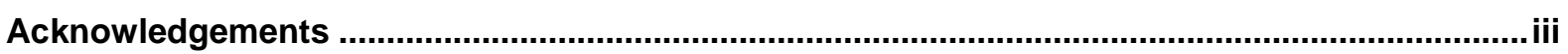

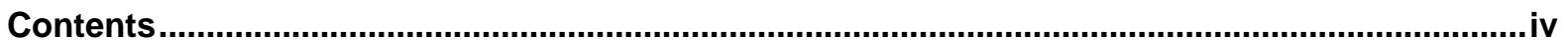

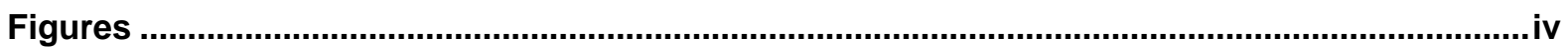

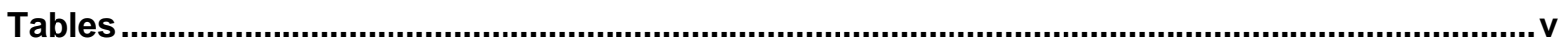

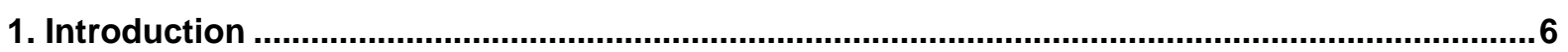

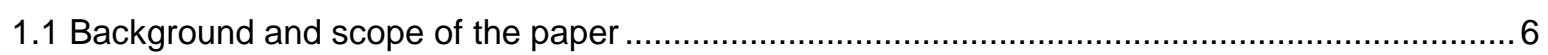

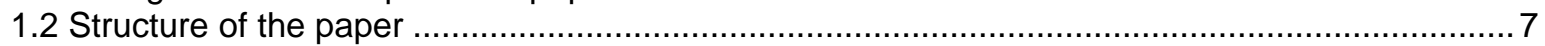

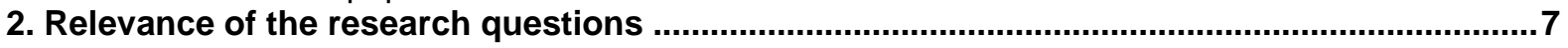

3. Related literature

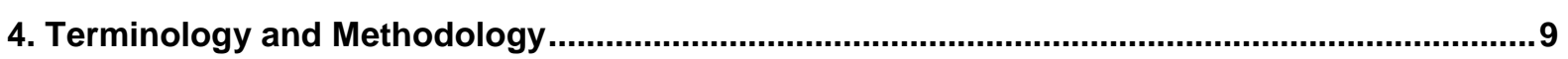

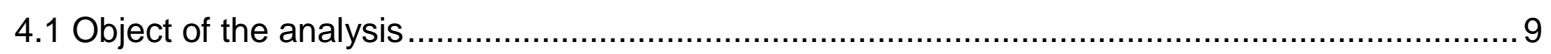

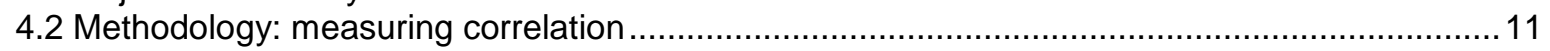

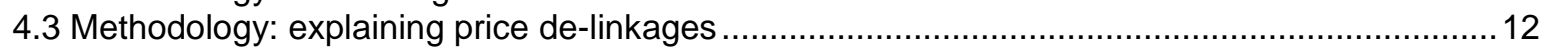

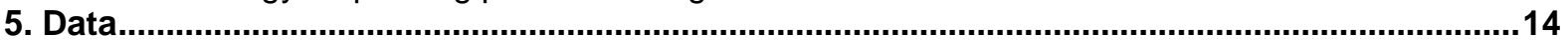

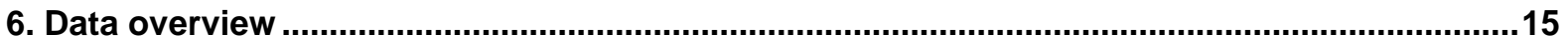

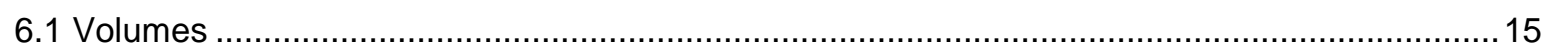

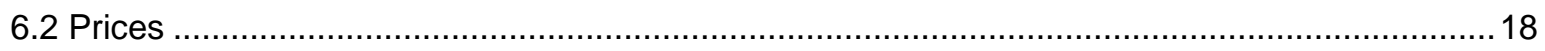

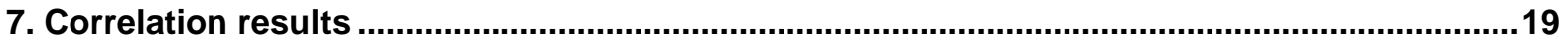

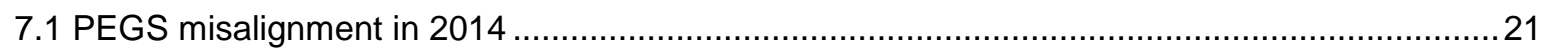

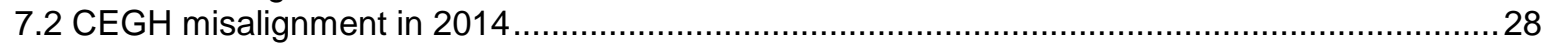

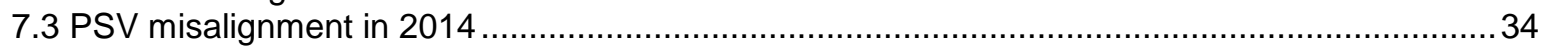

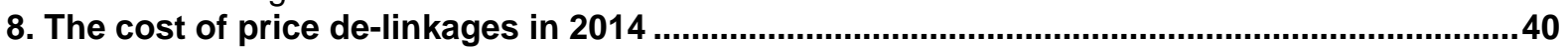

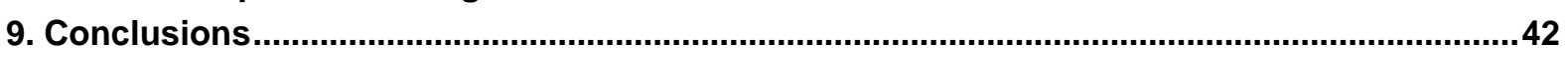

Appendix 1. Methodological notes on data creation ..............................................................

Appendix 2. Methodology to compute firm technical capacity and capacity utilization rate from

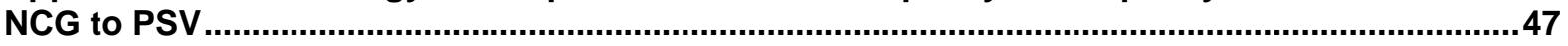

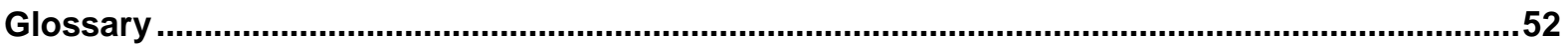

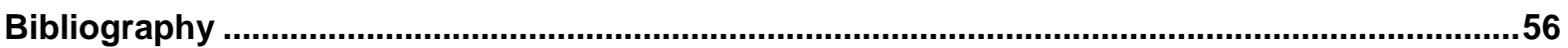

\section{Figures}

Figure 1: Illustrative de-linkage .............................................................................................. 12

Figure 2: Test to explain the nature of price de-linkages............................................................. 13

Figure 3: Total gross traded volumes, OTC market (TWh and \% of total EU28 consumption) ............16

Figure 4: Total gross traded volumes, OTC market by hub (TWh) ............................................... 16

Figure 5: Breakdown of number of OTC trades by product in 2014 (\% compared to total hub trades) 17 Figure 6: OTC DA traded volumes (left axis) and number of day ahead trades (right axis) in 2014 by

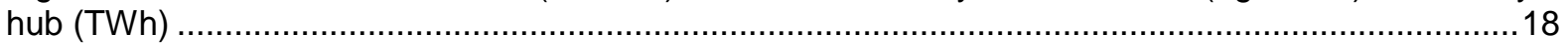

Figure 7: OTC Day ahead prices for European hubs in 2014 (€/MWh) .........................................18

Figure 8: Cross correlations between OTC day ahead daily prices (Pearson coefficients \%) .............19

Figure 9: Correlations between OTC day ahead daily prices for selected groups of hubs (Pearson

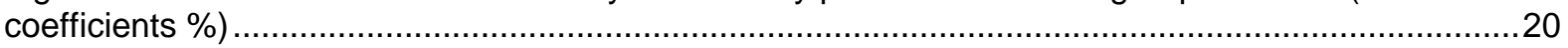

Figure 10: NCG, PEGS and PEGN OTC day ahead prices in 2012-2014 ..................................21 

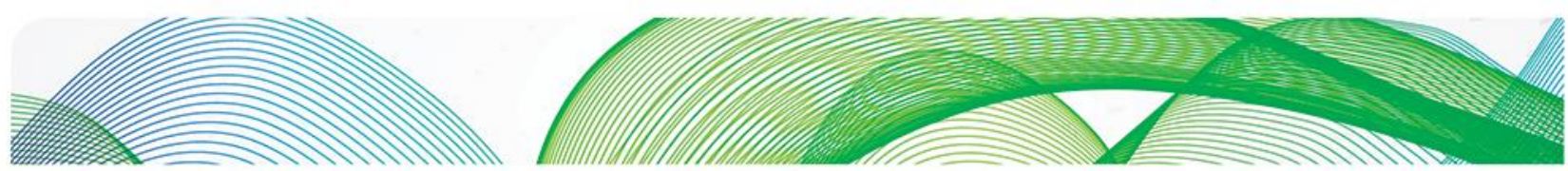

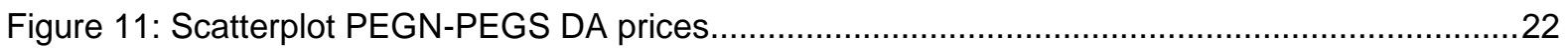

Figure 12: Absolute difference between PEGS DA price and PEGN DA price (€/MWh) ...................23

Figure 13: PEGS-PEGN OTC day ahead price spread (€/MWh) and utilization rate of the N-S link (\%)

Figure 14. Send-outs from French regasification terminals (monthly totals, $\mathrm{mcm}$ ), spread between PEGS DA and PEGN DA (€/MWh).

Figure 15: Quantities unloaded at Fos Cavaou terminal and LNG imports into French terminals (monthly totals, GWh)

Figure 16: Effective Capacity on the N-S link as a share of maximum technical capacity, spread between PEGS DA and PEGN DA (€/MWh)

Figure 17: Physical flows and technical physical capacity from PEGS to PEG TIGF at Interconnection

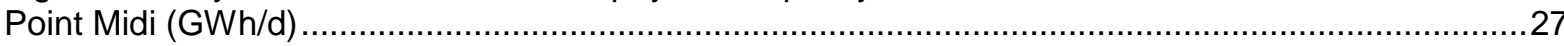

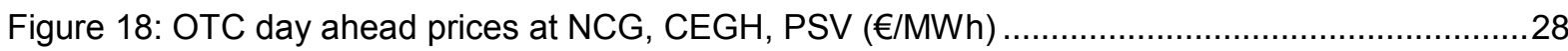

Figure 19: OTC day ahead price spread between NCG and CEGH (€/MWh) .................................2

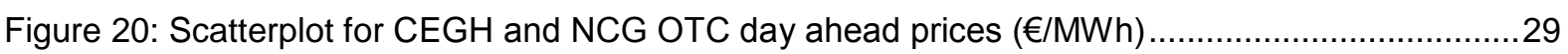

Figure 21: A simplified scheme for Oberkappel IP......................................................................

Figure 22: Firm Technical Capacity data for Oberkappel exit and entry, direction from DE to AT

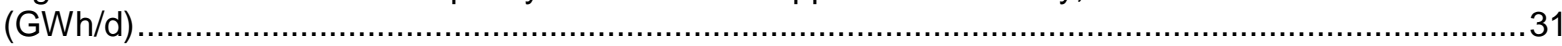

Figure 23: Physical Flows and Firm Technical Capacity data for Oberkappel exit from DE to AT $(\mathrm{GWh} / \mathrm{d})$.

Figure 24: Monthly flows and maximum flow capacity data for Oberkappel IP (DE->AT) (GWh/month)

Figure 25: Oberkappel IP (DE->AT) utilization rate and day ahead price spread between NCG and CEGH (\% and $€ / M W h)$.

Figure 26: Scatterplot: CEGH-NCG day ahead spread against utilization rate at Oberkappel IP, direction: NCG->CEGH ( $€ / M W h, \%)$...

Figure 27: Median OTC DA price spread between PSV and NCG against the price correlation scores

Figure 28: PSV-NCG DA OTC price spread, estimated reference level and estimated transmission charge from NCG to PSV (€/MWh).

Figure 29: Scatterplot for PSV-NCG DA OTC prices (€/MWh)......

Figure 30: Simplified representation of Wallbach and Gries Pass IP

Figure 31. Wallbach IP utilization rate and OTC day ahead price spread and $€ / M W h)$.

Figure 32: Gries Pass IP Utilization rate (CH-PSV, entry side) and day ahead price spread between NCG and PSV (\% and $€ / M W h)$.

Figure 33: PSV-NCG OTC day ahead price spread ( $€ / M W h)$ and utilization rate of the transmission capacity from NCG to PSV (\%).

Figure 34: Scatterplot: PSV-NCG day ahead spread against utilization rate of the transmission capacity connecting NCG to PSV

Figure 35: Estimated consumption subject to price increase (TWh) and cost of de-linkage in 2014 (€million)

\section{Tables}

Table 1: Sources for exchange prices used in this study 

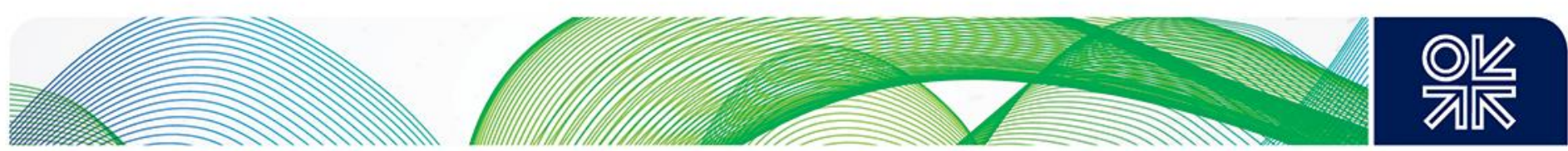

\section{Introduction}

\subsection{Background and scope of the paper}

Research papers published by OIES in 2013 and $2014^{1}$ have identified generally good correlation between European hub 2 prices in the January 2007-October 2013 period. Exceptions to good correlation, however, occur in periods where pipeline bottlenecks (physical or contractual) or closure (for maintenance) have caused a 'de-linkage' between prices at the main North Western European hubs and typically those of Italy (PSV), Austria (CEGH), Southern France (PEG Sud) and at times UK (NBP).

ACER reports the same finding in its 2014 Market Monitoring Report ${ }^{3}$ and comments that one of the main reasons for this was the re-negotiation of long term contract conditions where hub prices have been increasingly used as a reference or discounts have been granted, placing downward pressure on prices in higher priced markets.

However the causes of price de-linkages could not be fully explored in the Author's 2014 work $^{4}$, due to lack of reliable and consistent data on gas flows between the markets, in particular as far as the Italian and the Austrian hubs were concerned.

A great effort has been made by the Association of European Transmission System Operators (ENTSO-G) to bring about more transparency and consistency on data describing the use of interconnecting infrastructures. After the last OIES paper on hub price correlation was published, an upgraded version of the ENTSO-G Transparency Platform came online, disclosing flow data for all European interconnection points (IPs) starting from January 2014 and paving the way for a more robust analysis of the factors driving de-linkages.

The scope of this paper is to analyse the more recent evolution (up to December 2014) of price correlation across European hubs and investigate in more depth the causes of price de-linkages between the main European hubs. We rely on a new set of data on trades, which was made available by the Tankard Parties in 2015.

The key research questions are the following:

- In 2013 we saw a decrease in the overall price correlation coefficient, due to de-linkages between the main North Western Europe hubs and CEGH, PSV and PEG South: has anything changed in 2014 ?

- Are there any periods of low correlation ("de-linkages")? May these be explained by physical/contingent factors (using data on pipeline flows and capacity)?

- Can we better investigate the drivers behind price de-linkages using evidence on flow data from the ENTSO-G Transparency Platform?

- Can we provide a rough measure for the cost of price de-linkages?

\footnotetext{
Petrovich (2013), Petrovich (2014).

${ }^{2} \mathrm{~A}$ gas hub is the location, physical or virtual, where a traded market for gas is established ${ }^{3}$ ACER (2014a), P.172

${ }^{4}$ Petrovich (2014)
} 

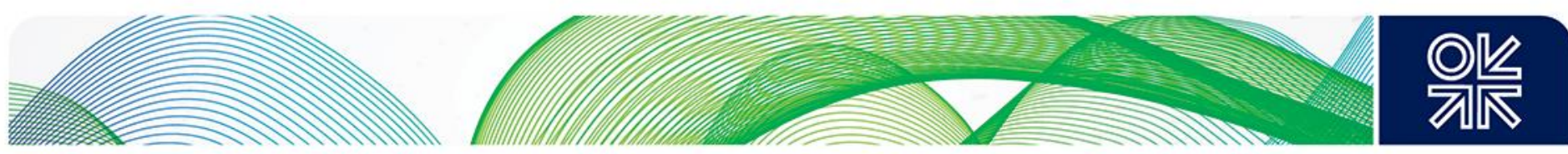

\subsection{Structure of the paper}

The paper is organized as follows. Chapter 2 discusses the relevance of the research question, Chapter 3 presents related literature. Chapter 4 illustrates the terminology and methodology, while Chapter 5 presents the data.

After an overview of data (price and volume patterns) in Chapter 6, Chapter 7 is dedicated to correlation analysis and to the analysis of the drivers of price de-linkages. Chapter 10 attempts to provide a rough measure for the cost of price de-linkages. Chapter 9 concludes.

\section{Relevance of the research questions}

Price alignment ("correlation") is a relatively simple metric which tells us something about both the degree of integration between different markets (or hubs) and the extent to which prices in these markets are the result of demand and supply forces ${ }^{5}$.

Parallel price movements suggest that there are no barriers to trade across borders, and no evidence of price manipulation or anticompetitive behaviour by local players. When the prices of a commodity quoted in different interconnected markets move in tandem, and transportation costs can be considered constant over time ${ }^{6}$, this suggests that the freedom to trade the commodity across borders is driving to zero any price differentials above transportation costs. Good price correlation between European gas hubs supports the argument that hub prices are the result of supply and demand forces, rather than being determined by other factors, such as indexation to the price of other commodities (oil in particular).

While the creation of a single European gas market is an important goal of the European Union energy policy, reliable market-based hubs are the natural candidates to provide reliable gas price benchmarks in the transition away from oil-indexed pricing ${ }^{7}$ in long term gas contracts.

Strong price alignment is, however, only a necessary, not a sufficient, condition for the absence of barriers to trade and competitive markets ${ }^{8}$; this said, correlation metrics provide easy-to-understand measures indicating where there is a need for a more in-depth assessment.

Analysing the evolution of price correlation between adjacent markets helps to identify the periods when prices are less strongly correlated (price de-linkages) and when, therefore, it is likely that barriers are preventing gas from flowing across borders.

Once these episodes are identified, the nature of such de-linkages can be explored, as we attempt to do in this paper, in particular with the aim of distinguishing whether the issue is physical or nonphysical. This exercise has relevant policy implications as different measures will need to be undertaken depending on the nature of the de-linkage's drivers, assuming that the policy maker is interested in avoiding price misalignments. Physical barriers (so called "physical congestion") can be solved by additional investment in the infrastructure, non-physical ones instead need to be addressed by rules which optimize the use of existing infrastructures. The most relevant non-physical barrier to

\footnotetext{
${ }^{5}$ For a more detailed discussion, including a review of possible downsides of this approach, please refer to Petrovich (2014) and Petrovich (2013).

${ }^{6}$ Alternatively, they account for a little source of volatility. We consider this a realistic assumption for natural gas. For discussion please refer to Petrovich $(2013,2014)$

${ }^{7}$ Which has been successfully anticipated and tracked by OIES Gas Programme research: see amongst others Stern, and Rogers (2011).

${ }^{8}$ For further discussion please refer to Petrovich $(2013,2014)$
} 

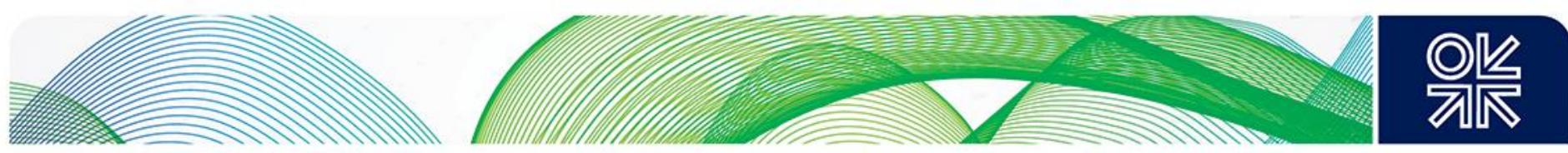

trade is contractual congestion, which happens if physical interconnecting capacity is available but is reserved by some users but not fully used, possibly with a commercial aim.

In the context of European gas market liberalization, contractual congestion is seen as an urgent issue, to the point that a fast-track procedure has been envisaged for designing congestion management procedures (CMPs) at EU level ${ }^{9}$ and the Agency of European Energy Regulators (ACER) has been required to continuously monitor contractual congestion occurrences in Europe, as well as implementation of CMPs in the Member States ${ }^{10}$. Further, according to CMP Guidelines, ${ }^{11} \mathrm{a}$ very strict CMP (the "firm day ahead use it or lose it", FDA-UIOLI' ${ }^{12}$ ) should automatically apply in July 2016 to contractually congested interconnection points, as identified by ACER's monitoring report. This said, views differ on how contractual congestion can be effectively detected and distinguished from physical congestion, as discussed in Chapter 4 . So it is appropriate to devote some discussion to the determination of a robust methodology to spot contractual congestion.

Finally, another relevant issue addressed in this work is the 'cost' of price de-linkages, which may be highly relevant from a policy point of view, especially in the assessment of the costs and the benefits of debottlenecking initiatives.

\section{Related literature}

For a literature review of studies on gas price correlation and gas price convergence (convergence not correlation is taken into account in many other works) please refer to the previous paper by this Author ${ }^{13}$.

As far as the analysis of congestion of transmission capacity is concerned, ACER published two reports on contractual congestion at interconnecting points' sides across the EU (in September 2014 ${ }^{14}$ and in May 2015 ${ }^{15}$ ). It is important here to note that interconnecting points (IPs) have capacity specified by the system operators operating the networks up and downstream of the IP - or each 'side' of the IP.

The first ACER Congestion Monitoring Report (published in 2014) indicated contractual congestion at one third of the relevant IP sides during the last quarter of 2013. At the same time, the report admits that supporting data evidence was poor and incomplete, therefore preventing the report from offering a full picture on IP congestion. The methodology used in the report to spot contractual congestion, in the sense laid down by the Regulation 715/2009, is twofold: when auctions for the allocation of

\footnotetext{
${ }^{9}$ CMPs were approved by European Commission Decision of 24 August 2012 on amending Annex I to Regulation (EC) No $715 / 2009$ of the European Parliament and of the Council on conditions for access to the natural gas transmission networks (2012/490/EU), OJ L 213/16, 28.8.2012

${ }^{10}$ Both the Congestion Monitoring Report and the Implementation Monitoring rRport are obligatory tasks of ACER (the legal basis for the Congestion Monitoring Report is provided in paragraph 2.2.1.2 of the European Commission Decision of 24 August 2012 on amending Annex I to Regulation (EC) No 715/2009 of the European Parliament and of the Council on conditions for access to the natural gas transmission networks (2012/490/EU). The Congestion Report focuses on the question whether actual congestion has occurred at IPs. The Implementation Monitoring Report focuses on the question whether the CMP provisions have been implemented, and what their effects have been. So far two Congestion Monitoring Reports have been published, in 2014 and in 2015: ACER (2014b) and ACER (2015c).

${ }^{11}$ European Commission Decision of 24 August 2012 on amending Annex I to Regulation (EC) No 715/2009 of the European Parliament and of the Council on conditions for access to the natural gas transmission networks (2012/490/EU), OJ L 213/16, 28.8.2012

12 This is a restriction of re-nomination right of capacity. See Glossary.

13 Petrovich (2013)

${ }^{14}$ ACER (2014b)

${ }^{15}$ ACER (2015c)
} 

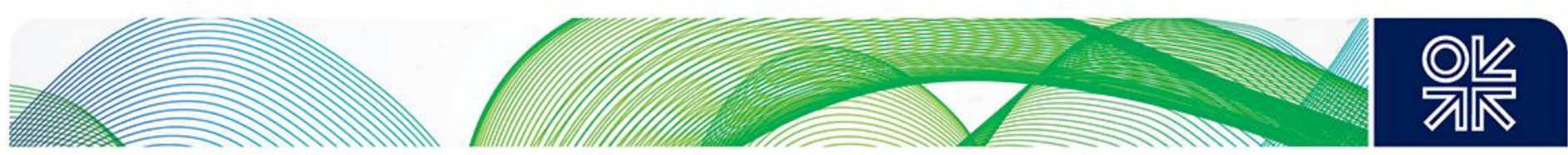

transmission capacity are in place, contractual congestion is indicated by auctions clearing with an auction premium; when auctions are not yet in place $^{16}$ then contractual congestion is indicated by a situation where firm capacity is fully booked; demand for interruptible capacity products is also taken into account, as a proxy for potential interest for additional firm capacity .

ACER's first congestion report has apparent contradictory conclusions:

- Most congestion was identified in North West Europe, which may be actually at odds with the very good price correlation featured by gas hubs in this region (as shown in this work).

- The IUK pipeline is regarded as contractually congested in the last quarter of 2013 , while an analysis of flow data reveals that the de-linkages of the British market have instead an underlying physical explanation.

- Some IPs that were found contractually congested already have FDA UIOLI ${ }^{17}$, despite this measure being regarded as the "ultimate remedy" against contractual congestion. (IPs that were found to be congested in 2014 and 2015 are potentially subject to the mandatory application of FDA UIOLI from July 2016).

ACER's second congestion report (published in May 2015) covers the 2014 period, underpinned by a largely improved data set based on auction and gas flows. Using the same methodology as in the first issue, it detects contractual congestion at about $15 \%$ of IP sides across the EU. Most contractual congestion is found in the South and South-East region. In the North-West region the congestion is detected but ACER states that it is mitigated by active secondary trading and CMP application. The report also contains an analysis of price spreads between adjacent market zones in congested versus non congested situations ${ }^{18}$.

The ACER 2014 Market Monitoring Report provides a similar exercise to the determination of the cost of price de-linkages: ACER computes the potential annual net welfare gain if cross-border transmission capacities were fully used ${ }^{19}$. For the PSV the maximum annual net welfare gain is estimated at around 270 million euro/year ${ }^{20}$, however, according to ACER's analysis, this figure can range widely depending on the assumption made on how much margin is left to the new entrant using the additional "freed" capacity.

\section{Terminology and Methodology}

\subsection{Object of the analysis}

To explain the object of the analysis, first of all, we need to define the prices being examined ${ }^{21}$ in terms of:

- Geographical market

- Product or contract

- Time interval of prices

\footnotetext{
${ }^{16}$ According to the European Network Code on Capacity Allocation Mechanisms (Commission Regulation (EU) No 984/2013 of 14 October 2013 establishing a Network Code on Capacity Allocation Mechanisms in Gas Transmission Systems and supplementing Regulation (EC) No 715/2009 of the European Parliament and of the Council, OJ L273/5, 15.10.2013) transmission capacity at EU IPs shall be allocated through auctions by November 2015

${ }^{17}$ For instance, Oude Statenzijl H entry into Gaspool market area from the Netherlands. Out of 118 IP sides that were classified as "contractually congested", 73 were already subject to FDA UIOLI. Source: ACER (2014b) P.10 and P. 20

${ }^{18}$ ACER (2015c) P.20-21.

${ }^{19}$ See ACER (2014a), P.183-184.

${ }^{20}$ This is the net welfare gain assuming physical capacity optimization and that the new entrant sells gas with a $25 \%$ profit. Refer to ACER (2014a), P.182-184, for details.

${ }^{21}$ Refer to Petrovich $(2013,2014)$ for further details.
} 

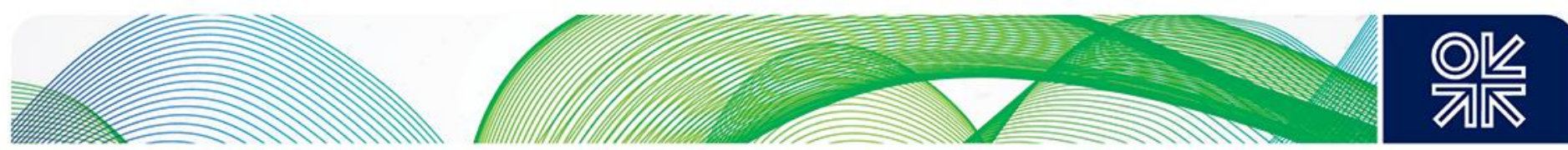

Geographical location. As one of the aims of the paper is exploring whether there are geographical differences in gas price patterns across Europe, it is important to define which price areas we are considering. We limit our attention to gas traded at the following locations or hubs ${ }^{22}$ :

- National Balancing Point (NBP), based in Great Britain with prices quoted in pence/therm ${ }^{23}$

- Title Transfer Facility (TTF), based in the Netherlands with prices quoted in euro/MWh

- Zeebrugge Hub (ZEE), based in Belgium with prices quoted in pence/therm ${ }^{24}$

- Central European Gas Hub $(\mathrm{CEGH})^{25}$, based in Austria with prices quoted in euro/MWh

- Gaspool (GSL), based in Germany with prices quoted in euro/MWh

- Net Connect Germany (NCG), based in Germany with prices quoted in euro/MWh

- Point d'Echange de Gaz Nord (PEGN), based in France with prices quoted in euro/MWh

- Point d'Echange de Gaz Sud (PEGS), based in France with prices quoted in euro/MWh26

- Punto di Scambio Virtuale (PSV), based in Italy with prices quoted in euro/MWh.

These hubs were chosen based on Heather (2012), with the exception that PEGS and PEGN have been treated separately, as, starting from 2012 we observed a de-linkage between the two main French hubs ${ }^{27}$ so it is appropriate that they should be considered as separated price areas.

Product. Gas may be traded using a wide range of trading contracts or products differentiated essentially by the future delivery period. In order to avoid time frame inconsistency, when computing correlation between different hubs, we consider prices that, although implying delivery at different geographical locations, refer to the same delivery timeframe (that is: we use the same contract).

We chose ${ }^{28}$ the "over the counter" contract representing a firm commitment to buy or sell a uniform quantity of gas in the following trading day 29 (that is: OTC DA contract). The day ahead product is the most liquid contract across all the hubs, as shown in Chapter 6.

\footnotetext{
${ }^{22} \mathrm{~A}$ gas hub is a virtual or physical location within the grid where the exchange of gas volumes takes place. In fact a gas hub is a market for gas, where the commodity is traded on a standardized basis between market participants.

${ }^{23}$ For purposes of analysis these data are converted to $€ / M W h$ prior to correlation computations using daily exchange rates (refer to Appendix I for details). This suggests that the $£ / €$ exchange rate is implicitly taken into account by traders arbitraging between NBP and continental hubs.

${ }^{24}$ For purposes of analysis these data are converted to $€ / M W h$ prior to correlation and volatility computations using daily exchange rates (refer to Appendix I for details). This suggests that the $£ / €$ exchange rate is implicitly taken into account by traders arbitraging between NBP and continental hubs.

${ }^{25}$ With the launch of the new Austrian Gas Act in January 2013, trading within the Austrian market changed from a flangebased system to an Entry/Exit regime. Trading activities are now centralized at the Virtual Trading Point (VTP), which is operated by CEGH. For the sake of easy comparison to previous papers by this Author we simply name it CEGH, however it should be noted that strictly speaking CEGH is only the name of exchange now, not the name of trading hub/point, which is VTP.

${ }^{26}$ In April 2015 the French Southern market areas of PEG TIGF and the PEGS (managed by Southern GRTgaz) merged and the new "Trading Region South" (TRS) hub was created, replacing the existing GRTgaz PEG Sud and the TIGF market areas. As a consequence of this, as from 1 April 2015, shippers will no longer have to subscribe capacities to the interconnection of the two networks. Source: https://www.eex.com/en/about/newsroom/news-detail/pegas-introduces-trading-for-new-commonmarket-area--trs--in-southern-france-on-31-march---trs-to-replace-existing-peg-sud-and-peg-tigf-market-areas/84950 ${ }^{27}$ Petrovich (2013).

${ }^{28}$ Refer to Petrovich (2013) for a detailed discussion and references.

${ }^{29}$ Note that if the trading day is Friday then the delivery day is the following Monday.
} 

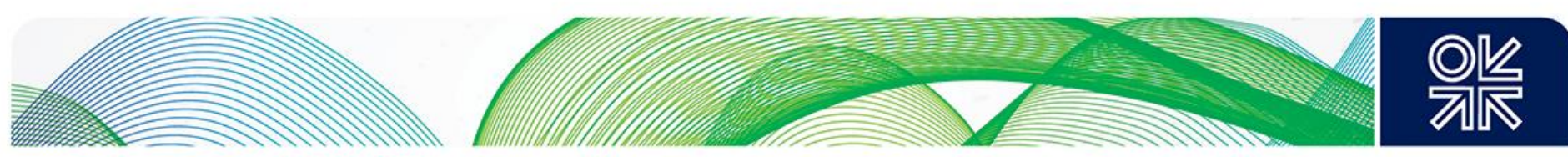

We chiefly focus on OTC market data as, in general, OTC remains the predominant source of trading in Europe $^{30}$, however where relevant we also consider the exchange price (especially in the case of the French energy exchange, Powernext).

Time interval. We consider a daily time interval by looking at daily weighted average prices (WAP), computed by averaging over all the trades in the sample executed in a given day, weighting them according to the corresponding volume. Note that in the literature end-of-day (or settlement prices) are often used. However we found that the difference between WAP and end-of-day prices is not significant ${ }^{31}$.

\subsection{Methodology: measuring correlation}

This study principally uses the same methodology to measure price correlation as the previous papers $^{32}$ in order to facilitate comparison. A simple metric to quantify the strength of price alignment (or "linear correlation") between gas hubs is the Pearson Product-Moment correlation coefficient ${ }^{33}$. When this score is close to $100 \%$, this indicates the strongest price alignment, meaning that when price in market $A$ goes up by $\mathrm{x} \%$, price in market $\mathrm{B}$ also goes up by $\mathrm{x} \%$, and vice versa. If the Pearson coefficient is close to zero, the price series are said to be non-correlated.

More specifically, we compute daily volume weighted average prices (VWAP) ${ }^{34}$ for each hub; and then we compute the sample Pearson Product-Moment correlation coefficients for each pair of daily VWAP by periods (half years and years). Although this partitioning is somewhat arbitrary, the periods were chosen to represent three possible different phases, consistently with data availability. Following Doane and Spulber ${ }^{35}$, we performed the correlation calculation once with a window of $n$ days.

Note that an alternative approach would be to compute the arithmetic average of the results of performing the correlation calculation using a rolling window of $n$ days.

Only daily prices for weekdays were considered and this eliminates the impact of the different dynamic between weekdays and weekend ${ }^{36}$.

The resulting correlation scores tell us something about the correlation between each pair of hubs in each period.

Then, we compute arithmetic averages over groups of scores to determine group correlation scores. By excluding hubs one by one, we separate out the marginal contribution of each to the global correlation in a given period. If all the hubs move in tandem in a given period, we would expect that excluding one does not improve group correlation in that period. In contrast, in the case where one hub moves differently from the others, we would expect its exclusion to increase group correlation. The first hub to be excluded is the one that, based on the analysis of pairwise correlation results, appears to be the one most "de-linked" in the most recent data ${ }^{37}$.

\footnotetext{
30 Heather (2012), P.71, ACER(2013), P. 185.

${ }^{31}$ Petrovich (2014).

32 Petrovich $(2013,2014)$

${ }^{33}$ Petrovich (2014) and see also Boisseleau (2004), P.22, for a review of the most widely used measures of market interdependence.

${ }^{34}$ A daily average was chosen as many trades for the same contract are concluded every day.

35 Doane and Spulber (1994).

${ }^{36}$ For discussion see Petrovich (2014) and Boisseleau (2004), P.217

${ }^{37}$ A similar approach to test the separation of different price areas is used by Boisseleau (2004), P.229. Boisseleau (2004) uses correlation coefficients between different electricity price locations in Europe to investigate which subgroups of locations are more integrated with each other.
} 

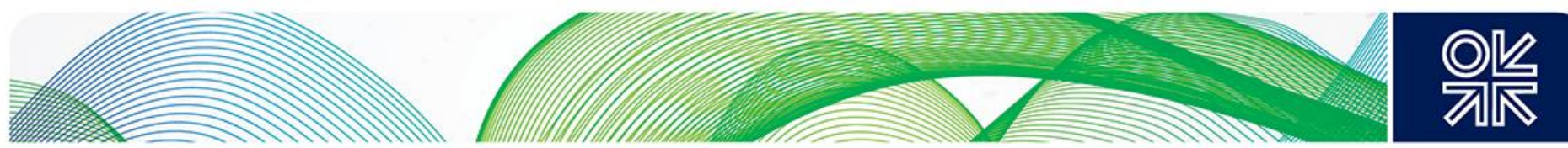

By using the Pearson correlation coefficient, we measure only the strength of the linear relationship between two daily price series, therefore non-linear relationships are beyond the scope of this work ${ }^{38}$.

\subsection{Methodology: explaining price de-linkages}

The methodology for explaining the drivers behind price de-linkages is not based on the academic literature but on an original simple test, already applied in the 2014 paper by this Author ${ }^{39}$.

The test is as follows: once a price de-linkage is identified between market $A$ and market $B$ (based on visual interpretation of price time series as well as based on the analysis of price correlation coefficients, as illustrated in Figure 1), we assume that barriers prevent gas flowing across borders and we check how much physical interconnecting capacity between $A$ and $B$ was unused during the de-linkage period.

Figure 1: Illustrative de-linkage

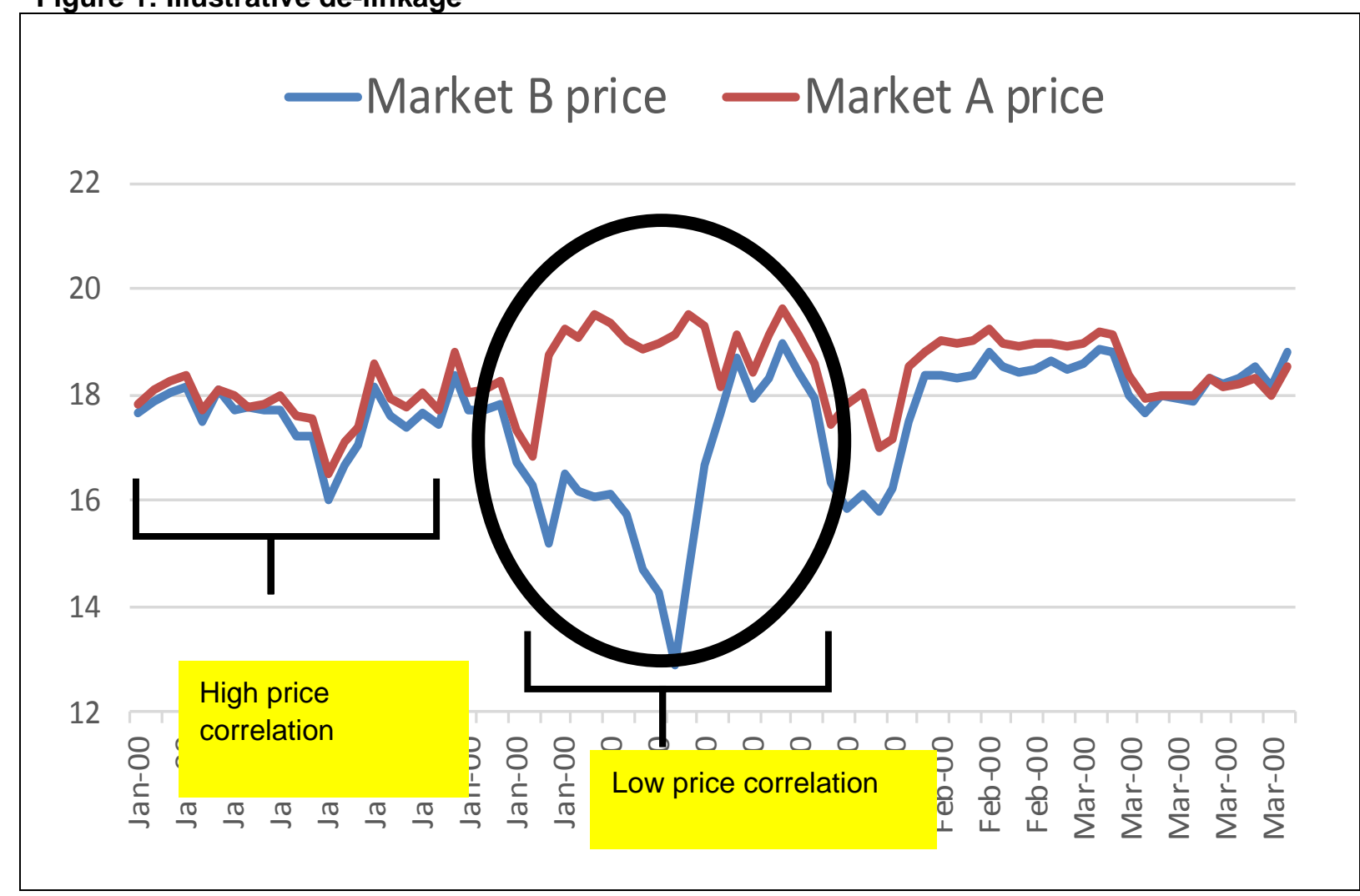

Source: Author

If there was no unused/spare physical interconnecting capacity, we infer that the price de-linkage was due to physical congestion. If persistent, this may indicate need for further investment in interconnecting capacity or that baseline technical capacity levels are set too low ${ }^{40}$. Note that, as observed by $A C E R^{41}$, the optimal level of investment is not necessary the one that allows a $100 \%$ price alignment as the cost of the new infrastructure could outweigh the benefits of lower gas prices resulting from increased price alignment.

\footnotetext{
${ }^{38}$ For discussion see Petrovich (2014) and Boisseleau (2004), P.217

${ }^{39}$ Petrovich (2014)

${ }^{40}$ Baseline capacity levels are the quantities that the TSO offers to the market, it is possible to set them in a variety of ways, see Petrovich (2014) P. 20 for discussion on this.

${ }^{41}$ ACER (2013), P. 179.
} 

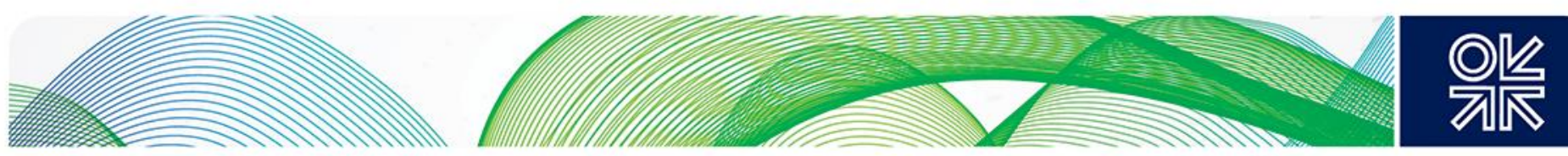

If there was some unused physical capacity on the existing cross border interconnection, then we infer that there may be non-physical barriers to trade. One possible non-physical barrier is that unused contracted capacity is not being made available to other users (a situation hereafter defined as "contractual congestion") and arbitrage opportunities are not fully exploited. Other barriers include inconsistency in the adjacent market systems (for instance lack of harmonization of timing of capacity allocation at the two sides of the IP), too high transaction costs and information asymmetry (for instance lack of transparency in the capacity allocation process).

A simple representation of the test is presented in Figure 2.

Figure 2: Test to explain the nature of price de-linkages

NO

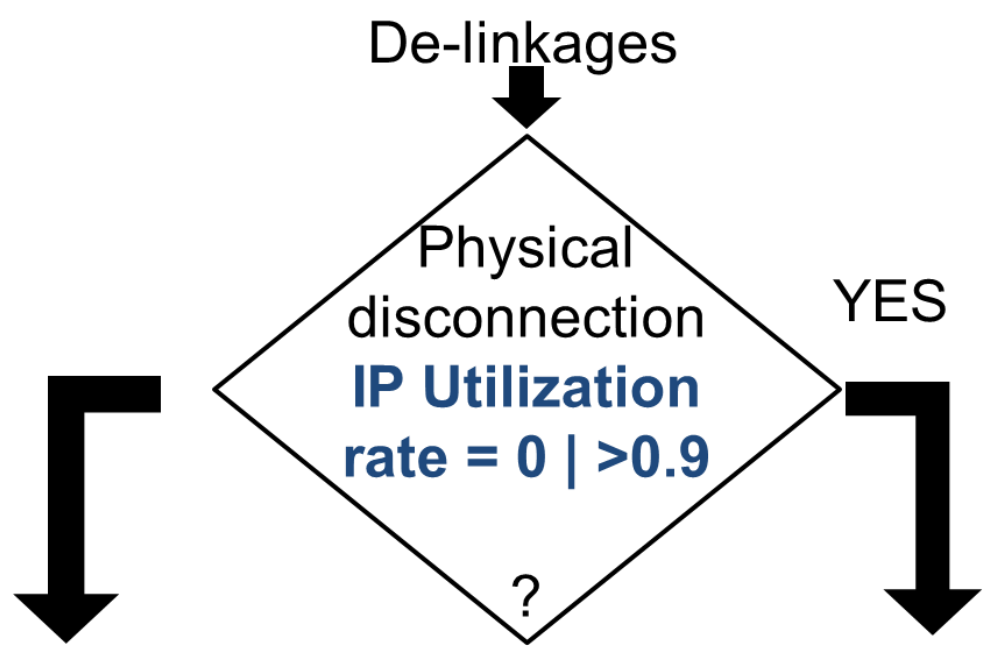

May be non physical

barriers to trade

(including contractual

congestion)

May be need for

enforcing CMP

Physical
congestion

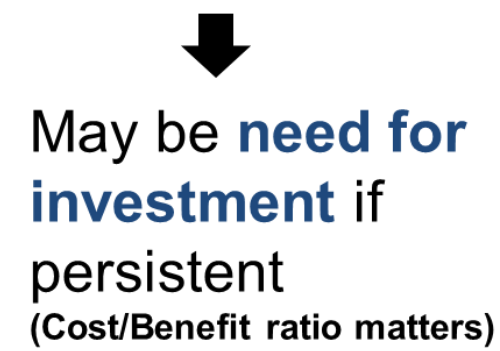

Source: Author

As already mentioned, among non-physical barriers to gas trading, capacity hoarding has been deemed as one of the main obstacles to the development of an open and competitive European gas market. The concern about the capacity hoarding, notably by users holding long term contracts on transmission capacity, is at the origin of the creation of European CMPs and the monitoring of the occurrence of contractual congestion is one of the mandatory tasks of ACER.

However, there are different approaches to the definition of contractual congestion ${ }^{42}$. In the EU Regulation ${ }^{43}$ it is defined as a situation where "the level of firm capacity demand exceeds the

${ }^{42}$ See for instance EFET (2014) 

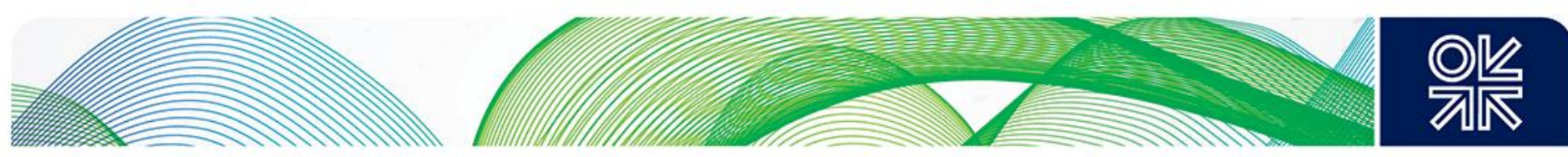

technical capacity"; such definition, however, may not distinguish between physical congestion (as defined above) and a situation where there is spare transmission capacity (contractual congestion, as defined above).

In fact, it may be argued that the "real" contractual congestion (CC) occurs when there is spare capacity and there is somebody who wants that capacity but is refused. Under this approach, a situation where a) there is no spare capacity or b) there is spare capacity but nobody is asking for it may not be considered CC. However, in order to detect CC correctly under this approach, information on requests for capacity at IPs should be used, which may be rather complex, although this will be facilitated when auctions for capacity are in place for all the IPs, according to provisions set in the European Network code on Capacity Allocation Mechanisms (CAM) ${ }^{44}$.

In our test we assume that, if there is a misalignment in day ahead prices, then there should be someone wanting to get that transmission capacity; and that, if at times of price misalignment part of the transmission capacity is still not used, then non-physical barriers to trade gas, and particular CC, should exist.

It is fair to note that there are limitations in the methodology used in this work to identify CC.

More specifically, imperfect DA price correlation, even in the absence of physical congestion, does not necessary imply CC.

First there could be other non-physical barriers to trades. Second, there are other reasons that lead shippers not to trade in the direction suggested by the spread:

- DA prices are not the whole market and market players may optimise in a different way: there may be internal portfolio optimization reasons that justify that fact that the trader is "leaving money on the table" without exploiting arbitrage opportunities.

- Some contractual obligations to flow gas to clients exist, possibly limiting the amount of gas that can be traded day ahead.

- Some load flow obligations (or load flow commitments) exist between TSO and shippers, according to which shippers are paid for flowing gas in one direction and the benefit they get may be higher than the gain from arbitrage. This possibly limits the amount of gas that can be traded on the day ahead market.

- When the market is not liquid enough, a large player may not undertake arbitrage to avoid revealing its strategies to other players.

\section{Data}

\section{Price data}

Daily weighted average price data were computed, for the DA contract, starting from raw data on single trades concluded with broker intermediation on the OTC market. Evidence on raw trades used in this work is based on raw data from about four million trades recorded by the Tankard Parties (ICAP, Marex Spectron and Tullett Prebon) over the period 2007-2014; OIES accesses this database under licence for research purposes only and estimates that the database represents about $70-80 \%$

\footnotetext{
${ }^{43}$ Article 2.1 (21) of Regulation (EC) 715/2009.

44 EU Regulation 984/2013. The deadline to implement auctions is November 2015 and aggregate auction results should be disclosed. Please not that some Member States have already decided for early implementation of CAM.
} 

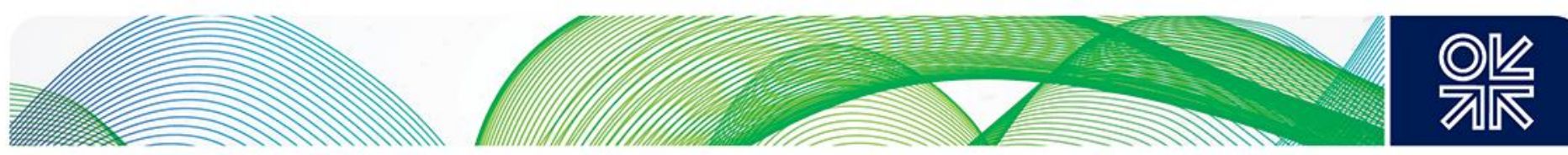

of total European OTC hub traded volumes ${ }^{45}$. Note that these data are transactional data, not pretransactional data: data on bid and offer prices (usually found in order books used by traders) are outside the scope of this work.

We also considered exchange daily weighted average prices for the day ahead product (sourced from exchanges) when relevant and available: on some hubs, notably the PEGN and the PEGS, exchange deals play an important role and the share of total trading which is exchange trading is higher than elsewhere in Continental Europe ${ }^{46}$.

While the period January 2007-October 2013 was covered in past research ${ }^{47}$, the time frame of the analysis in this work covers November 2013 through December 2014, but we focus mostly on calendar year 2014.

\section{Gas flow data}

In order to compute daily utilization rates we rely on data disclosed by transmission operators such as Interconnector, GRTgaz, and on ENTSO-G Transparency Platform (TP) data. In principle daily available capacity, daily maximum technical capacity and daily flow data at all the cross-border IPS should be available in ENTSO-G TP from October 2013. ENTSO-G has plans to extend data availability from 2010 . Occasionally we refer also to monthly flow data disclosed by IEA ${ }^{48}$.

\section{Data overview}

\subsection{Volumes}

Although the analysis of liquidity at different European hubs is beyond the scope of this paper, it is interesting to present both the gross traded volumes ${ }^{49}$ and the number of deals behind the considered prices.

Since 2008, gross traded volumes ${ }^{50}$ delivered at the main European hubs have steadily increased on the OTC market, which still accounts for the majority of trades ${ }^{51}$ (Figure 3). As the "same" molecule may get traded within a specific (entry/exit) zone many times before delivery to final end users, total traded volumes may be several times total demand in the corresponding $\operatorname{area}^{52}$.

\footnotetext{
${ }^{45}$ Refer to Petrovich (2013) for a detailed discussion regarding data.

${ }^{46}$ Petrovich (2014)

47 Petrovich (2013 and 2014)

48 www.iea.org/gft/

${ }^{49}$ Gross traded volumes per hub per product are computed as the sum of total traded volume over all the deals for that product delivered at the considered hub, whereby total traded volume for one deal equals the agreed daily flow rate times the number of days in the contract (1 day for DA, 28-30-31 days for MA according to the delivery month).

50 The total gross traded volume is the entire gas volume delivered pursuant to all the trades concluded for delivery at the hub, including all delivery periods.

${ }^{51}$ Heather (2012)

52 Total demand (consumption plus export) originating in the area connected to the hub may be complex to be determined where hubs do not overlap perfectly with national borders. See Heather (2012) for discussion on churn ratio.
} 

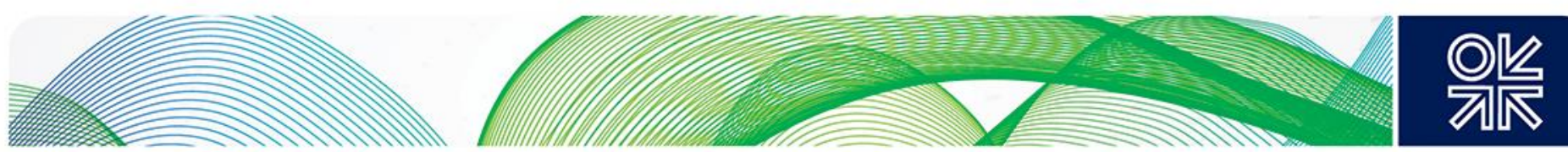

Figure 3: Total gross traded volumes, OTC market (TWh and \% of total EU28 consumption)

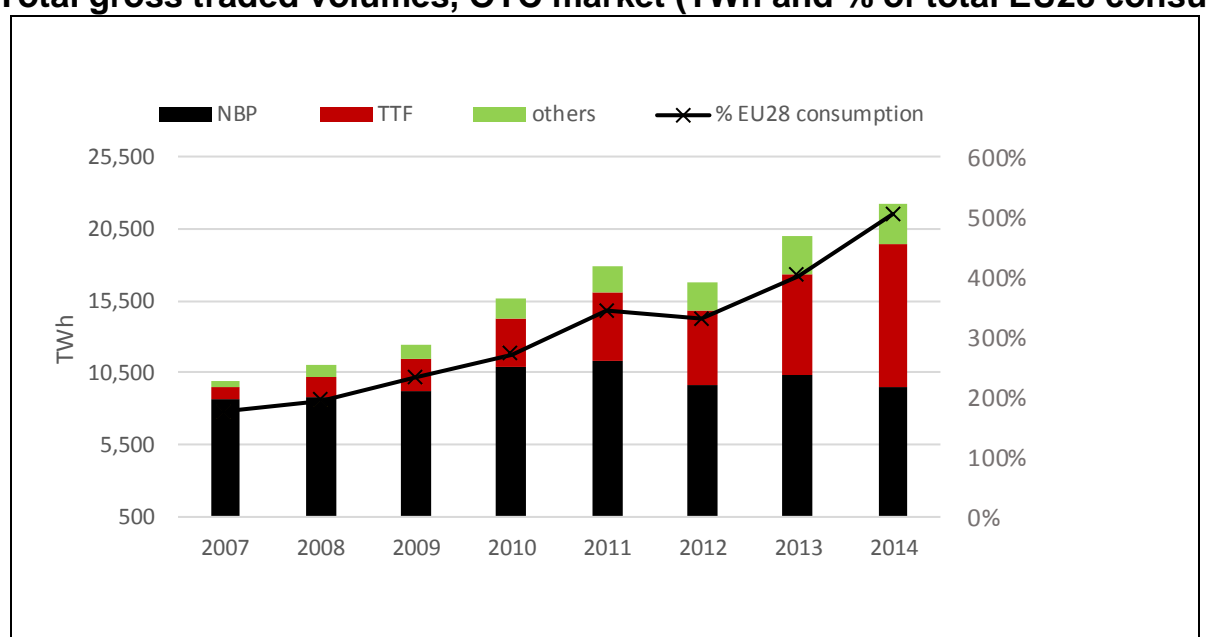

Source: Tankard, Eurostat and Eurogas

The growth in traded volumes reflects the fact that, since 2007, the sale and purchase of natural gas in Europe has been evolving from a "traditional" model based on bilateral long term contracts with prices (largely) linked to those of oil products, to trading by means of standardised contracts concluded between a large number of participants with prices set by supply and demand "at the hub"53.

Hub trades are highly concentrated at the NBP and TTF which have almost an order of magnitude higher traded volumes than those of France, Germany, Italy, Belgium and Austria. However, the pace of growth (Figure 4) has been very fast for some of the less liquid hubs: CEGH volumes in 2014 for instance were over 40 times larger than in 2007, while the NBP volume remained relatively stable. In 2014, only ZEE and the French hubs experienced a significant decline (more than $40 \%$ ) in OTC traded volumes, possibly due to the creation of a new euro-quoted hub (ZTP), and players preferring trading on the (French) Powernext exchange rather than the OTC.

\section{Figure 4: Total gross traded volumes, OTC market by hub (TWh)}

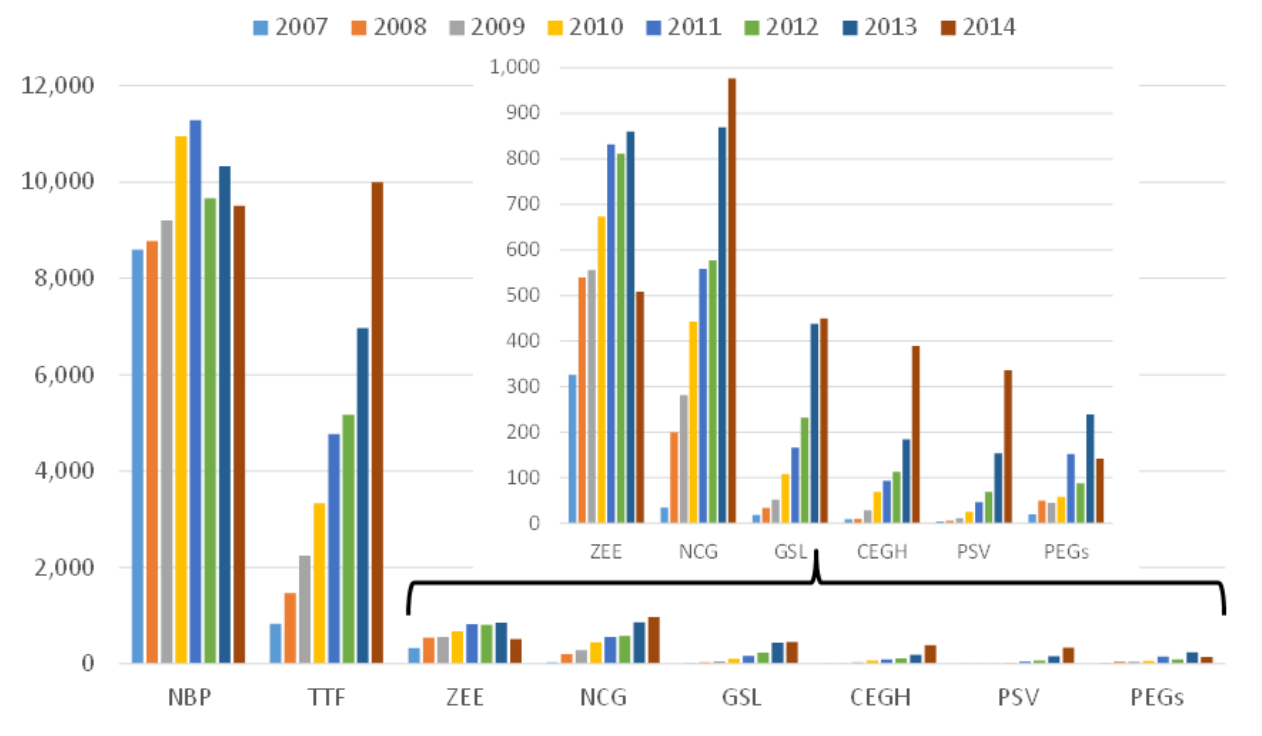

Source: Tankard Parties

\footnotetext{
${ }^{53}$ Heather (2012).
} 

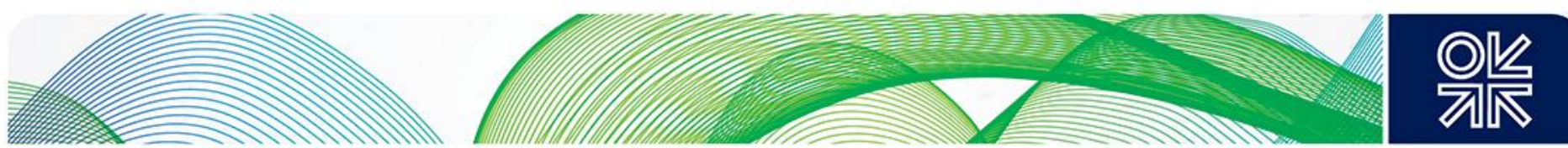

Day ahead is by far the most frequently traded product in Europe (Figure 5). In all markets, but for TTF and NBP, at least $50 \%$ of trades are for day-ahead delivery. Products for future delivery (quarterly, seasonal, calendar and gas year products) are traded mostly on TTF and NBP, which account for almost $90 \%$ of European curve trade. This indicates that at least some hubs are mainly used for short-term balancing purposes ${ }^{54}$, while curve trading is concentrated on NBP and on TTF, the latter being a reference for the other Continental European hubs.

Figure 5: Breakdown of number of OTC trades by product in 2014 (\% compared to total hub trades)

DA ather < month $\quad$ MA wother curve

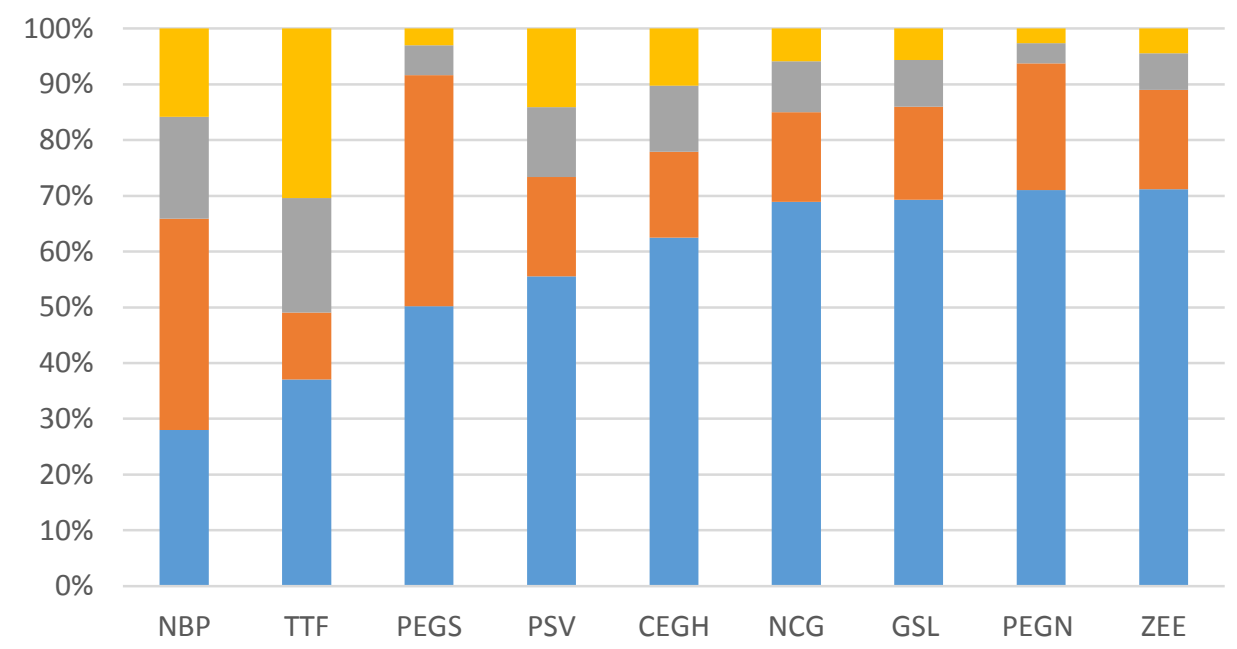

Note: $\mathrm{da}=$ day ahead; $\mathrm{ma}=$ month ahead

Source: Author's analysis of Tankard Parties data

Day ahead volumes have been growing, sharing the same trend as total traded volumes (Figure 6). In 2014 volumes traded for day ahead deliveries ranged from about 1 TWh on the PEGS, accounting for $1 \%$ of gas consumption in the South of France ${ }^{55}$, to over 200 TWh on the TTF and NBP, accounting for over $70 \%$ and about $40 \%$ of gross inland consumption in the Netherlands and in the UK, respectively.

\footnotetext{
${ }^{54}$ Heather (2012), P. 11, ACER (2013), P. 186.

${ }^{55}$ Source: GRTgaz data on consumption in France, available at: http://www.smart.grtgaz.com/en.
} 

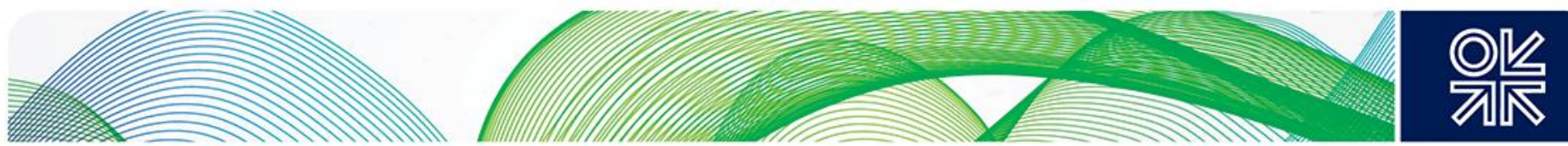

Figure 6: OTC DA traded volumes (left axis) and number of day ahead trades (right axis) in 2014 by hub (TWh)

- TOT VOL (TWh) @ n.trades

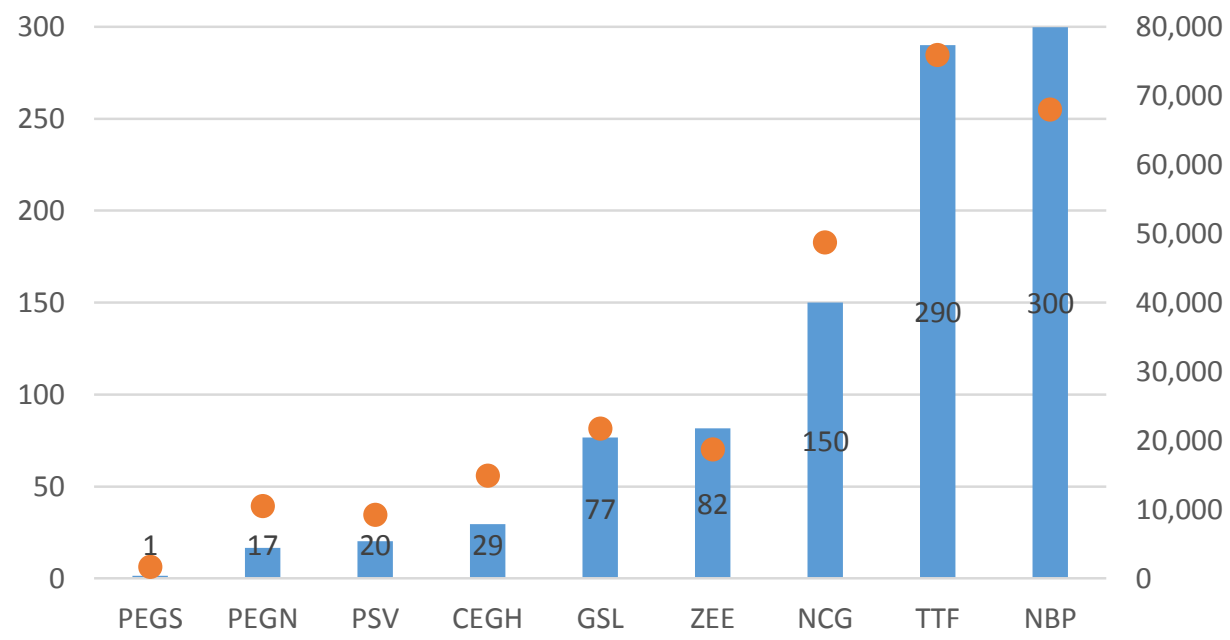

Source: Tankard Parties, author's analysis

\subsection{Prices}

Notwithstanding differences in traded volumes, the European hubs in 2014 expressed a broadly aligned price signal suggesting that, with few exceptions (PEGS until November, PSV and CEGH in the second half of the year), they are well spatially integrated and competitive.

Figure 7: OTC Day ahead prices for European hubs in 2014 (€/MWh)

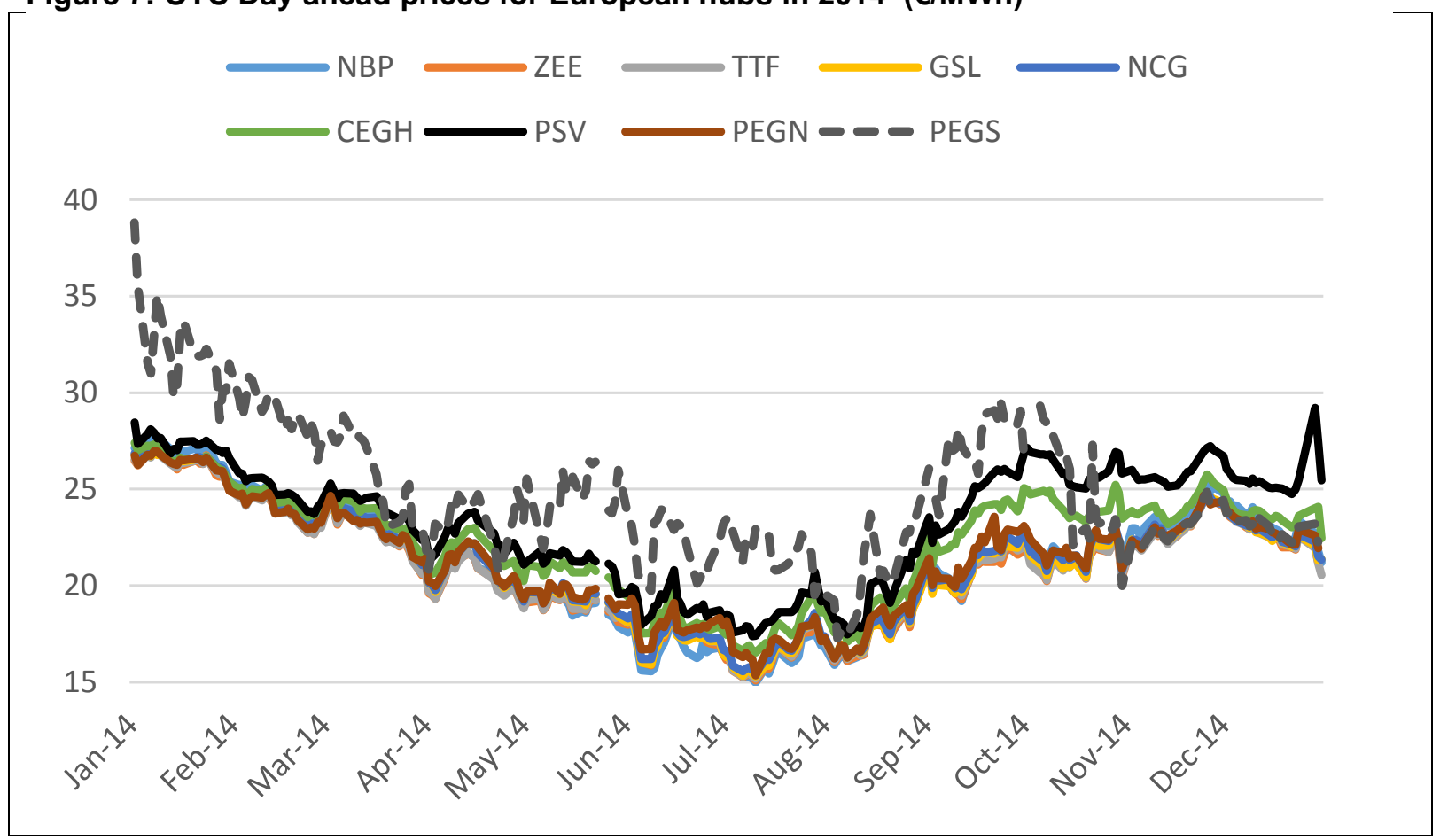

Source: Tankard Parties, author's analysis 

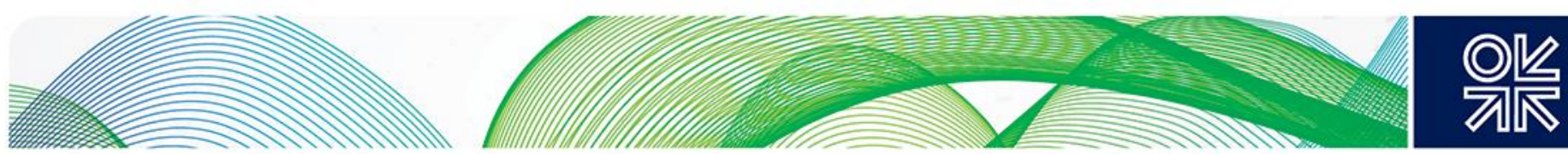

\section{Correlation results}

Pair-wise correlation coefficients (Figure 8 and 9) show an improvement in price correlation in 2014 compared to 2013, and particularly when comparing H1 2014 to H1 2013. PEGS remains an exception: PEGS correlation with all the other hubs collapsed in 2014 and in particular in $2 \mathrm{H} 2014$ when it was down at $40-50 \%$ - much worse than in previous periods.

Figure 8: Cross correlations between OTC day ahead daily prices (Pearson coefficients \%) ${ }^{56}$

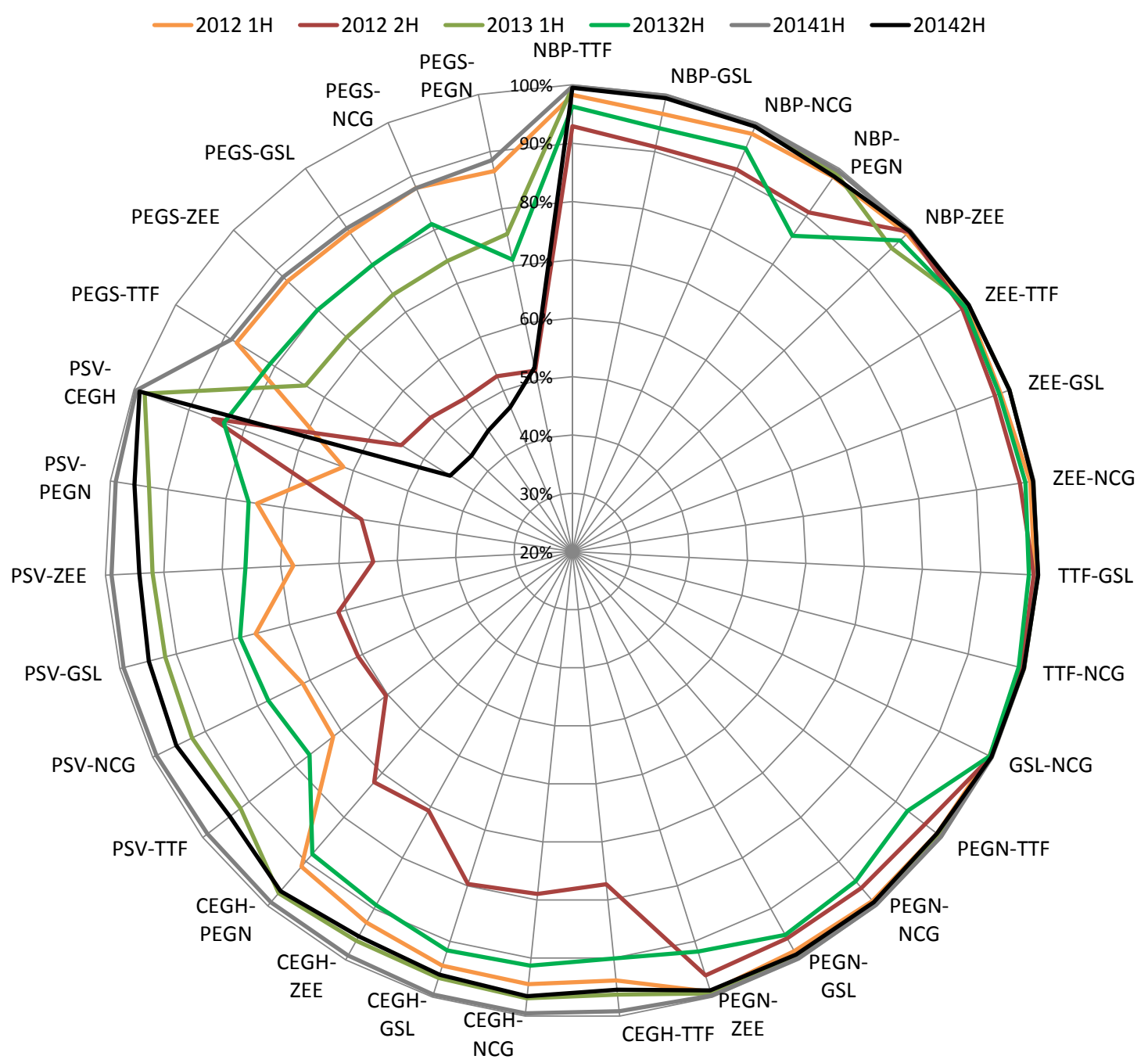

Note: Only correlation coefficients significant at the $5 \%$ level or better are displayed.

Source: Tankard Parties, author's analysis

\footnotetext{
${ }^{56}$ For the sake of clarity some pairs are not included in the graphs, as they refer to less interesting cross correlations: NBPPSV, NBP-CEGH, NBP-PEGS, PEGS-CEGH, PEGS-PSV.
} 

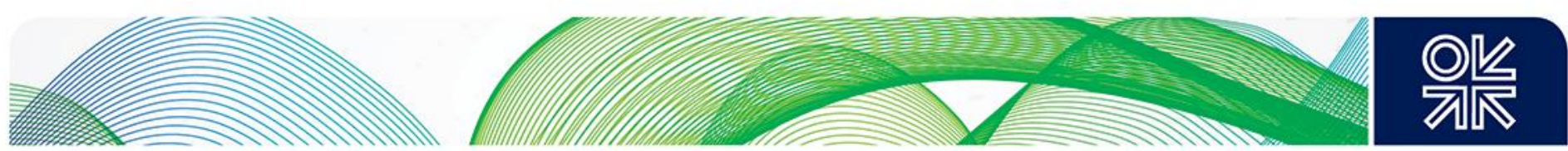

Figure 9: Correlations between OTC day ahead daily prices for selected groups of hubs (Pearson coefficients \%)

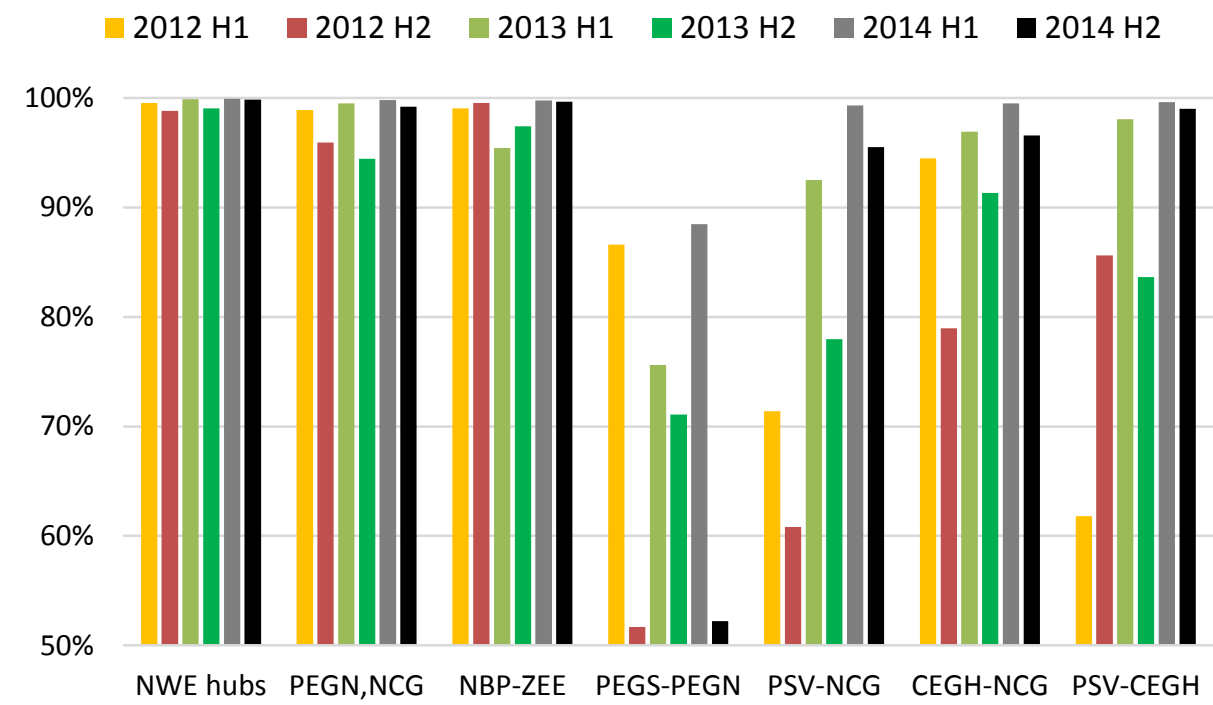

NEW hubs= NCG, GSL, TTF, ZEE

Source: Tankard Parties, author's analysis

Day ahead OTC prices within the North West Europe "core" group (ZEE, TTF and the German hubs) remain highly correlated: correlation coefficient are stable over time and above $95 \%$. This is consistent with findings in previous papers. Over the whole period, ZEE, TTF and the German hubs behave as a single integrated market area.

PEGN remains well correlated to its neighbouring markets in North West Europe (ZEE, NCG), improving day ahead correlation scores compared to H2 2013. Correlation to ZEE and NCG is almost perfect in 2014, with Belgium, Germany and North of France behaving as a single integrated market area for day-ahead gas.

While the NBP was less correlated to TTF and ZEE in 2013 (as discussed in the 2014 paper), in 2014 day ahead prices in these markets moved in tandem and show almost perfect correlation.

The OTC day ahead prices at the two main French hubs show a notably different pattern over the period and they eventually came into line in the very end of 2014, as discussed further below. Consequently, PEGS correlation to the adjacent PEGN reached minimum levels in H2 2014, when it was as low as in $\mathrm{H} 2$ 2012: this is a marked decrease compared to the level reached in the beginning of 2014. Reasons behind the price de-linkage are likely the same as in 2012-2013, as presented in Petrovich (2014).

PSV correlation seems to be coming into line with NW Europe: PSV-NCG correlation coefficients, after the drop observed in $2013^{57}$, improved remarkably in the first half of 2014 . However less alignment between PSV and NCG is found in H2 2014, when correlation metrics are similar to the levels observed in H1 2013. In H2 2014 the PSV-NCG spread also enlarged.

As mentioned above, and observed in $2013^{58}$, the CEGH-PSV correlation remains higher than the NCG-PSV one, with PSV apparently moving more closely with CEGH than NCG. The gap widened in H2 2014.

\footnotetext{
57 Petrovich (2014)

${ }^{58}$ Petrovich (2014).
} 

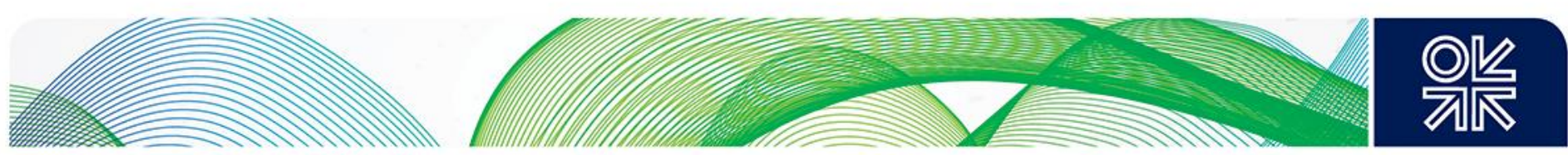

As far as CEGH is concerned, correlation with the adjacent German market NCG recovered in the first half of 2014 after the drop observed in $2013^{59}$, but then, similarly to PSV, declined again.

Summarising, correlation metrics highlight the following price de-linkages in 2014: between PEGS and PEGN (discussed in Chapter 7.1), between CEGH and NCG (discussed in Chapter 7.2), between PSV and NCG (discussed in Chapter 7.3).

\subsection{PEGS misalignment in 2014}

Since April 2012 the evolution of prices on PEGS has become quite unrelated to all other hubs, in particular in the winter 2013/2014 and in the end of the summer of 2014 (Figure 10). However there are some periods when PEGS followed the other hubs more closely: during the winter of 2012/2013 and again starting from November 2014.

Figure 10: NCG, PEGS and PEGN OTC day ahead prices in 2012-2014

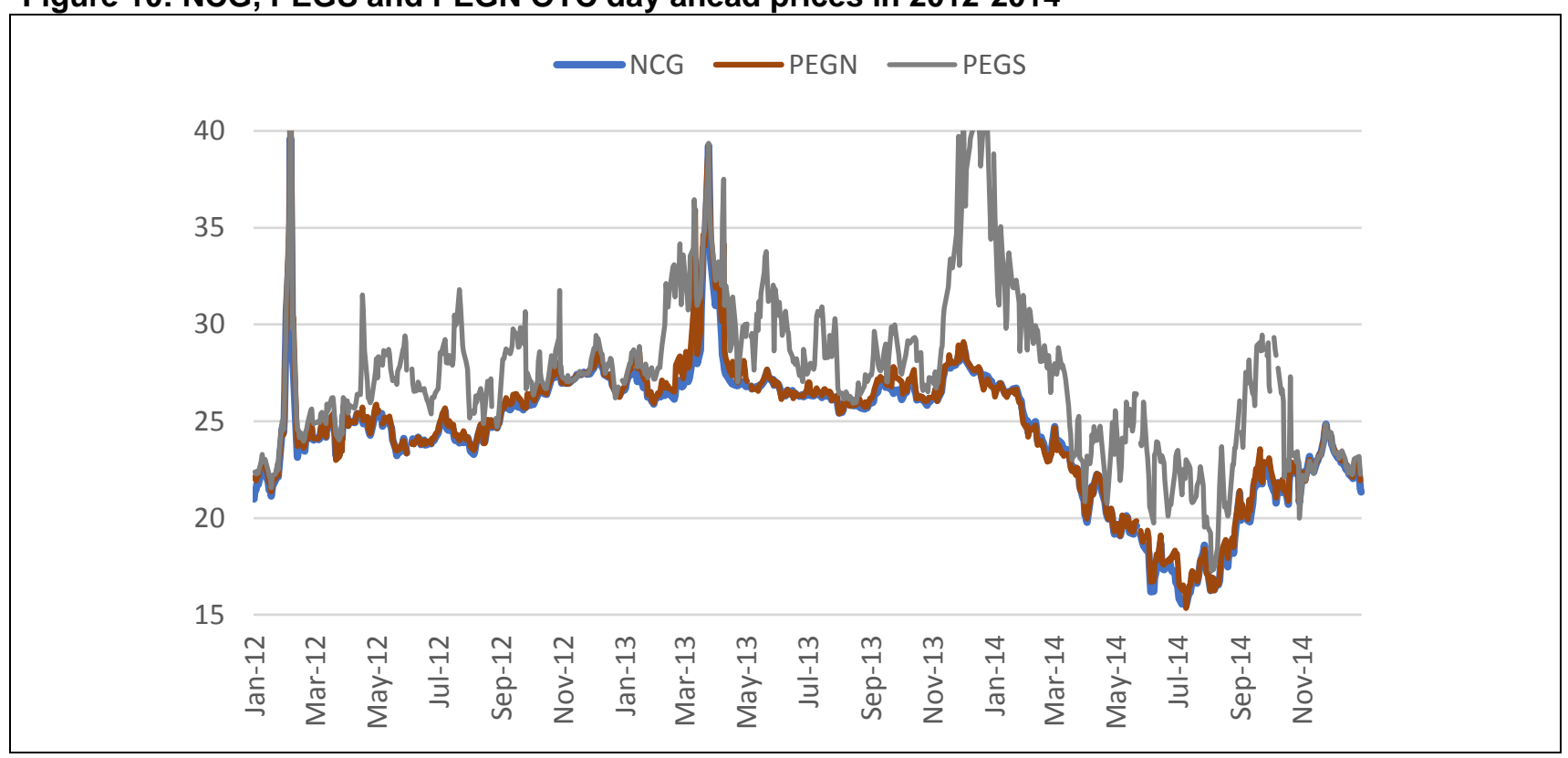

Source: Tankard Parties data

There are no significant differences between OTC prices and exchange price data: Powernext price quotations for PEGN and PEGS 60 are virtually identical to the daily weighted average prices calculated on the basis of Tankard data. In fact, in 2014, for the DA contract with delivery at PEGN, the average absolute difference between Powernext and OTC daily prices equals $0.1 € / \mathrm{MWh}$ and on $90 \%$ of the days the difference was below $0.5 € / M W h$. When turning to PEGS, the average absolute difference is slightly higher $(0.24 € / \mathrm{MWh})$ and the absolute difference was higher than $0.6 € / \mathrm{MWh}$ on only $10 \%$ of the days during the same period.

As noted above, PEGS correlation with NCG and PEGN collapsed in 2H 2014.

The fact that correlation is at a very low level is confirmed by the scatterplot (Figure 11): the relationship between PEGN and PEGS DA prices is not strong in during $\mathrm{H} 2$ 2014, apart from November and December 2014 (red circle). It may actually be the radical change from the JulyOctober period (when PEGS is misaligned) to the Nov-Dec 2014 one (when PEGS re-aligns) that pushes the $20142 \mathrm{H}$ correlation score down.

\footnotetext{
${ }^{59}$ Petrovich (2014).

${ }^{60}$ We refer to Daily Weighted Average Day Ahead prices as published by Powernext.
} 

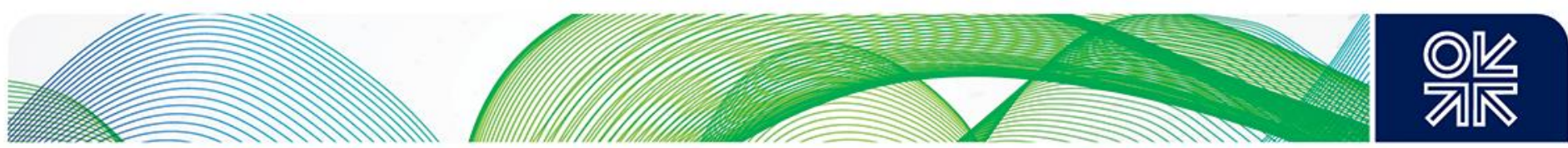

Figure 11: Scatterplot PEGN-PEGS DA prices
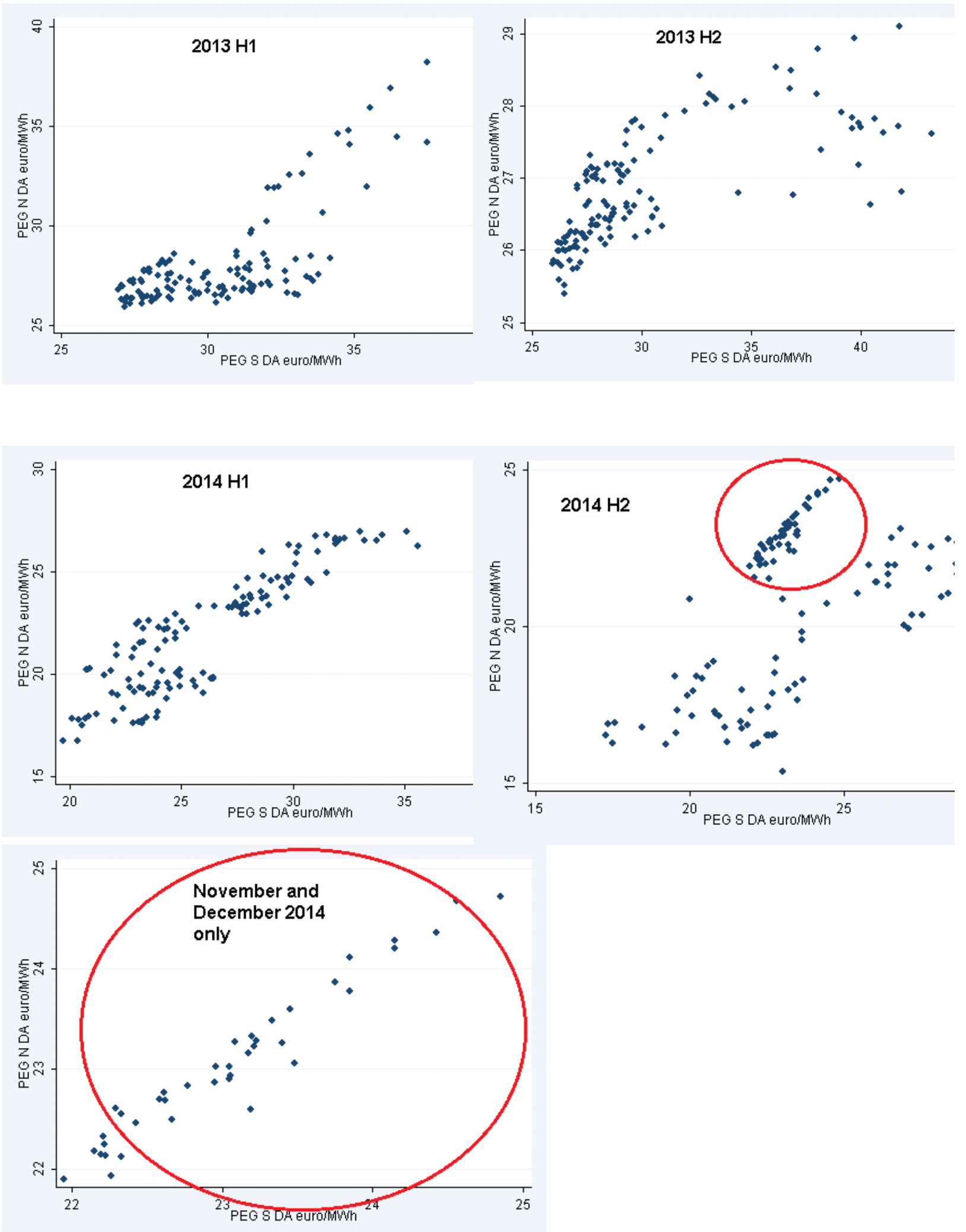

Source: Analysis of Tankard Parties data 

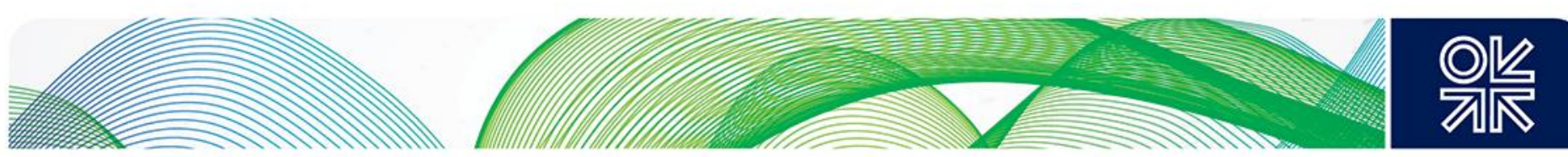

The low correlation score is also confirmed by the analysis of the evolution of the absolute difference between PEGS DA price and PEGN DA price: in H2 2014 the spread is very volatile compared to previous periods (Figure 12). In November 2014 gas for day ahead delivery at PEGS was even on average slightly cheaper than PEGN.

Figure 12: Absolute difference between PEGS DA price and PEGN DA price (€/MWh)

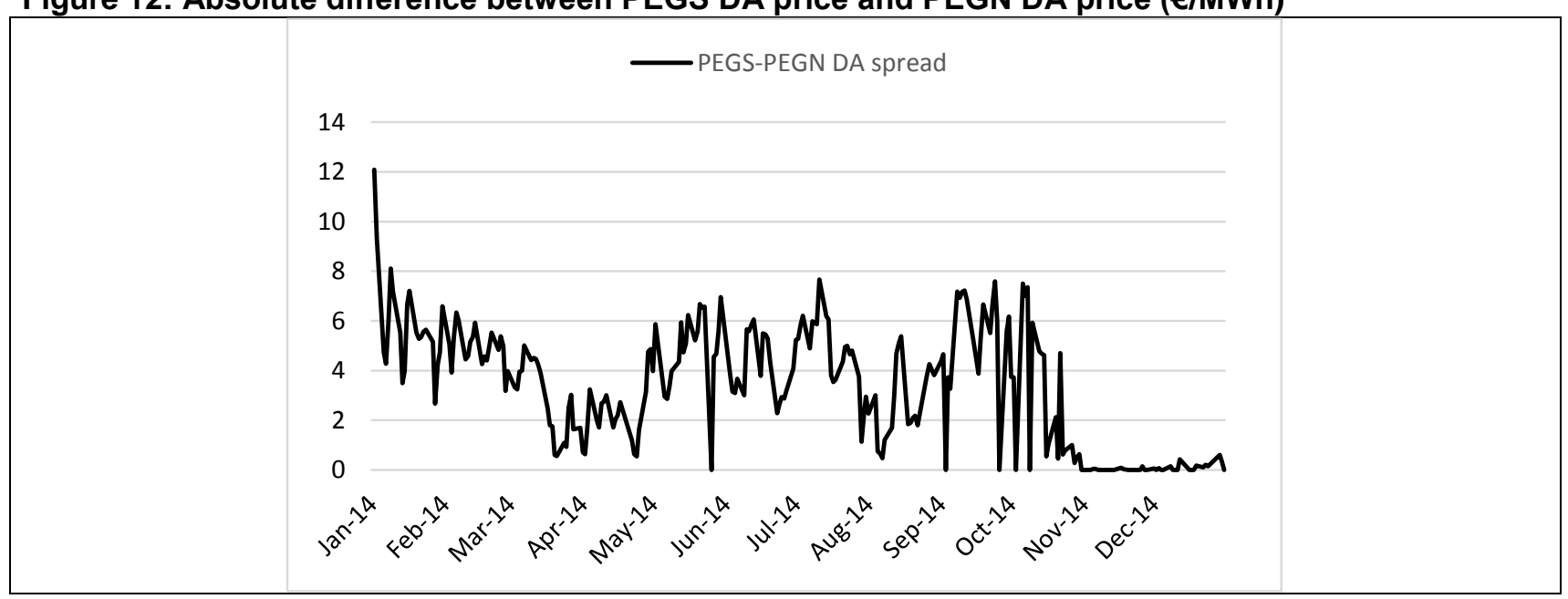

Source: Tankard Parties

We now investigate whether the observed PEGS-PEGN de-linkage in 2014 occurred when the connecting infrastructure between PEGS and PEGN, the French North South link (N-S link), was congested. Congestion in the N-S link constrains supply from the North of France and may produce a worse PEGS alignment with PEGN. The North-South link ${ }^{61}$ was physically congested from January to October 2014, as shown by GRTgaz data (Figure 13).

Figure 13: PEGS-PEGN OTC day ahead price spread (€/MWh) and utilization rate of the N-S link (\%)

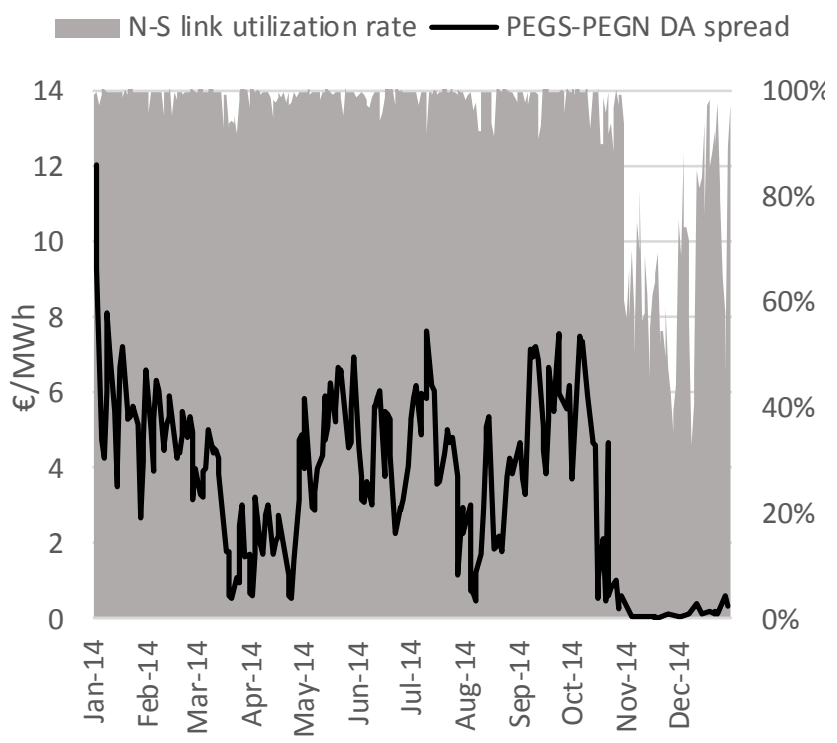

Source: Analysis Tankard Parties, GRTgaz

\footnotetext{
${ }^{61}$ Physical congestion defined as allocated quantities virtually equal to effective technical capacity. Allocated quantities are commercial flows, data on physical flows not available on GRTgaz website.
} 

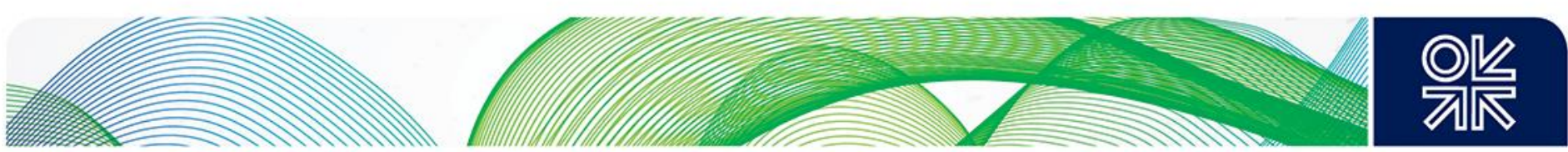

Starting from November 2014 the physical congestion is resolved, with allocated flows from PEGN to PEGS being less than interconnecting capacity on offer.

The end of the congestion clearly coincides with PEGS and PEGN day ahead prices becoming aligned again. In fact when we exclude those days in which the utilization rate is above 0.9 (i.e. consider only November and December 2014) PEGS-PEGN correlation in 2014 increases to $97 \%$.

The following factors may have played a significant role in creating physical congestion on the French North-South link in January-October 2014:

- decline of LNG deliveries into the Southern French grid since 2012

- the maintenance of the North-to-South link in September 2014,

- the progressive increase of exports to Spain, requiring additional supplies from northern France.

According to what we found in Petrovich (2014), lower LNG deliveries in the South of France may lead to congestion of the French North-South Link and therefore to a worse PEGS alignment with NWE hubs. More specifically, congestion of the French North-South Link occurs because, while the gas imported via pipeline from Northern Europe is enough to supply PEGN, this is not the case for PEGS, where LNG terminal send-outs play a more important role in ensuring the physical balance of the network. More LNG available in the South of France therefore contributes to PEGS re-alignment to PEGN prices.

Gas deliveries from French LNG terminals actually decreased over 2014, following a downward trend that started in 2012, possibly due to LNG diversions to the more profitable Asian markets (Figure 14).

Figure 14. Send-outs from French regasification terminals ${ }^{62}$ (monthly totals, $\mathrm{mcm}$ ), spread between PEGS DA and PEGN DA ( $€ / M W h)$

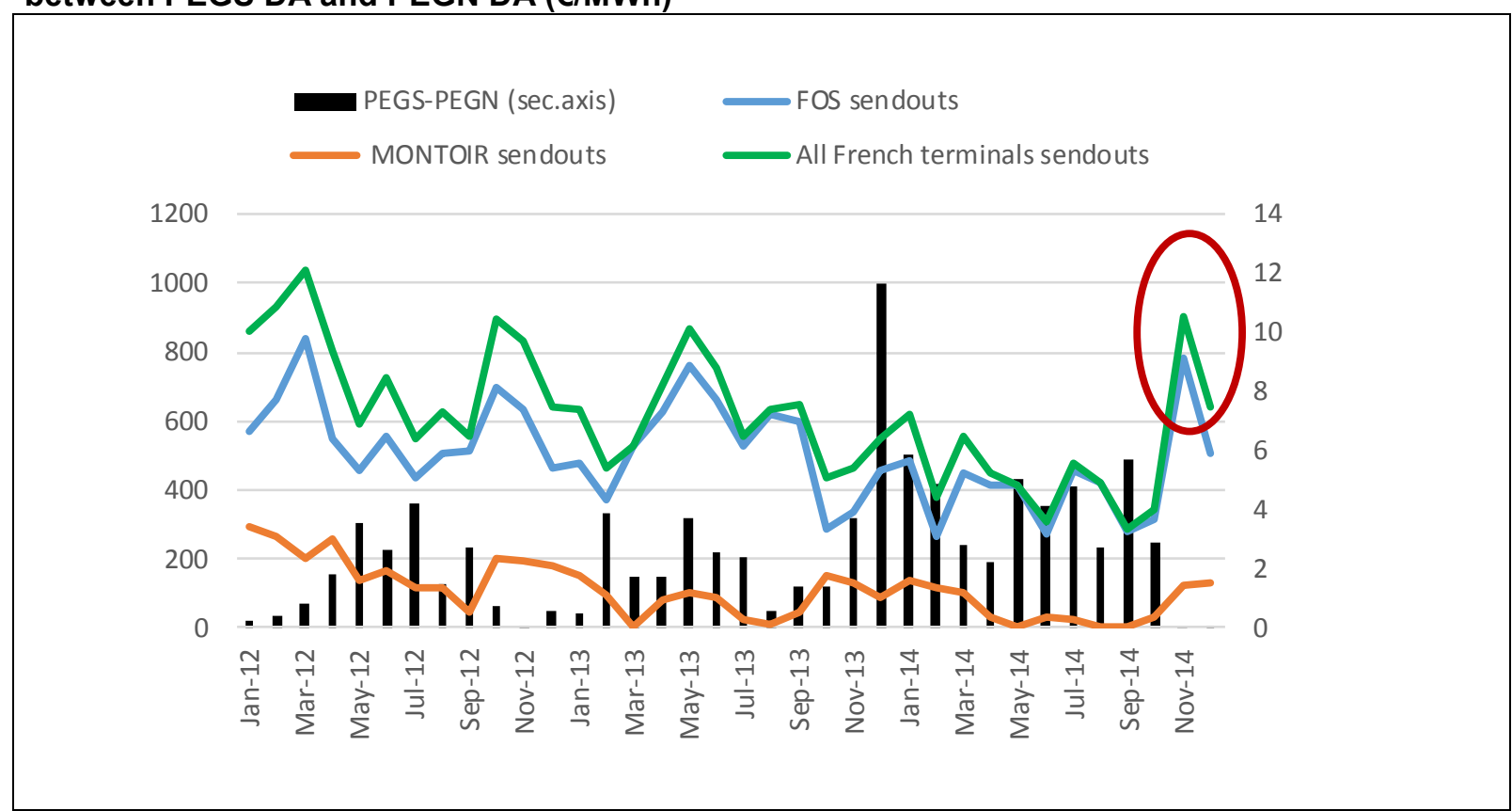

Source: GRTgaz, Tankard Parties

\footnotetext{
62 These are the physical flows entering the French grid at the LNG terminal interconnection points (PITTM), as published by French TSO GRTgaz. The Fos PITTM is the entry point into the transmission system for gas from the Fos Tonkin and Fos Cavaou LNG terminals. The Montoir PITTM is the entry point into the transmission system for gas from the Montoir LNG terminal. Entry capacities at PITTM on the GRTgaz network are directly allocated on the basis of regasification volumes subscribed by the terminal operator (Elengy or Fosmax LNG).
} 

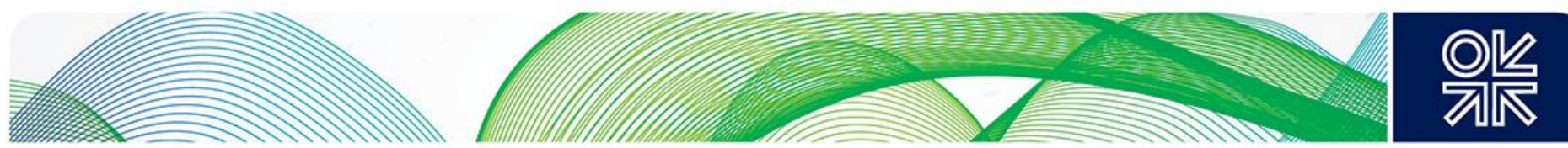

The negative trends in send-outs from France terminals reversed in November 2014, when LNG facilities' injections into the grid dramatically increased (red circle) as a consequence of an increase in LNG imports into France, in particular at the Fos Cavaou terminal, located in the South of France (Figure 15).

Figure 15: Quantities unloaded at Fos Cavaou terminal and LNG imports into French terminals (monthly totals, GWh)

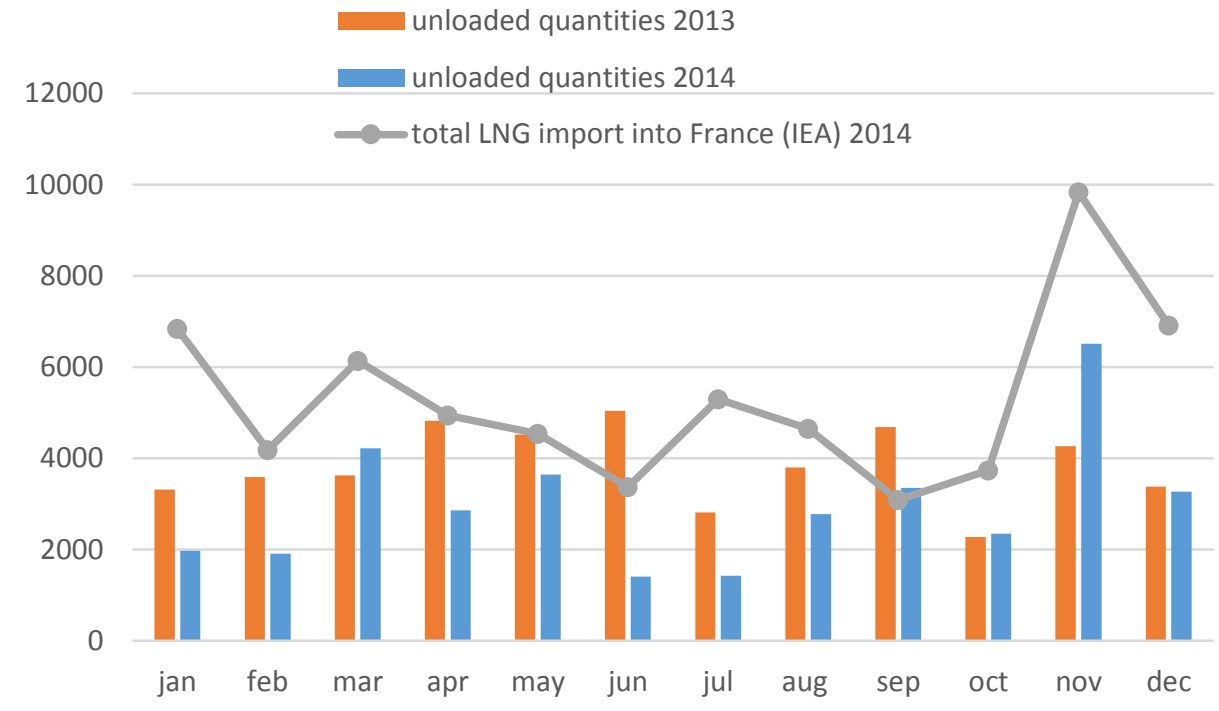

Note: we assumed a gross calorific value of $10.6 \mathrm{kWh} / \mathrm{cm}$ when converting IEA data on LNG imports (originally expressed in million cubic metres) to GWh.

Source: IEA, Fos Cavaou website (via GIE website)

The increase in LNG supply in the South of France may explain the improvement PEGN-PEGS correlation for the last two months of 2014, as well as the other periods in 2014 when the gap between the two French hubs narrowed. For instance, CRE observed that, following an improvement in LNG deliveries at Fos between Mid-July and Mid-August, the spread between PEGN and PEGS declined in July 2014 and in the 1st week of August.

According to CRE, maintenance of the North-South link in September 2014 led the spread to widen to levels above $7 € / M W h$ during several trading days. In fact, data suggest that when available capacity is below the maximum technical capacity, the two French prices tend to diverge (Figure 16). In particular in September 2014 capacity effectively available on the N-S link was less than $50 \%$ of the maximum and in the same period the spread was above $6 € / \mathrm{MWh}$. On the contrary, in November 2014 the interconnecting capacity on the N-S link was very close to the maximum level, a factor that may contribute to more alignment between PEGS and PEGN day ahead prices. 

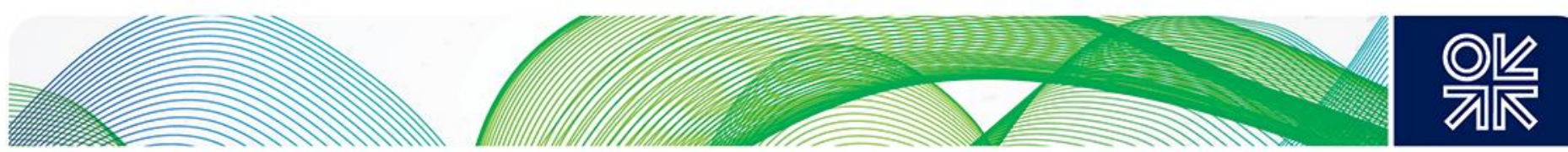

Figure 16: Effective Capacity on the N-S link as a share of maximum technical capacity, spread between PEGS DA and PEGN DA (€/MWh)

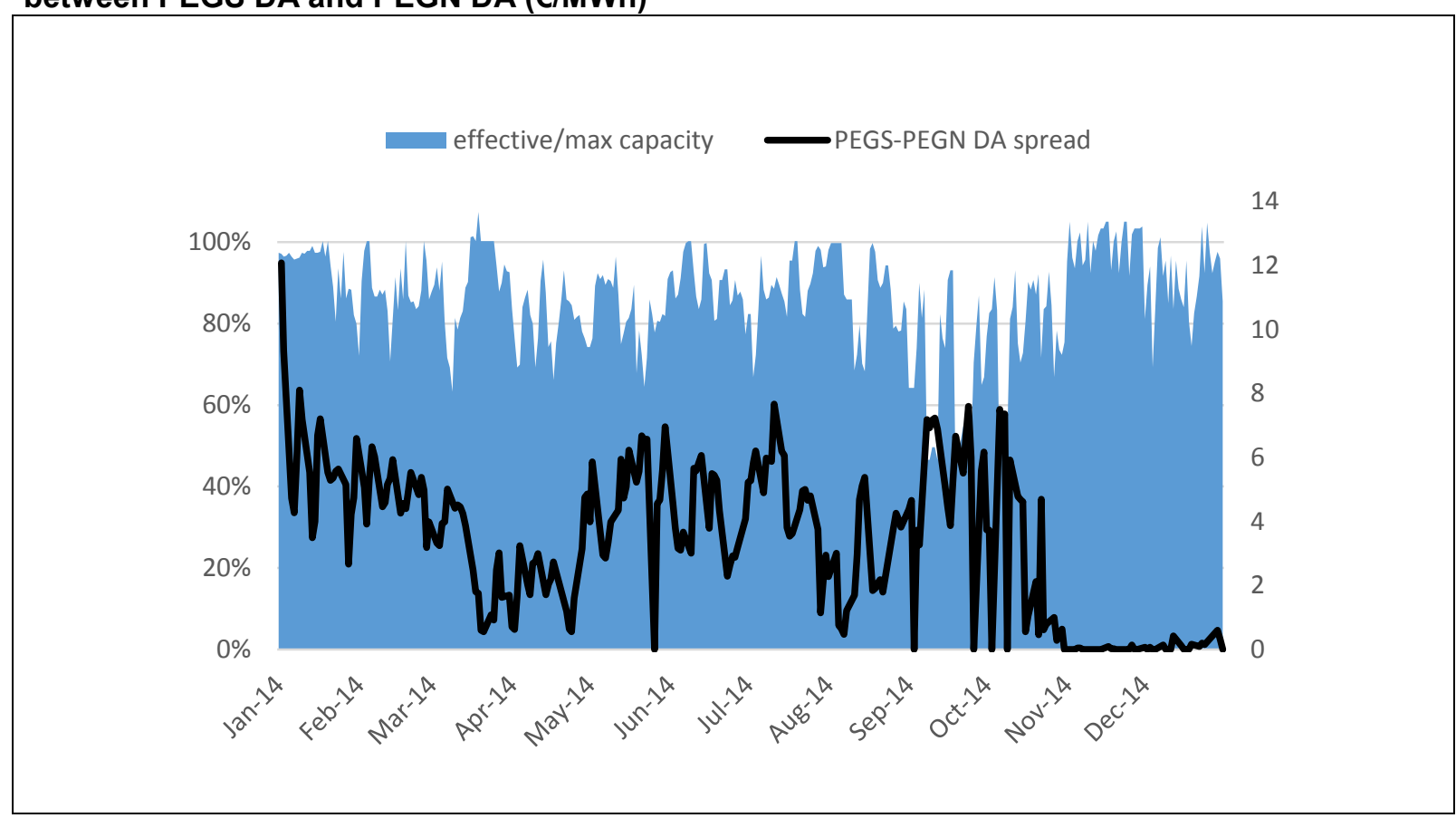

Source: GRTgaz, Tankard Parties

Another factor leading to N-S link congestion is exports from France to Spain, which according to CRE exceeded $160 \mathrm{GWh} / \mathrm{d}$ at the end of Q3 2014. Spain is connected to the PEG TIGF hub, which in turn is well connected to PEGS.

In the May 2014- August 2014 period consistent gas volumes flowed from PEGS toward PEG TIGF, passing through at Midi IP, possibly heading towards the Spanish market ${ }^{63}$ (Figure 17). This may have actually increased PEGS reliance on gas coming from PEGN. Starting from September 2014 PEGS outflows through Midi IP declined. 

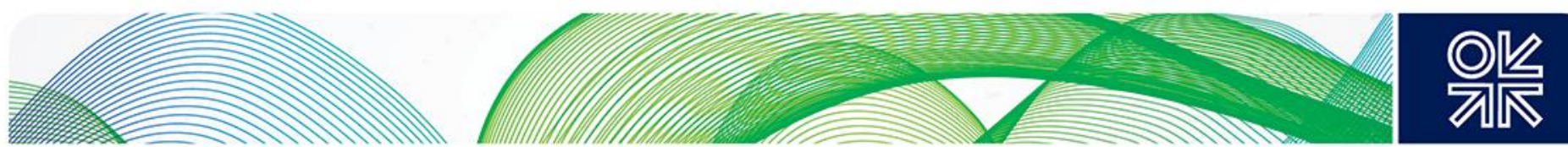

Figure 17: Physical flows and technical physical capacity from PEGS to PEG TIGF at Interconnection Point Midi (GWh/d)

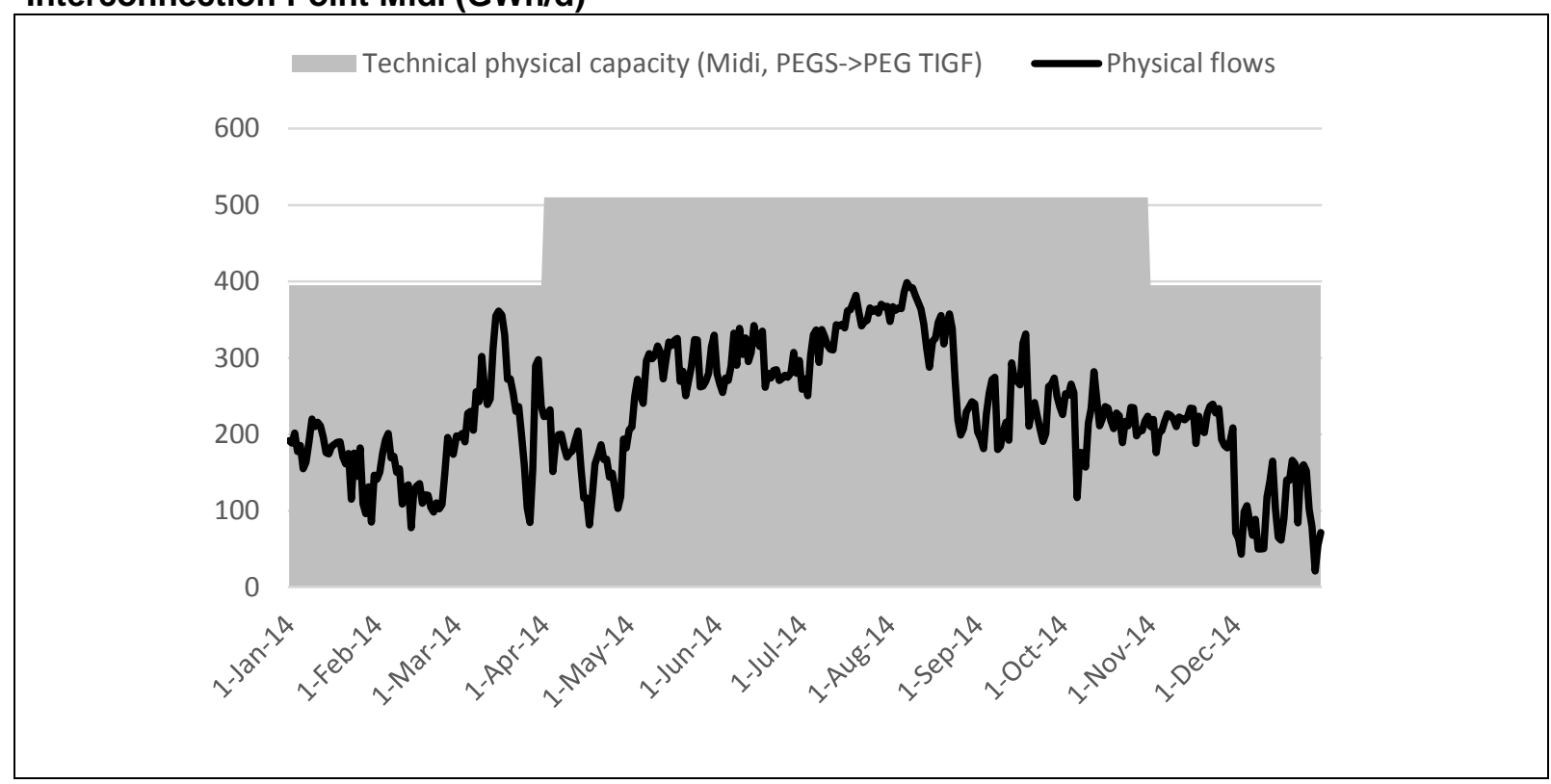

Source: GRTgaz, ENTSO-G Capacity Map

These dynamics suggest that there should be strong price correlation between gas prices in Spain and those in PEGS. Unfortunately we do not have trade-backed price data for the Spanish gas market. However, the French Energy Regulator reports that there is convergence between the monthahead prices at PEGS and in the Spanish market ${ }^{64}$.

Price alignment between South of France and Spain may strengthen in the future due to planned investment in the interconnecting infrastructure: the project of building a new cross-border pipeline (Midcat, with a capacity equal to $8 \mathrm{bcm} /$ year) connecting France and Spain has been prioritised in a recent memorandum between the European Commission and the governments of South Western Europe ${ }^{65}$.

Based on this market context, in 2014 CRE declared its willingness to further optimise the use of the North- South link ${ }^{66}$. Such measures include:

- extension of the additional firm capacity service (JTS67);

- improvement of North-South interruptible capacity availability;

- purchase of services to have gas located in the south-east in the event of congestion, for instance by reserving capacity and building up stocks of gas in the storage facilities located in the south of France;

- a reduction in short-term capacity tariffs at the North-South link;

- strengthening of GRTgaz's regulatory incentive on the JTS.

\footnotetext{
${ }^{64}$ Source: CRE (2014) P.7.Data for Spanish MA contract are based on ICIS Heren price assessment.

65 Source: http://www.snam.it/en/Media/energy-morning/20150625_1.html

${ }^{66}$ Deliberation of the French Energy Regulatory Commission dated 7 May 2014 setting out guidelines for the creation of a single marketplace in France by 2018

${ }^{67}$ Joint Transport Storage: Capacity at the North-South link available thanks to the joint optimisation of GRTgaz's system and Storengy's storage facilities, sold by GRTgaz on a day-ahead basis.
} 

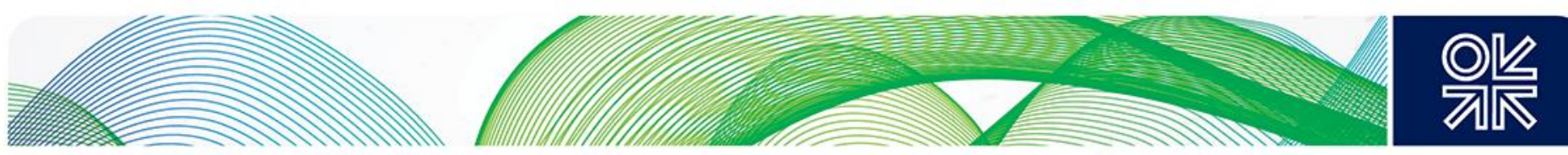

At this stage a merger of the North and South zones is not deemed worth the cost, according to CRE, however it is targeted for 2018. In particular, the planned reinforcement of the North-South link (notably through the construction of the Arc de Dierrey ${ }^{68}$ and the Val de Saone ${ }^{69}$ projects) should ease the bottleneck between the Southern France and the rest of the country and Europe.

Note that a pilot GRTgaz project of coupling the PEG Nord and PEG Sud markets (implicit allocation scheme), for a limited amount of the full interconnection capacity, has been in place since $2011^{70}$. The merger of the two Southern market zones, with the creation of the new TRS hub, may be seen as first step towards the creation of a single wholesale gas market in France by $2018^{71}$.

\subsection{CEGH misalignment in 2014}

Correlation metrics point out some misalignment of CEGH day ahead prices compared to NW Europe hubs (TTF/NCG/GSL), in the second half of 2014. Starting from August 2014 the NCG-CEGH spread widened, while CEGH and PSV remained well aligned (Figure 18).

Figure 18: OTC day ahead prices at NCG, CEGH, PSV (€/MWh)

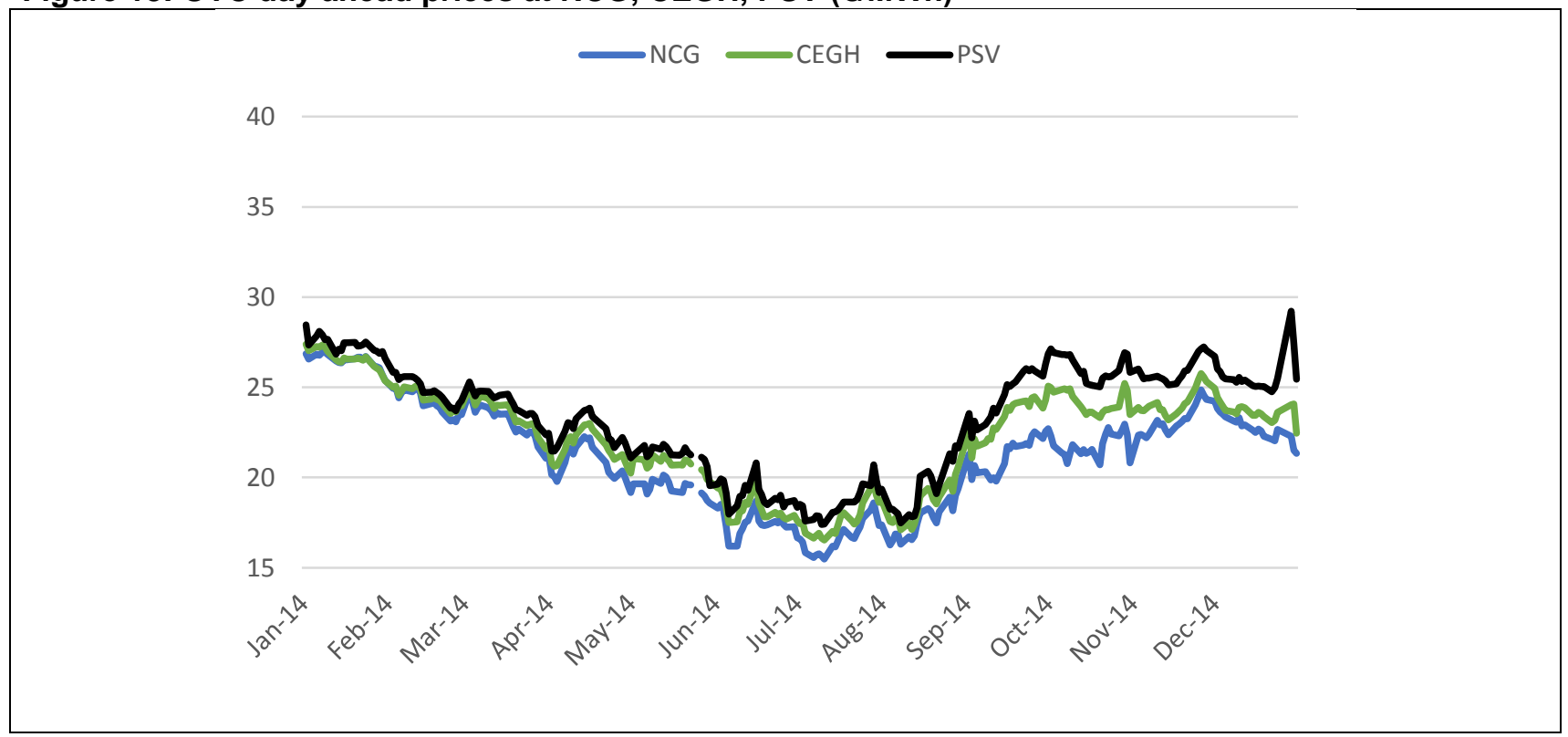

Source: Tankard Parties

The day ahead spread between NCG and CEGH was volatile in the second half of 2014, spiking to 4 $€ / \mathrm{MWh}$ in October $2014^{72}$, after gradually rising from around $0.1 € / \mathrm{MWh}$ in January and about 1 $€ / M W h$ in the summer season (Figure 19).

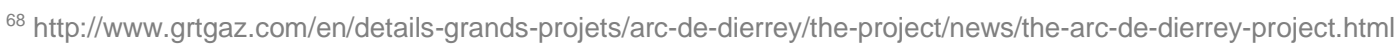

${ }^{69} \mathrm{http}: / /$ www.grtgaz.com/en/major-projects/val-de-saone-project/presentation/news/val-de-saone-project.html

70 Source: ACER (2015a), Annex 6 p.18

71 Source: https://www.eex.com/en/about/newsroom/news-detail/pegas-introduces-trading-for-new-common-market-area--trs-in-southern-france-on-31-march---trs-to-replace-existing-peg-sud-and-peg-tigf-market-areas/84950

72 This is much higher than the transmission tariff. The cross-border transmission charge to exit Germany towards Austria ranged between 86 to 161 thousand euros in 2013, for an assumed 1GWh/day/year flow, while the cross-border transmission charge to enter Austria from Germany equalled 61 thousand euros in 2013.Source: ACER (2013) P.194
} 

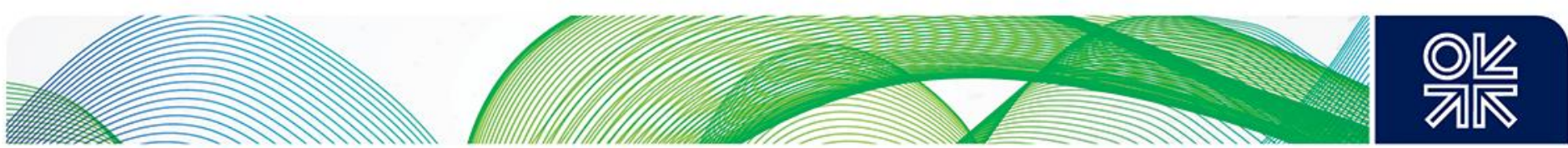

Figure 19: OTC day ahead price spread between NCG and CEGH (€/MWh)

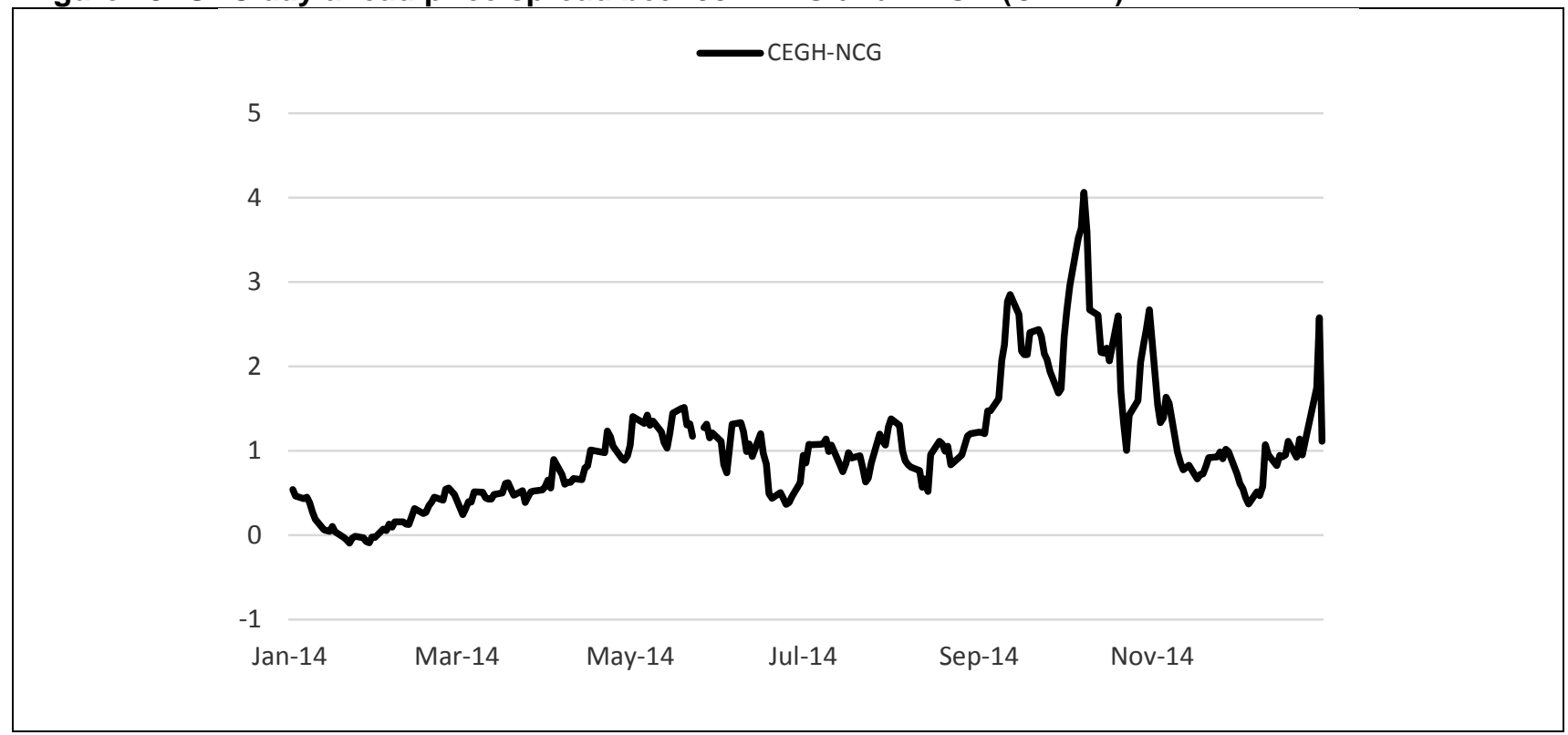

Source: Tankard Parties

Scatter plots confirm that the correlation between NCG and CEGH became weaker in 2014 H2; in particular the red circle refers to prices in September to December 2014, when CEGH had a substantial premium to NCG.

Figure 20: Scatterplot for CEGH and NCG OTC day ahead prices (€/MWh)

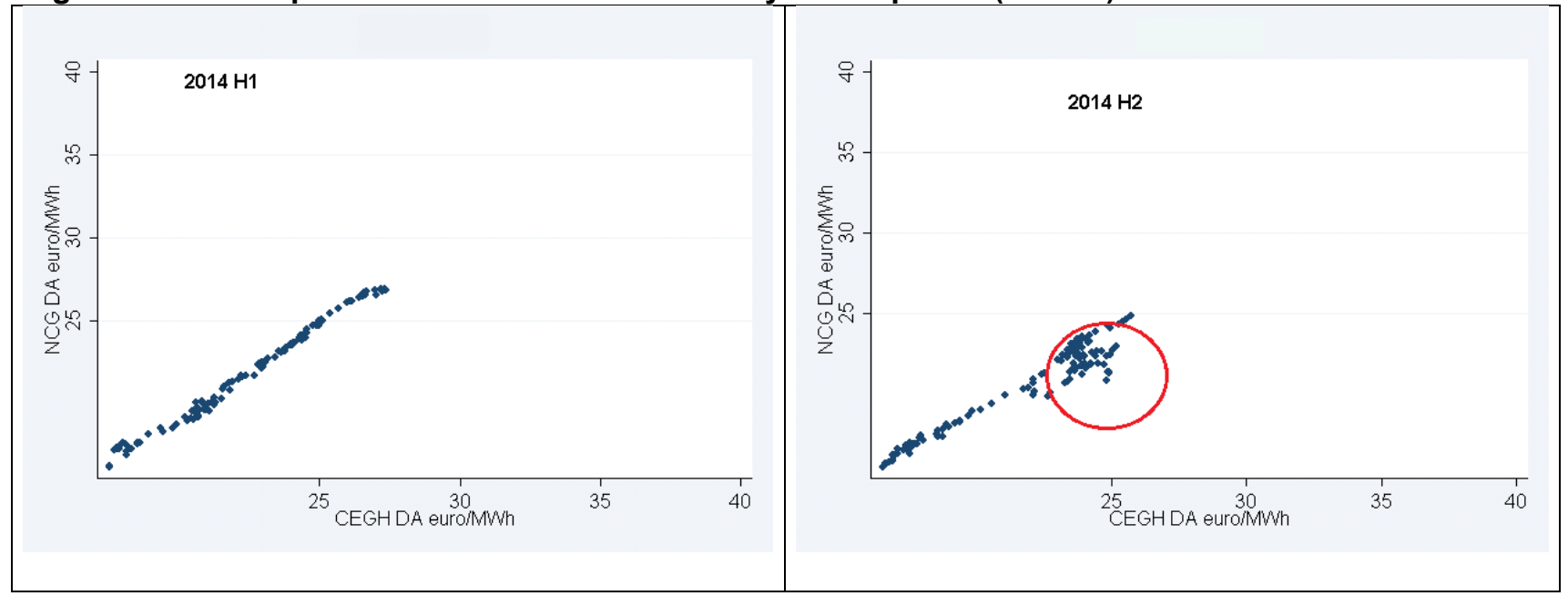

Source: Tankard Parties

Based on our theoretical framework this evidence suggests that there may have been some form of congestion of interconnecting capacity between the German NCG and Austrian CEGH in the second half of 2014. 

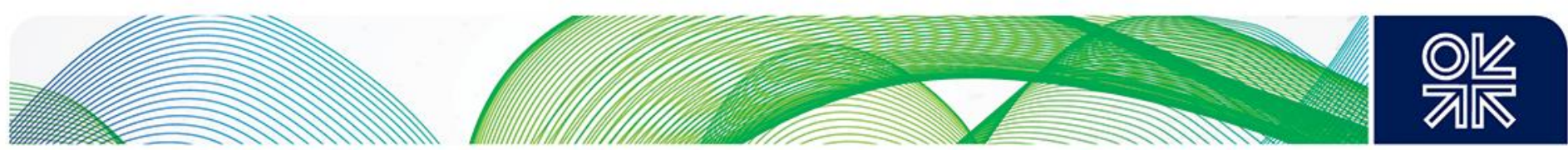

As $\mathrm{CEGH}$ is physically linked to $\mathrm{NCG}^{73}$, we looked for evidence of physical congestion at the main interconnection point between the two markets, which is Oberkappel, located on the Germany-Austria border, at the extreme of the bidirectional WAG pipeline ${ }^{74}$.

A simplified scheme for Oberkappel IP is presented below (Figure 21).

Figure 21: A simplified scheme for Oberkappel IP IP side 1 (DE to AT)

IP side 2 (DE to AT)
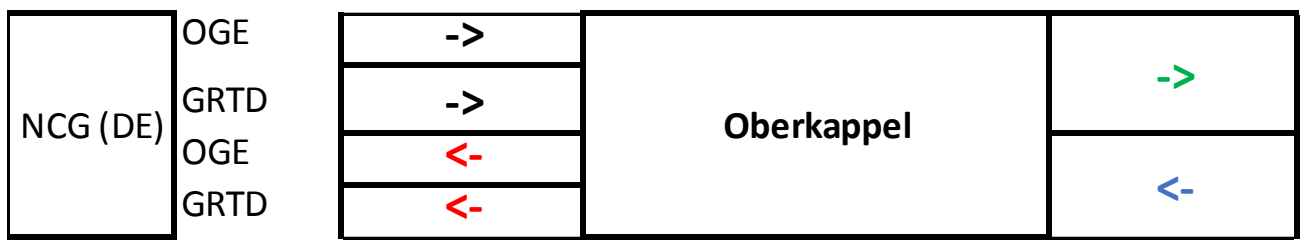

GCA

GCA

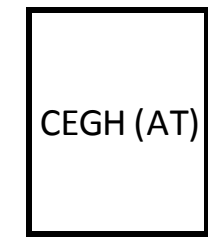

IP side 2 (AT to $D E$ )

IP side 1 (AT to $D E)$

Source: Author

Oberkappel connects the German MEGAL BIS Pipeline with the WAG pipeline. WAG can be used in a flexible way for arbitrage flows. Through WAG Austria can import gas directly from NCG, in addition, gas coming mostly from Russia can also flow through this pipeline in the opposite direction ${ }^{75}$. Gas is typically sold from Austria to NCG in winter and from Germany to Austria in the summer.

Two TSOs operate NCG to CEGH flows at Oberkappel: Open Grid Europe (OGE) and GRTgaz Deutschland (GRTD). Gas Connect Austria (GCA, formerly BOG ${ }^{76}$ ) operates Oberkappel entry and exit from Austria. CMPs are implemented on both sides of the IP in the Germany to Austria direction. More specifically the firm day-ahead Use-It-Or-Lose-It (FDA UIOLI) mechanism applies ${ }^{77}$.

The maximum technical available capacity at Oberkappel for the NCG-to-CEGH direction is equal to $199.5 \mathrm{GWh} / \mathrm{d}$, while the maximum technical available capacity at Oberkappel for the CEGH-to-NCG direction is lower $\left(159.9 \mathrm{GWh} / \mathrm{d}^{78}\right)$.

Moreover, in the Germany to Austria direction, at Oberkappel IP the entry capacity to Austria is greater than the exit capacity from Germany ${ }^{79}$ (Figure 22). ACER reports that the sum of technical exit capacity on the German side is only $63 \%$ of the respective Austrian entry capacity, and, in the opposite direction, the German entry only has $43 \%$ of the Austrian exit capacity. ACER comments that in case of high demand for flows, the German side would in both cases constitute the physical bottleneck; interruptible capacity is offered and used to reduce the mismatch but may not be enough to solve the bottleneck.

\footnotetext{
${ }^{73}$ Note that CEGH is indirectly linked to GSL as gas may flow from Germany to the Czech Republic and then to Slovakia via the Lanzhot IP and finally from Slovakia to Austria via the Baumgarten IP

${ }^{74}$ Uberackern (AT)/Burghausen(DE) IP allows for flows from Austria to Germany only.

${ }^{75}$ Note that gas may flow from Austria to Germany passing via Oberkappel IP (technical capacity equal to $159.9 \mathrm{GWh} / \mathrm{d}$ )

,Überackern ABG/ Burghausen IP (technical capacity equal to $54.3 \mathrm{GWh} / \mathrm{d}$ ) and Überackern SUDAL / Burghausen IP (technical capacity equal to $230.1 \mathrm{GWh} / \mathrm{d}$ ). Source: ENTSO-G Capacity Map June 2014.

${ }^{76}$ BOG as TSO of the West Austria pipeline („WAG”) was merged into GAS CONNECT AUSTRIA GmbH („GCA”) on 1

September 2014. Source: http://www.bog-gmbh.at/.

${ }^{77}$ ACER (2015b), P. 35.

78 Source ENTSOG Capacity Map June 2014. ENTSOG Capacity Map applies the lesser rule where different Maximum Technical Capacities in the same direction are defined by the neighbouring TSOs for the same Interconnection Point side. Hence ENTSO-G Capacity Map data is closer to the capacity to exit Germany.

${ }^{79}$ ACER (2015b), P.36
} 

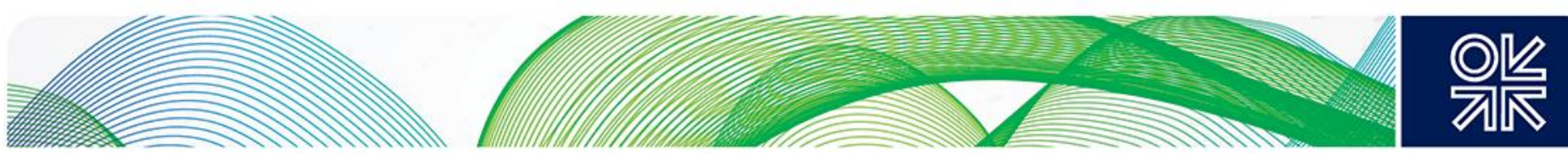

Figure 22: Firm Technical Capacity ${ }^{80}$ data for Oberkappel exit and entry, direction from DE to AT (GWh/d)

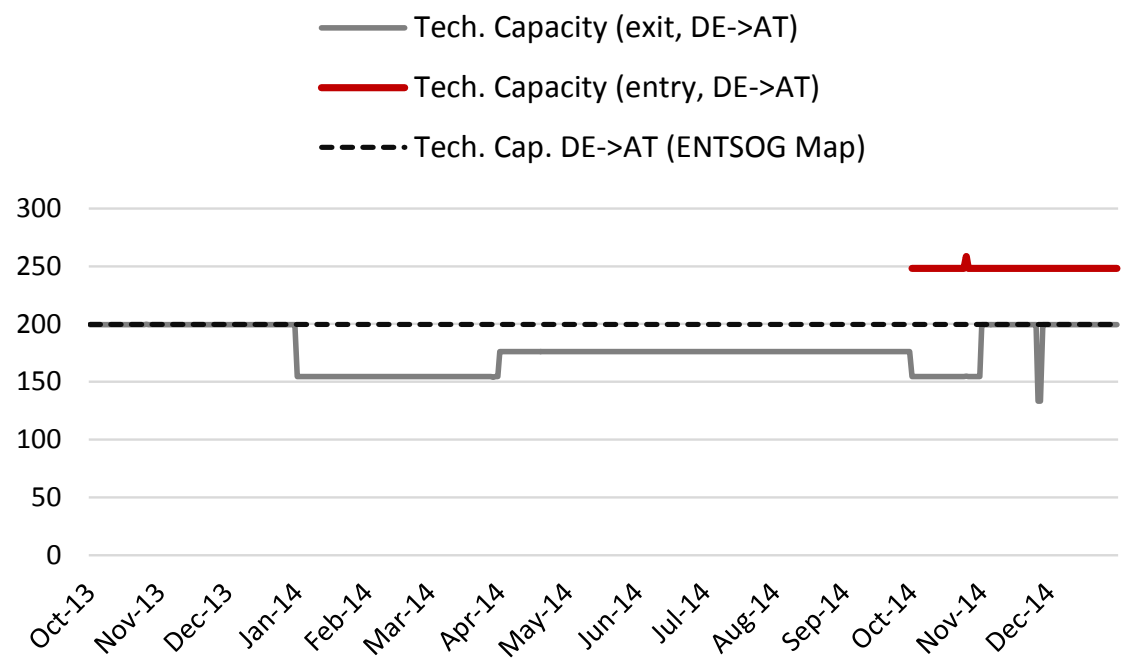

Source: ENTSOG Transparency Platform (data available from Oct-2013 exit from NCG and from October 2014 for entry to Austria), ENTSOG Capacity Map June 2014

Data for Oberkappel IP in the direction from German NCG to the Austrian market show that physical flows stay constantly above maximum technical capacity (computed with reference to the exit side), in particular starting from 2Q 2014 and in October 2013 (Figure 23).

Figure 23: Physical Flows ${ }^{81}$ and Firm Technical Capacity data for Oberkappel exit from DE to AT (GWh/d)

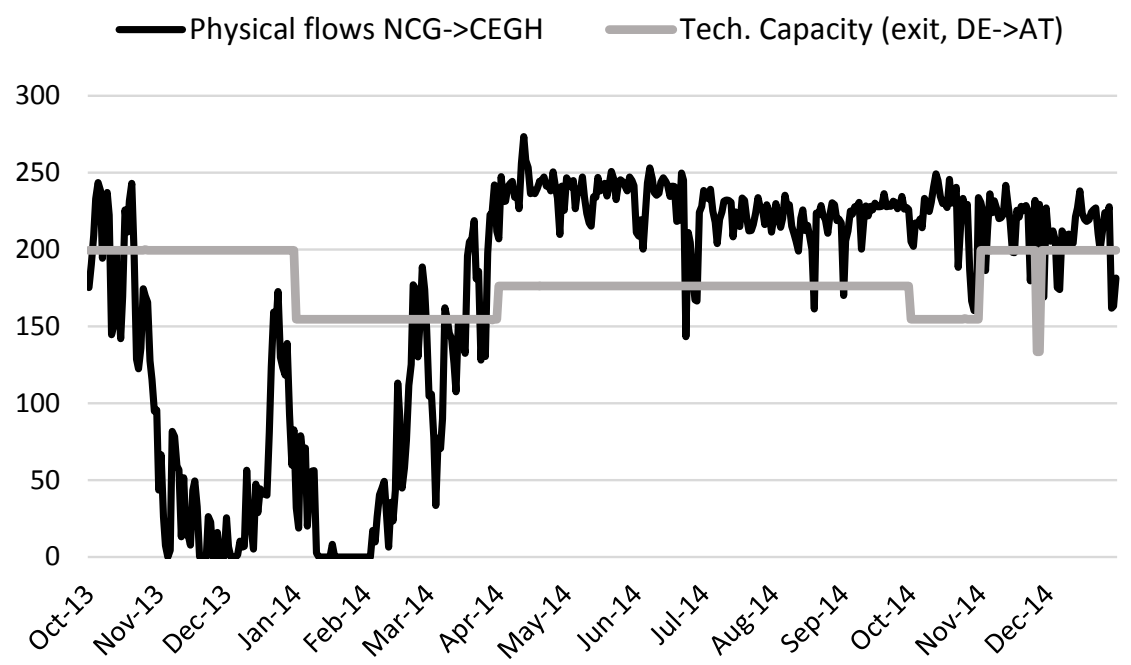

Source: ENTSOG Transparency Platform (data available from Oct-2013) and ENTSOG Capacity Map June 2014

\footnotetext{
${ }^{80}$ ENTSOG Capacity Map applies the lesser rule where different Maximum Technical Capacities are defined by the neighbouring TSOs for the same Interconnection Point side

${ }^{81}$ We assume that physical data reported by OGE represents total physical flows.
} 

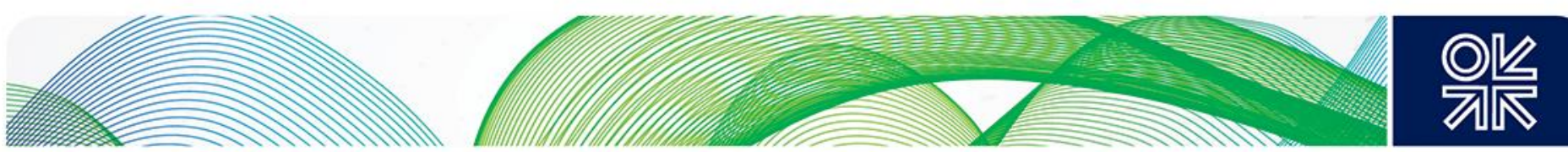

Monthly flow data published by IEA indicate that a high utilization rate of the interconnection from NCG and CEGH was frequent also in the past, especially during the summer season, when gas is typically sold from Germany to Austria (Figure 24). IEA data confirm also that physical flows exceeded the maximum technical capacity starting from April 2014 up to December 2014.

Figure 24: Monthly flows and maximum flow capacity data for Oberkappel IP (DE->AT) (GWh/month)

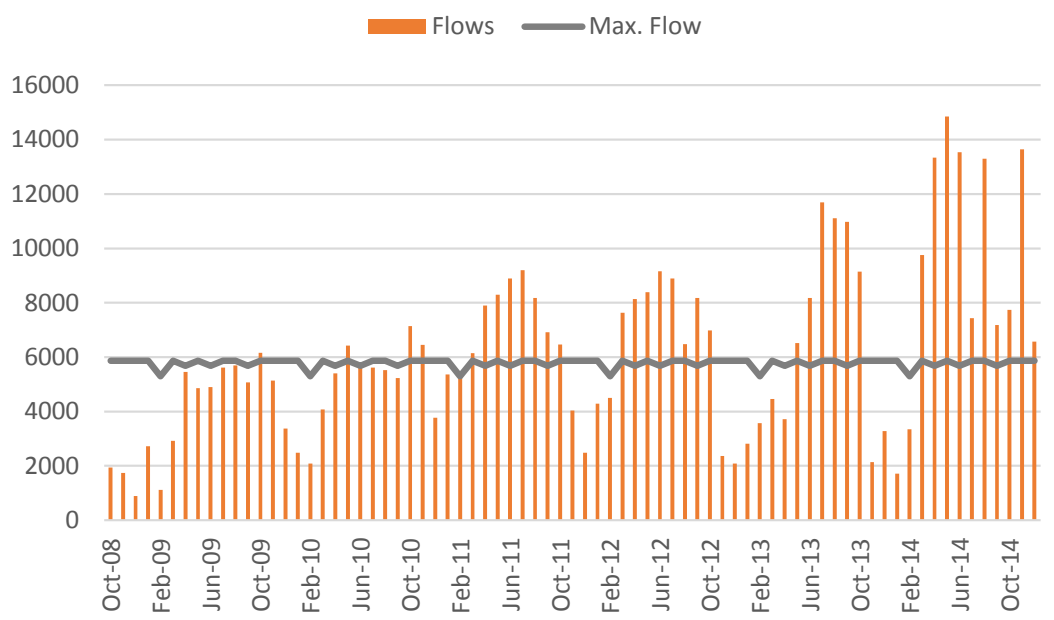

Source: IEA

Based on these data, the utilization rate of the link connecting Germany to Austria ${ }^{82}$ was constantly above 100\% starting from April 2014 (Figure 25). The physical flow exceeded the technical capacity at the German (exit) side on more than $70 \%$ of the days in 2014 .

This would point to semi-permanent physical congestion.

Figure 25: Oberkappel IP (DE->AT) utilization rate and day ahead price spread between NCG and CEGH ( $\%$ and $€ / M W h)$

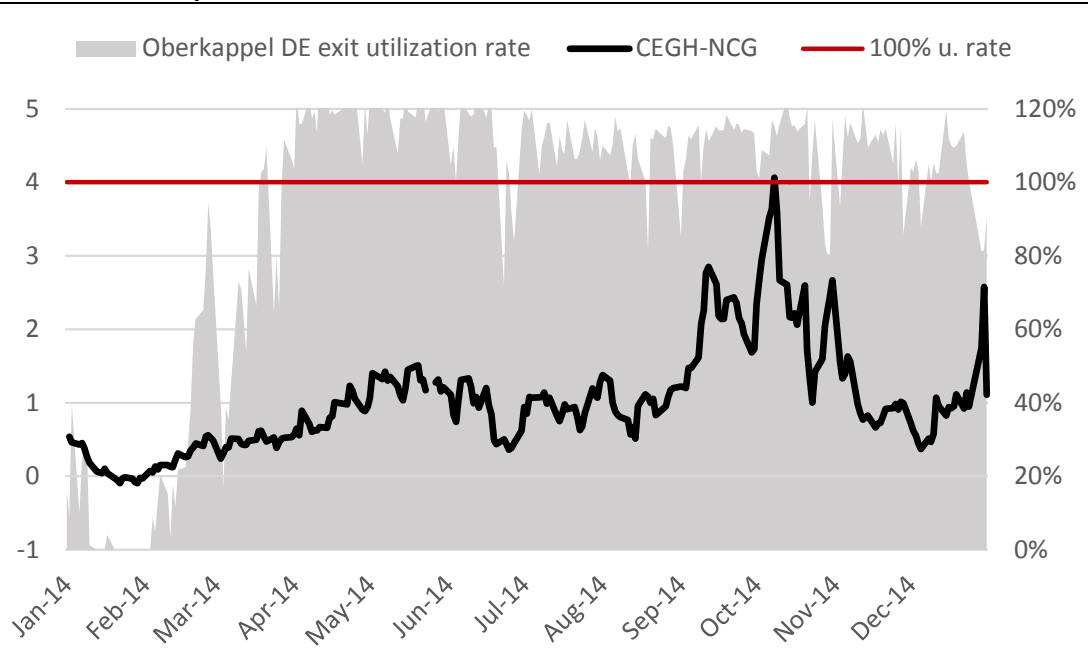

Source: Transparency Platform, Tankard Parties

\footnotetext{
${ }^{82}$ Computed as physical flows divided by the total technical capacity at Oberkappel exit, the latter being the maximum technical physical capacity to flow gas from Germany to Austria. We look at exit capacity from Germany, rather than at entry capacity to Austria, as the latter is higher. Data from Transparency Platform.
} 

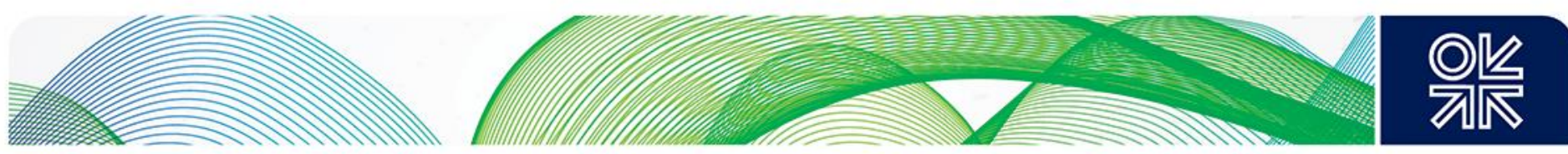

Does this actually indicate physical congestion? The fact that reported physical flows normally exceed the declared maximum technical capacity suggests that the TSOs operating Oberkappel exit from Germany have the capability to flow more gas than the 'official' maximum technical capacity. The latter may in fact be computed in a conservative way, particularly as far as firm technical capacity is concerned.

ACER in its CMP Implementation report confirms that "usage in direction DE->AT in winter periods is at times above technical firm capacity of DE single TSOs, due to very strong usage of interruptible capacity products (i.e. due to either netting with the adjacent TSO or favourable pressure conditions upstream)"83. However, ACER also notices that interruptible capacity in the direction from Germany to Austria is interrupted relatively frequently, due to pressure constraints in the Megal System. Negotiations about a pressure service agreement are still ongoing to increase technical capacity at the DE side and to prevent/reduce interruptions ${ }^{84}$.

This suggests that in 2014 the offer of interruptible capacity was not enough to solve the bottleneck.

If more spare capacity is made available in the direction from NCG to CEGH, in particular as far as the exit side from Germany is concerned, it is likely that price alignment between CEGH and NCG would strengthen.

The relationship between the availability of capacity at the German exit side and the price spread is supported by the fact that in Q1 2014, when the utilization rate was on average below $100 \%$, the CEGH-NCG price correlation was higher than in the April-December 2014 period, when instead the capacity to exit Germany was highly saturated.

In addition, data for 2014 show that when the utilization rate of the interconnection between NCG and CEGH was below $80 \%$ the spread was around $0.5 € / \mathrm{MWh}$, while higher spreads occurred on days when the utilization rate was above 100\% (Figure 26).

Figure 26: Scatterplot: CEGH-NCG day ahead spread against utilization rate at Oberkappel IP, direction: NCG->CEGH (€/MWh, \%)

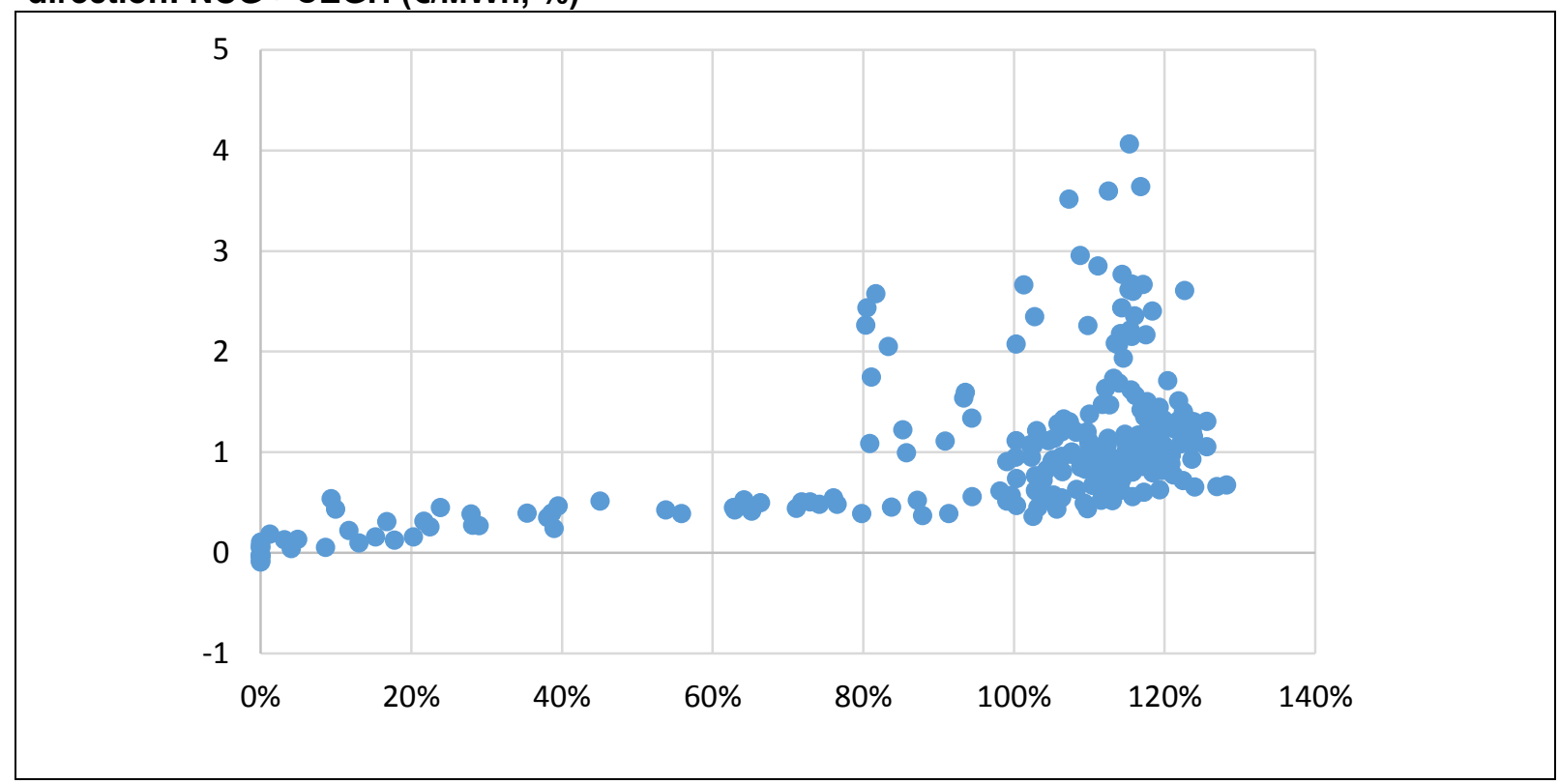

Source: Transparency Platform, Tankard Parties

${ }^{83}$ ACER (2015b), P.35-36.
${ }^{84}$ ACER (2015b), P.35-36. 

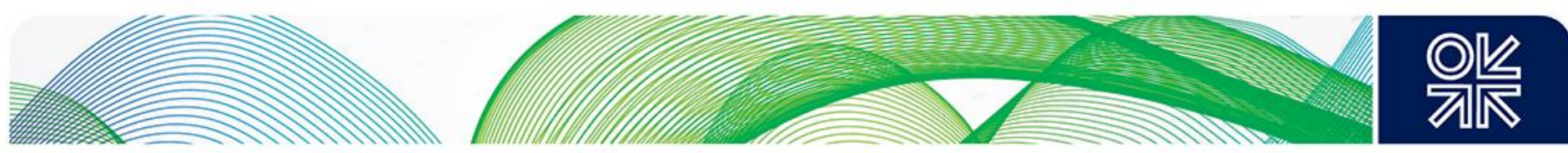

As stated above, and confirmed using IEA data, gas flows from NCG to Austria typically peak during the summer season, when gas is typically sold from Germany to Austria. In 2014, however, flow levels remained high also at the beginning of the winter, possibly as a consequence of reverse flow to Ukraine and unmet nominations of Russian gas passing through the Ukraine corridor, which had to be replaced by gas coming from Germany.

The heavy and more prolonged resort to exports (than in the past) from Germany to Austria via Oberkappel may have prevented arbitrage between NCG and CEGH, reducing the price alignment in the last three quarters of 2014 compared to Q1 2014.

However, even if Oberkappel IP was fully saturated, arbitrage between CEGH and NCG may also have occurred indirectly, as CEGH is linked to NCG via GSL, Slovakia and the Czech Republic. Some other factors hence may have prevented the "indirect" arbitrage between GSL and CEGH. As noticed in Petrovich (2014), in May 2013 the Slovak TSO Eustream increased the Lanzhot entry tariff and this may have prevented some "indirect" arbitrage between GSL and CEGH ${ }^{85}$.

\subsection{PSV misalignment in 2014}

Evidence shows some misalignment of PSV day ahead prices compared to NW Europe hubs (TTF/NCG/GSL), starting from the second half of 2014.

The day ahead spread between NCG and PSV was volatile at the end of 2013 and in 2014, spiking in December 2013 and constantly increasing starting from April 2014. The PSV premium on the NCG stayed around $3 € / M W h$ in the last quarter of 2014.

The PSV-NCG price difference in the Q2-Q4 2014 period was above the typical spread we observed in times of virtually perfect alignment between the two market zones. In particular, in $1 \mathrm{H} \mathrm{2014}$, when the correlation coefficient was at 99\%, the median spread equalled about $1.3 € / M W h$ (Figure 27).

Figure 27: Median OTC DA price spread between PSV and NCG against the price correlation scores

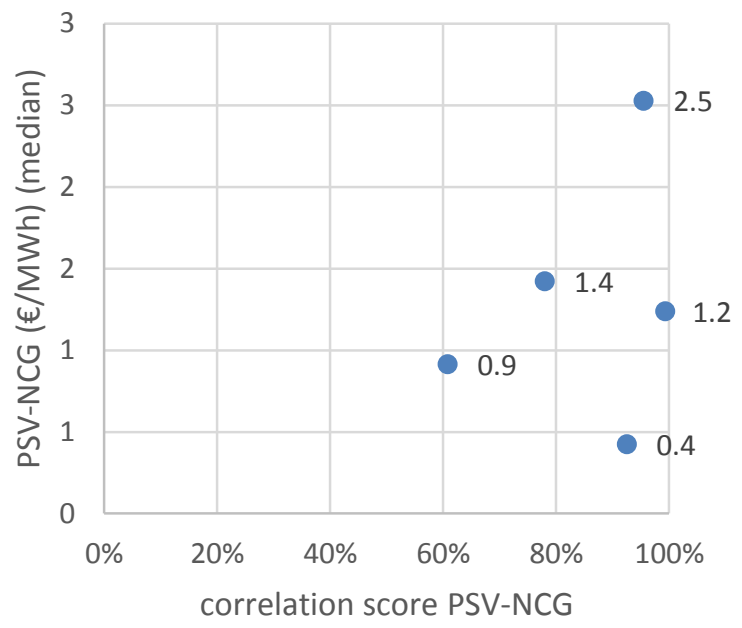

Note each dot refers to one of the following periods: $2 \mathrm{H} 2012,1 \mathrm{H} 2013,2 \mathrm{H} \mathrm{2013,1H} \mathrm{2014,2 \textrm {H }} 2014$.

Source: Tankard Parties

\footnotetext{
${ }^{85}$ Petrovich (2014).
} 

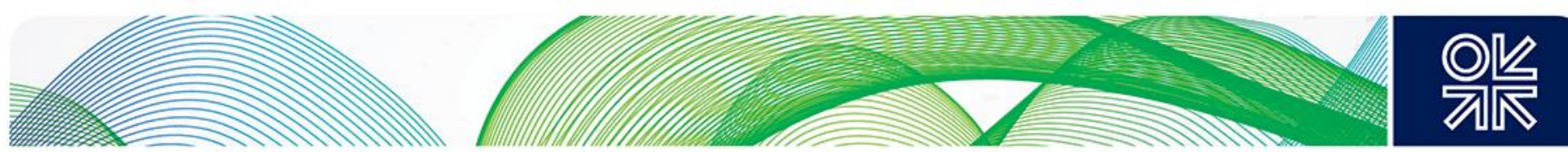

The spread observed in $2 \mathrm{H} 2014$ was also significantly higher than the transmission charge (the cost to bring gas from Germany to Italy is estimated at about $0.7 € / \mathrm{MWh}^{86}$, Figure 28). This is consistent with ACER (2013) which shows that, in the German-to-Italy direction, the average price spread was above transmission charges in $2013^{87}$.

Figure 28: PSV-NCG DA OTC price spread, estimated reference level and estimated transmission charge from NCG to PSV ( $€ / M W h)$

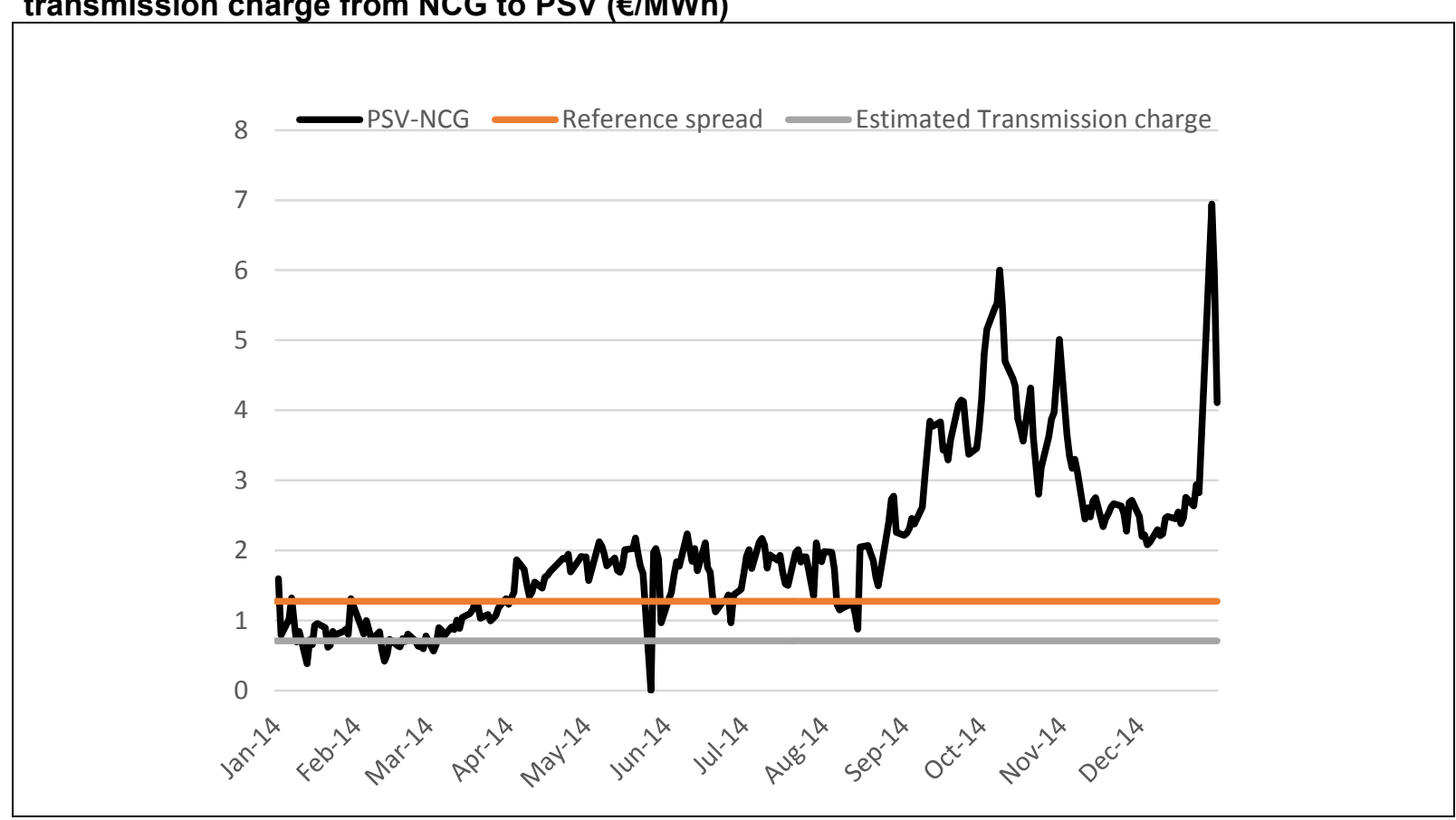

Note: Reference spread =average NCG-PSV spread when the NCG-PSV OTC DA price correlation coefficient was at $99 \%$. Estimated Transmission charge at respective IPs = estimate for the cost to transport gas from NCG to PSV. 88

Source: Tankard Parties, ACER (2013)

The correlation between NCG and PSV improved in the first half of 2014 compared to 2013 and then lessened in $2 \mathrm{H} 2014$, as shown in the scatterplots.

\footnotetext{
${ }^{86}$ The estimate accounts for the average transmission charge to exit Germany at Wallbach IP (2 TSOs active on this border) and the transmission tariff to enter Italy at Passo Gries IP. This figure does not account for charges paid for entering and exiting Switzerland due to missing data on the Swiss border. The estimate is based on Figure 72 in the ACER 2013 Market monitoring report, where ACER presents a simulation of cross-border charges for flowing $1 \mathrm{GWh} /$ day/year by entry/exit IP, based on published 2013 tariffs and a "certain consumption profile". Figures provided by ACER are average charges, weighted by IP capacity level for those borders featuring more than one IP or operated by more than one TSO applying different charges. ${ }^{87}$ ACER (2013) P.180

${ }^{88}$ The estimate accounts for the average transmission charge to exit Germany at Wallbach IP (2 TSOs active on this border) and the transmission tariff to enter Italy at Passo Gries IP. This figure does not account for charges paid for entering and exiting Switzerland due to missing data on the Swiss border. The estimate is based on Figure 72 in the ACER 2013 Market monitoring report, where ACER presents a simulation of cross-border charges for flowing $1 \mathrm{GWh} /$ day/year by entry/exit IP, based on published 2013 tariffs and a "certain consumption profile". Figures provided by ACER are average charges, weighted by IP capacity level for those borders featuring more than one IPs or operated by more than one TSO applying different charges.
} 

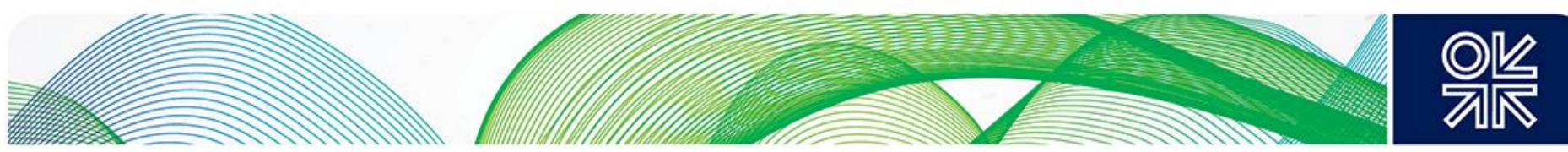

Figure 29: Scatterplot for PSV-NCG DA OTC prices (€/MWh)

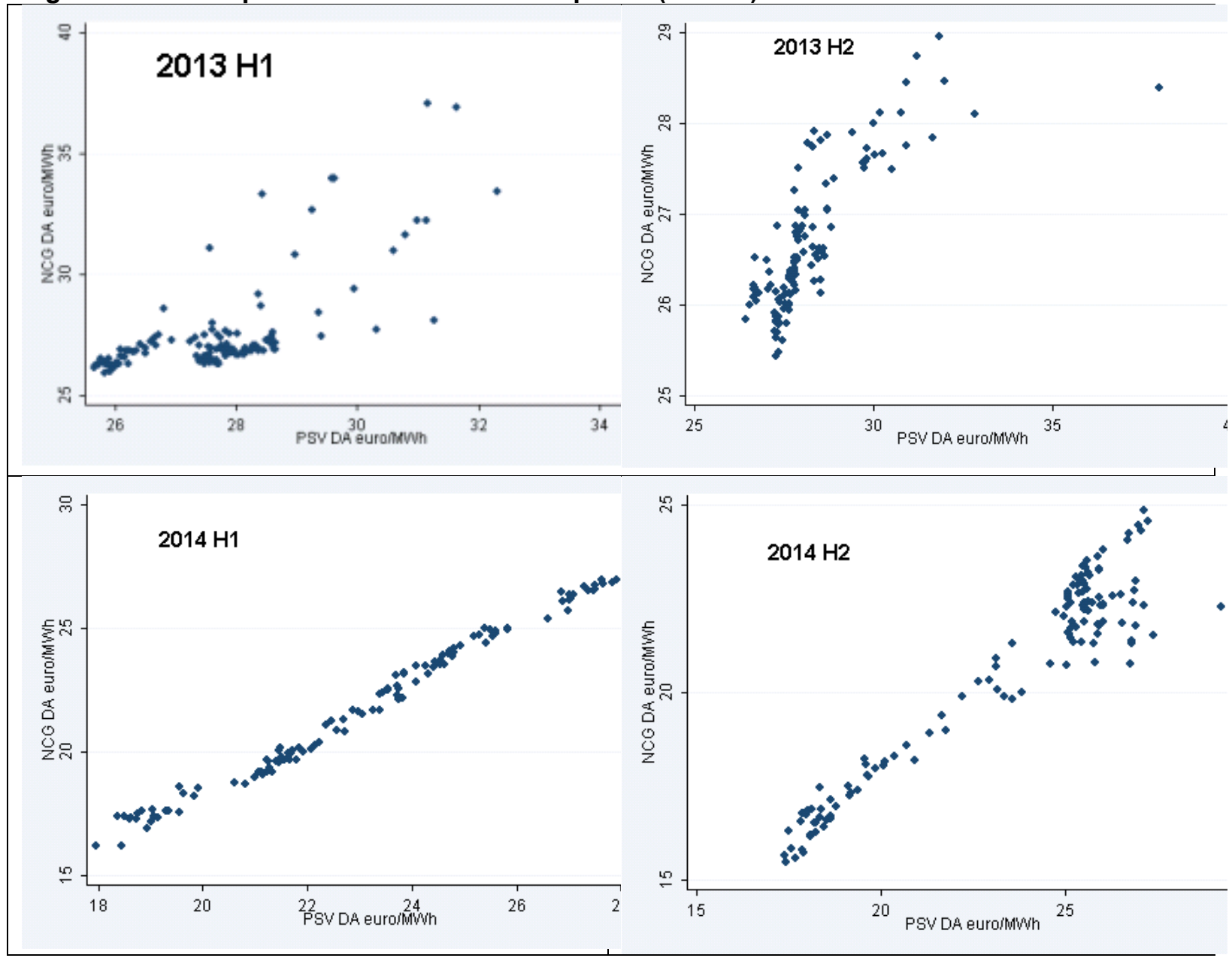

Source: Tankard Parties

Based on our theoretical framework this evidence suggests that there may be some forces preventing gas to flow from lower-priced NCG to the higher-priced PSV. One such force may be the physical congestion of interconnecting capacity between the German NCG and Italian PSV in the second half of 2014 .

Gas can flow from NCG to the PSV exiting Germany at Wallbach IP, at the end of the TENP pipeline, then passing through the Switzerland-based Transitgas pipeline and finally entering the Italian gas system at Gries Pass IP on the Italian-Swiss border (Figure 30). 

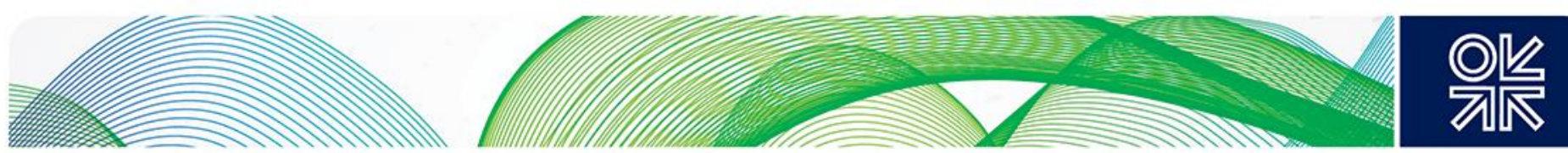

Figure 30: Simplified representation of Wallbach and Gries Pass IP

$\begin{array}{llll}\text { IP side 1 } & \text { IP side 2 } & \text { IP side 1 } & \text { IP side 2 } \\ \text { (DE to } & \text { (DE to } & \text { (CH to } & \text { (CH to } \\ \text { CH) } & \mathrm{CH}) & \text { IT) } & \text { IT) }\end{array}$
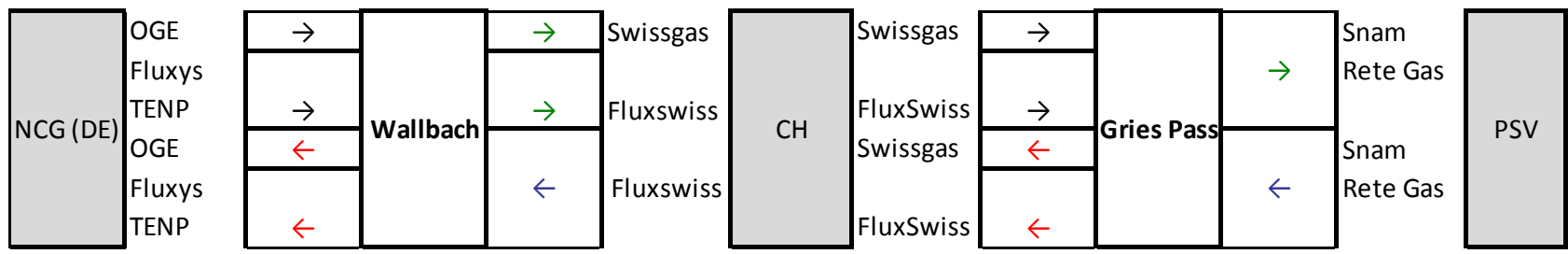

$\begin{array}{ll}\text { IP side } 2 & \text { IP side } 1 \\ \text { (CH to } & \text { (CH to } \\ \text { DE) } & \text { DE) }\end{array}$

$\begin{array}{ll}\text { IP side } 2 & \text { IP side } 1 \\ \text { (IT to } & \text { (IT to } \\ \text { CH) } & \text { CH) }\end{array}$

Source: Author, ENTSOG Capacity Map

In the second half of 2014 there is no evidence of physical congestion either at Wallbach IP in the NCG-Switzerland direction, or at Gries Pass IP in the Switzerland -PSV direction. The only exception is September 2014 when gas flows entering Italy saturated ${ }^{89}$ the infrastructure for 23 days (Figure 31 and 32).

Figure 31: Wallbach IP utilization rate and OTC day ahead price spread between NCG and PSV ( $\%$ and $€ / M W h)$

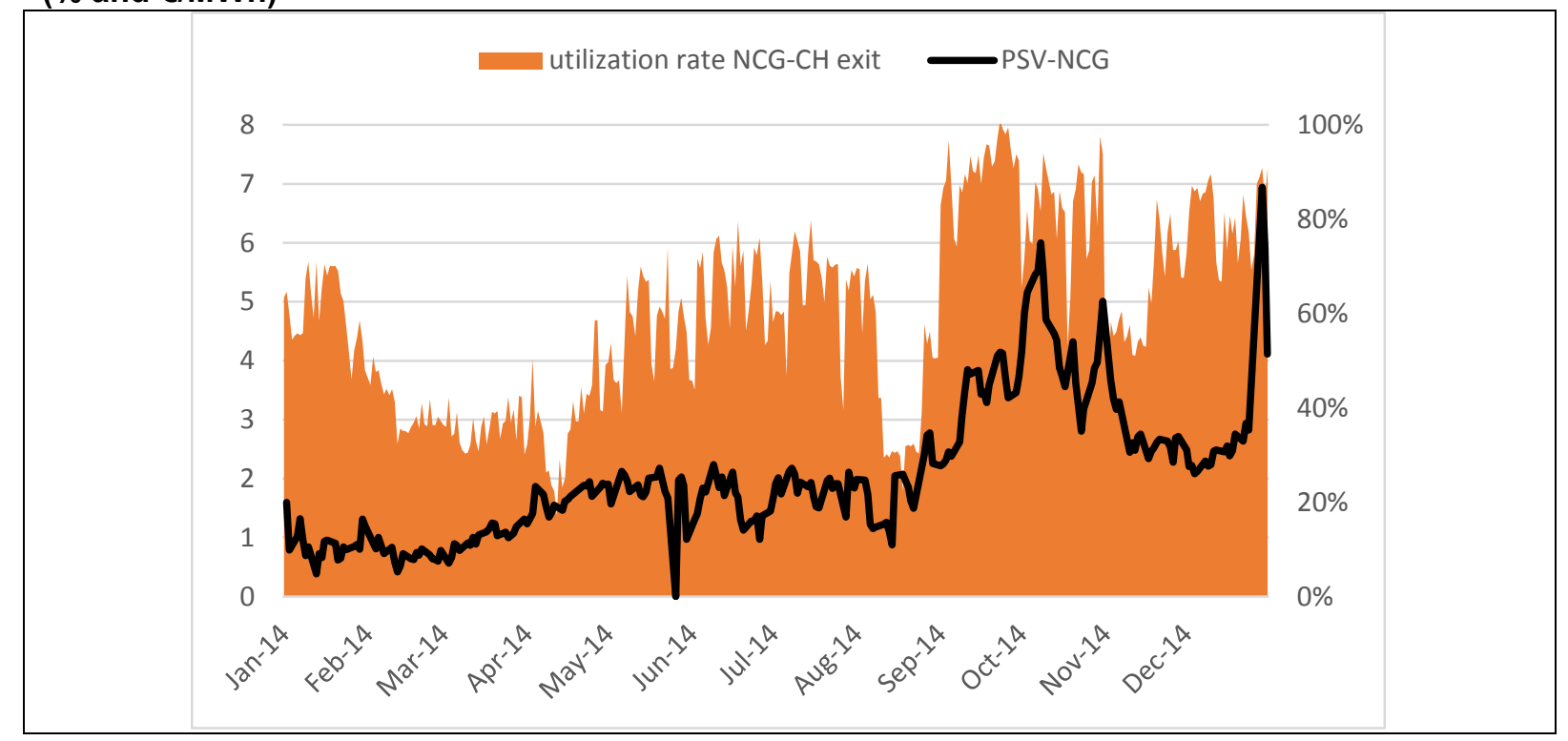

Source: Tankard, ENTSOG Transparency Platform

${ }^{89}$ Meaning utilization rate greater than $90 \%$. 

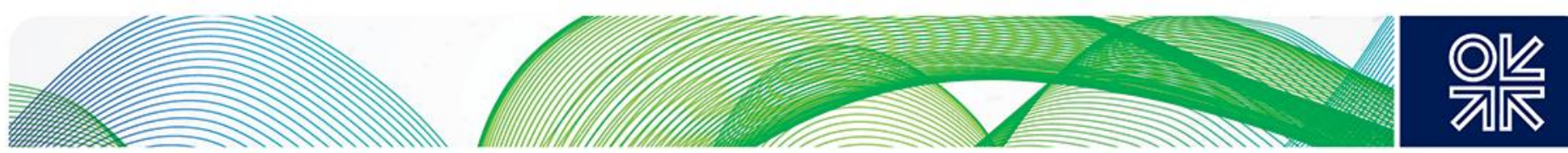

Figure 32: Gries Pass IP Utilization rate (CH-PSV, entry side) and day ahead price spread between NCG and PSV (\% and $€ / M W h$ )

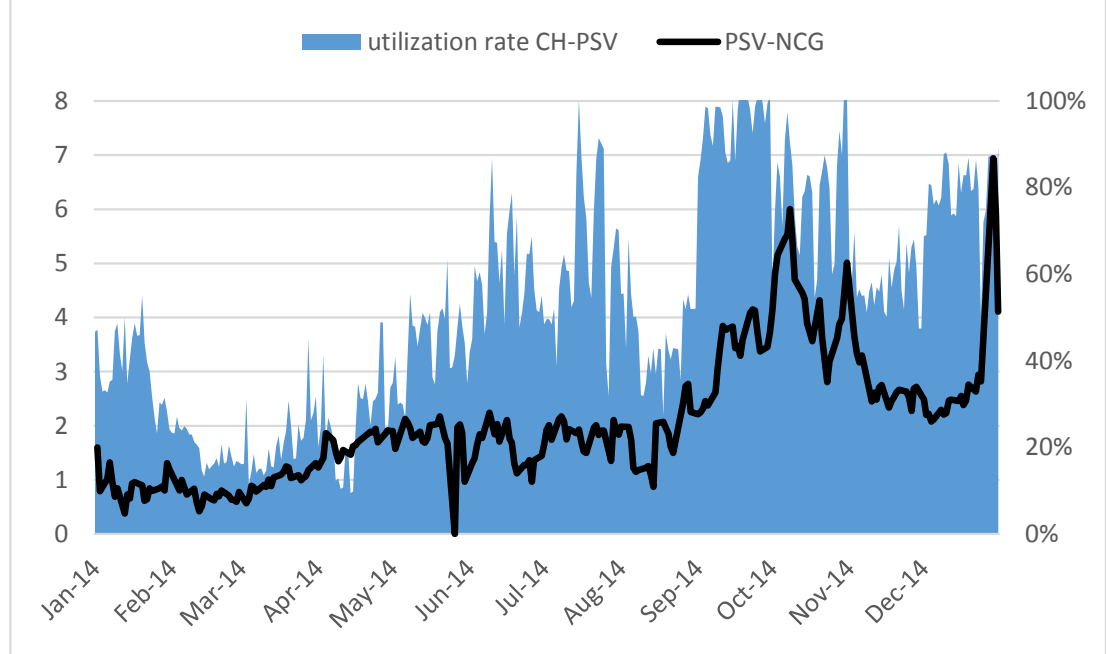

Source: Tankard, ENTSOG Transparency Platform, ENTSOG Capacity Map

At Wallbach IP, physical flows were close to maximum technical capacity only on $7 \%$ of the days in 2014, occurring in September and October 2014, while for the rest of the year a significant part of the interconnecting capacity was unused. Similarly to the Wallbach IP, physical flows on the Swiss-Italian border were close to maximum technical capacity only on $9 \%$ of the days in 2014 , concentrated in September 2014.

PSV is, in short, a somehow different story than other cases of price de-linkages occurring in 2014.

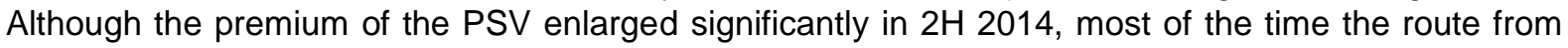
the lower-priced NW European hubs to the Italian hub was not physically congested: in 2014 at least $20 \%$ of interconnecting capacity ${ }^{90}$ was available, it was fully utilized only for limited periods, in September 2014 (Figure 33).

Figure 33: PSV-NCG OTC day ahead price spread (€/MWh) and utilization rate of the transmission capacity from NCG to PSV (\%)

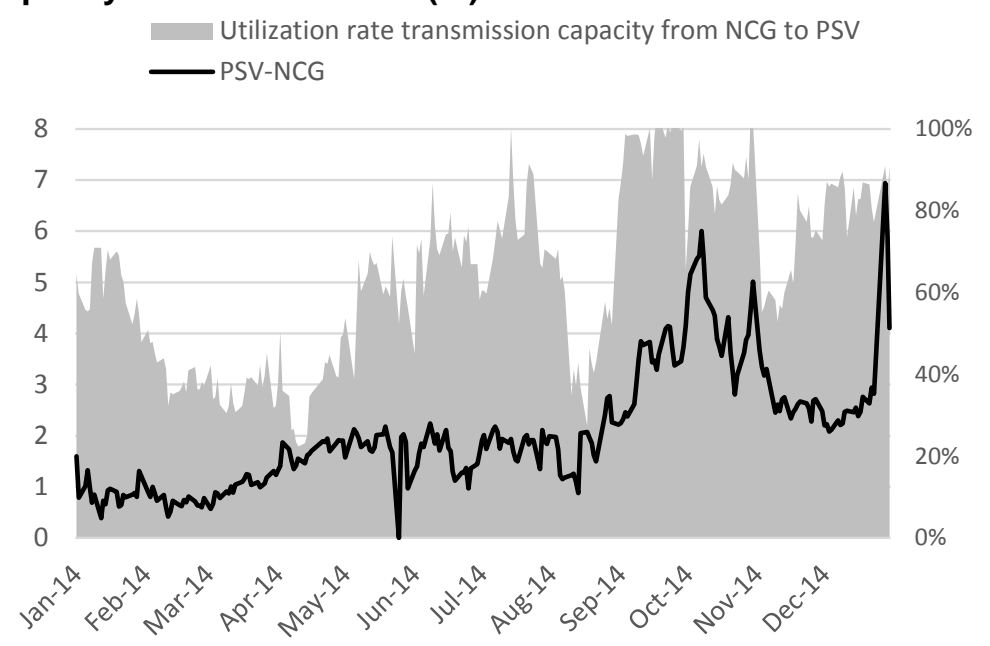

Source: Tankard Parties, ENTSOG Transparency Platform, ENTSOG Capacity Map

\footnotetext{
${ }^{90}$ Utilization rate computed as the maximum of the utilization rate of exit capacity from NCG to Switzerland at Wallbach IP and utilization rate of entry capacity from Switzerland to Italy at Griespass IP.
} 

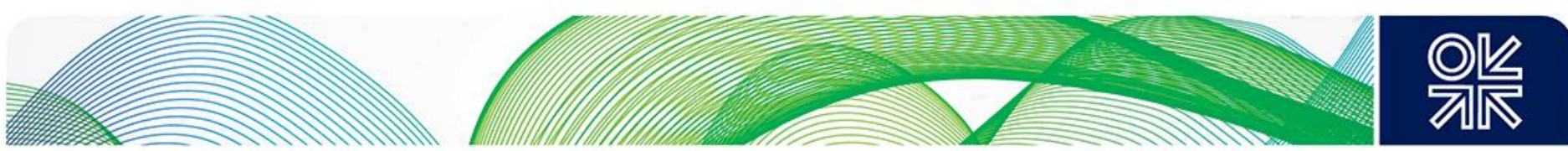

The PSV-NCG price spread stayed above $2 € / M W h$ (an amount roughly equal to double the transmission tariff) also when more than $10 \%$ of the capacity connecting NCG to PSV was unused (black area). In some days, at the same time, more than $50 \%$ of the capacity on the interconnecting link was free (utilization rate below 50\%) and the price differential was above $2 € / M W h$.

Figure 34: Scatterplot: PSV-NCG day ahead spread against utilization rate of the transmission capacity connecting NCG to PSV

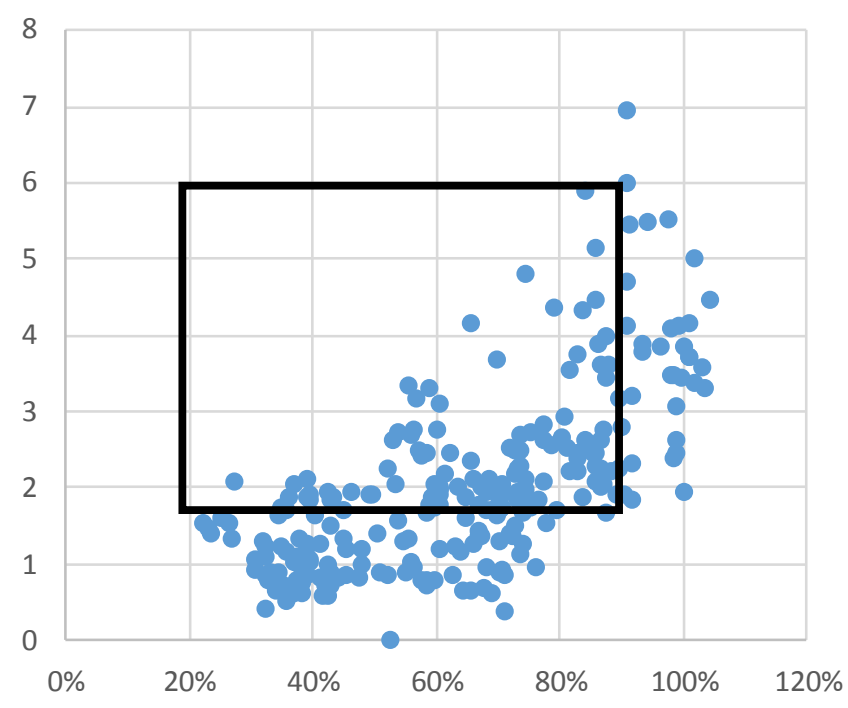

Black square: NCG-PSV price spread stayed above $2 € / M W h$ and more than $10 \%$ of the transmission capacity connecting NCG to PSV unused

Source: Tankard, ENTSOG Transparency Platform

This suggests that in this case market players do not fully exploit arbitrage opportunities due to the presence of other than physical barriers to trade, possibly relating to contractual congestion. Traders may not be able/willing to fully exploit the arbitrage opportunity - leading therefore to PSV and NCG day ahead prices not being aligned - for different reasons.

First of all, some transmission capacity on the route from NCG/TTF to PSV is booked long term by ENI ${ }^{91}$ and it may be not easily be made available to other participants when ENI does not use/nominate it, especially on the Swiss side, where transmission capacity allocation is performed through private auctions and EU rules on contractual congestion are not mandatory (unless an agreement is found with the Swiss authorities).

In fact in 2012, in response to an antitrust competition inquiry carried out by the Italian Antitrust Authority for alleged abuse of dominant position, ENI committed to release about $3 \mathrm{bcm}$ of transmission capacity booked on a long term basis on the TENP-Transitgas route, through subsequent system-marginal-price auctions ${ }^{92}$ to be held from September 2012 to October 2017.

\footnotetext{
91 Source: Case COMP/B-1/39.315- ENI - Commitments submitted to the European Commission,dated February 4, 2010, p.32 33. Available at: http://ec.europa.eu/competition/antitrust/cases/dec docs/39315/39315 2670 8.pdf. The Italian Antitrust Authority in September 2012 wrote that the share of transmission capacity on the Transitgas pipeline allocated to ENI on the basis of long term ship-or-pay agreements equals about 85-95\% of total capacity (Source: http://www.agcm.it/traspstatistiche/doc download/3287-a440chiusura.html , p.11)

${ }^{92}$ Source: http://www.agcm.it/trasp-statistiche/doc download/3287-a440chiusura.html
} 

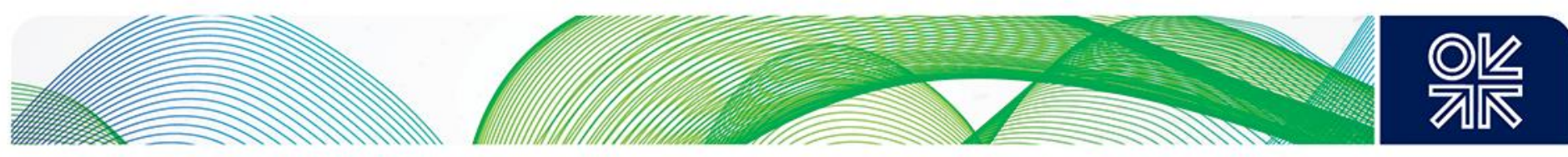

Auctions concern gas year and six-month capacity product and reserve price is equal to transmission tariffs paid by ENI to TSOs involved in the TENP-Transitgas, plus a "reasonable margin"93.

The results of such auctions are not publicly available. However, it is possible that some of the auctions did not clear as no player was interested in getting that capacity at those prices, leaving capacity unsold and not allowing for it to be used to exploit price differentials.

It may be argued that long term booked capacity, when not used by ENI, may have been made available to the market either on the secondary market, or by means of sales of interruptible capacity by the involved TSOs, or as a forced result of use-it-or-lose-it Congestion Management provisions (where these are implemented). In fact, the TSOs may have had an interest in selling the booked capacity (especially on an interruptible basis) if they believed that ENI would not be using it. Such capacity sales may have in fact allowed other participants to flow some gas from North West Europe to Italy, notwithstanding the presence of long term booked capacity.

However the persistence of the price differential and the under-utilization of cross border transmission capacity on the NCG-PSV pipeline system suggests that re-sales of pre-booked capacity were not enough to fully exploit arbitrage opportunities between the Italian market and other North West European markets.

Additionally, insufficient flexible capacity allocation procedures may have been an obstacle to price alignment. In fact traders may not be in a position to procure transmission capacity on time to exploit the price differential. Allocation procedures for capacity on the Swiss side are not totally transparent but it may be that capacity is not allocated on a day ahead/short term basis on the Swiss border.

If the barrier to trade between NCG and PSV is actually contractual congestion, it is possible that, once the mandatory resale of either systematically unused or non-nominated capacity on the TENPTransit pipeline system is enforced by Regulators by means of use-it-or-lose-it provisions ${ }^{94}$, the situation may change.

Another breakthrough may occur when the capacity at the Northern Italy border becomes bidirectional, so making it more attractive from a trader's perspective. In 2015 the TSO Fluxys made the final investment decision to turn Transitgas and TENP bidirectional; the physical reverse flow should be operating by the summer of $2018^{95}$.

\section{The cost of price de-linkages in 2014}

The latest available data show the record highest correlation scores: in 2014 the average correlation score is $96 \%$ and only one hub, the PEGS, displays prices which behave very differently from the others, while minor de-linkages are observed for Italy and Austria. However, these mis-alignments come at costs which are not negligible.

\footnotetext{
${ }^{93}$ Source: http://www.agcm.it/trasp-statistiche/doc download/3287-a440chiusura.html . See for instance the announcement for auction concerning the capacity for the October 2014-April 2015 period: http://www.eni.com/it_IT/azienda/attivita-strategie/gaspower/east-and-north-west-europe-auctions-winter2014-15.shtml?home_2010_en_tab=editorial\#.

94 Since April 2013 non-nominated capacity on the Italian side of the Gries Pass IP is offered on a day ahead interruptible basis. As of July 2015 LT UIOLI is not yet enforced on the Italian side of the Gries Pass IP.

${ }^{95}$ Source: http://www.fluxys.com/tenp/en/TenpSystemInfo/SouthNorthProject/ReverseFlow.
} 

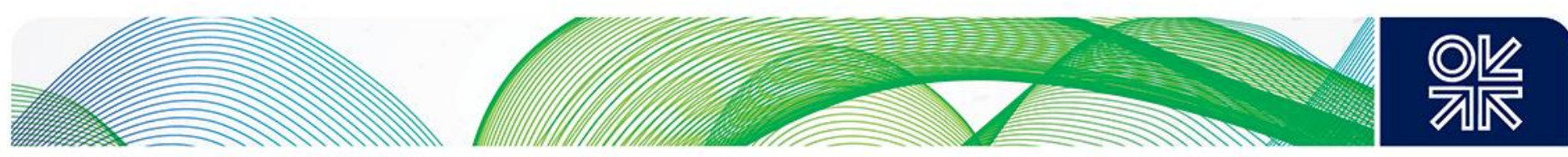

The cost of price de-linkage ${ }^{96}$ can be estimated as the increase in the gas procurement cost in the delinked market zone A, compared to a situation where gas is free to flow into A from another adjacent lower-priced market. The share of consumption in A subject to the cost increase caused by transmission capacity congestion can be estimated using IGU data on the share of hub-indexed consumption for that market. According to IGU/Nexant, the share of gas consumption priced on gason-gas competition is above $60 \%$ in the countries with the less aligned hubs (France, Italy and Austria) ${ }^{97}$ and we assume that the reference price for gas-on-gas competition is that of the hub located where consumption takes place (CEGH for Austria, PEGS for South of France and PSV for Italy).

Consumption volumes adopted to compute the cost estimates are based on Eurostat gross inland consumption data for Italy and Austria, and on GRTgaz data for consumption in the South of France ${ }^{98}$.

According to this approach (Figure 35), physical congestion between Germany and Austria resulted in an additional gas procurement cost in 2014 of about $€ 60$ million, most of which was generated by the CEGH price growing faster than NCG in September and October 2014.

Although the total volumes of gas sold at hub-based prices in the PEGS is similar to CEGH, the wider de-linkage of prices in the South of France compared to those in the adjacent PEGN translated into a cost four times higher than that estimated for Austria: about €240 million in 2014, concentrated mostly in January and February.

Due to the larger size of the Italian market, barriers to flow gas into PSV in 2014 translated into an estimated increase in gas procurement cost even higher than that of PEGS, amounting to $€ 330$ million. The cost burden was generated mostly in the September-December 2014 period, when the average premium against the NCG exceeded $2 € / \mathrm{MWh}$, but most of the time the cross border capacity was not fully utilized.

\section{Figure 35: Estimated consumption subject to price increase (TWh) and cost of de-linkage in 2014 (Emillion)}

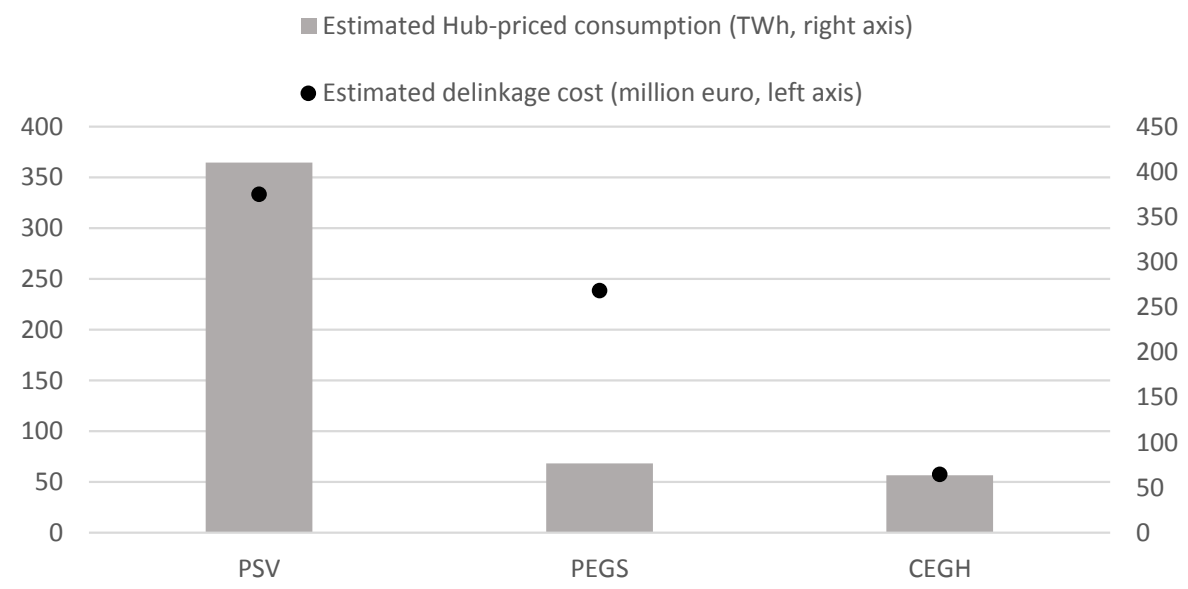

Source: Tankard Parties, Eurostat, GRTgaz, IGU/Nexant

\footnotetext{
${ }^{96}$ See ACER (2014a), P.184, for a similar exercise: ACER computes the potential annual net welfare gain if cross-border transmission capacities were fully used.

${ }_{97}$ Please note that IGU/Nexant kindly provided to OIES an estimate for France, Austria and Italy. We used France as an estimate for PEGS, ignoring the price differences between PEGN and PEGS. If PEGS oil escalation is more important in PEGS than in PEGN we may thus have overestimated cost of de-linkage for PEGS.

98. It is worth noticing however that this methodology slightly overestimates consumption corresponding to $\mathrm{CEGH}$, as two Austrian regions are actually part of NCG and not CEGH.
} 

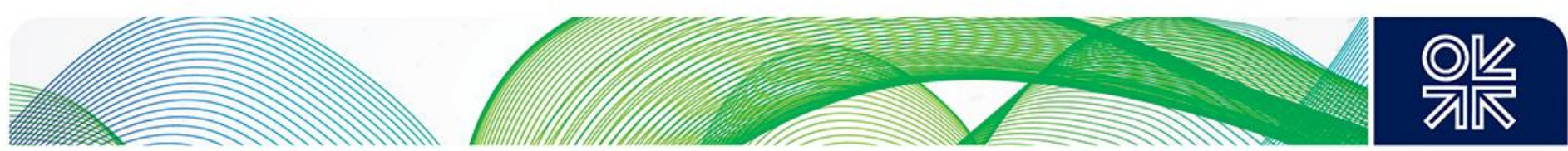

\section{Conclusions}

Previous work by OIES tracked the progressive path towards a Single European Gas Market ${ }^{99}$, with the aim of assessing the degree of integration of European gas markets and unveiling the remaining barriers to the free flow of gas across the borders.

Notwithstanding differences in traded volumes, this research ${ }^{100}$ has shown that, in the January 2007October 2013 period, day ahead prices set by demand and supply at the main European gas hubs ${ }^{101}$ were broadly aligned and featured generally good correlation, suggesting that the main European gas markets are spatially well integrated and competitive.

The same research also showed that exceptions to good correlation occurred in periods where pipeline bottlenecks (physical or contractual) or closure (for maintenance) had caused a de-linkage between prices at the main North Western European hubs and those of Italy (PSV), Austria (CEGH), Southern France (PEG Sud) and at times the UK (NBP). This finding supported the thesis that hub prices represent market prices (i.e. prices resulting from the interplay between demand and supply) in Europe.

The nature and causes of price de-linkages, however, could not be fully explored in the Author's 2014 work $^{102}$, due to lack of reliable and consistent data on gas flows between the markets, in particular as far as the Italian and the Austrian hubs were concerned.

Using the same simple approach, based on the analysis of price alignment (or "price correlation") between the main European gas hubs, the present report attempts to assess the recent evolution (up to December 2014) of integration in European gas markets and to provide a more robust analysis of the factors driving price de-linkages between the main European hubs. Secondly, the work assesses what is the cost for gas consumers of misalignment in gas prices across Europe, using an approach based on the determination of the increase in the gas procurement cost in a de-linked market zone, compared to a situation where gas is free to flow into this market from other adjacent lower-priced markets.

More specifically, the key research questions were the following:

- In 2013 we saw a decrease in the overall price correlation coefficient, due to price de-linkages between the main North Western Europe hubs and CEGH, PSV and PEG South: do we see an increasing gas price alignment in Europe in 2014? Are price de-linkages still occurring in 2014?

- What is the nature of the factors driving price misalignment? In other words, do price de-linkages signal physical or non-physical barriers to the trade of gas across borders?

- Can we provide a rough measure for the cost of price de-linkages?

This work relies on a new set of data on trades, which was made available by the Tankard Parties in 2015, and on flow data for all European interconnection points (IPs) starting from January 2014, released by the association of European gas TSOs (ENTSOG) at the end of 2014.

\footnotetext{
99 Petrovich $(2013,2014)$

100 Petrovich (2013), Petrovich (2014)

101 The main hubs where gas is delivered in Europe are: the NBP in Great Britain; TTF in the Netherlands; NCG and Gaspool (GSL) in Germany; Zeebrugge (ZEE) in Belgium; PEG Nord (PEGN), PEG Sud (PEGS), and PEG TIGF (PEGT recently merged into PEGS) in France; PSV in Italy and CEGH in Austria

102 Petrovich (2014)
} 

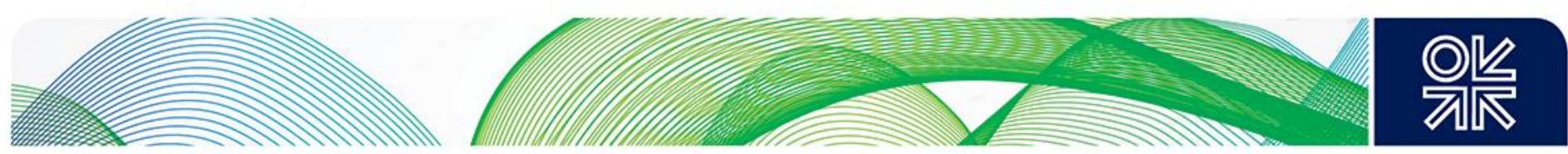

Latest available data show record high correlation scores: in 2014 the average correlation score was $96 \%$ (with $100 \%$ indicating perfect alignment) and only PEGS prices were substantially different from the other hubs, with minor de-linkages in Italy and Austria.

The North West Europe core group (ZEE, TTF, the German hubs and PEGN) stands out as it remains almost perfectly correlated over the whole period with these hubs behaving as a single integrated market area. In 2014 the NBP gas prices also moved in tandem with North Western Europe prices.

Periodic de-linkage, however, still occurs at the more peripheral hubs: not just at the PEGS, but also, although to a lesser extent, at the Italian and the Austrian hubs. Reductions in correlation scores signal that, still in 2014, we have barriers that prevented a full integration between the main gas hubs in Europe. The analysis shows that gas flows do not always fully exploit the arbitrage opportunities emerging between these peripheral markets and the core group, so impeding full price alignment.

The nature of these barriers is found to be mainly physical: de-linkages occur when there is physical congestion of the interconnecting infrastructure. On the other hand there is no evidence of widespread non-physical barriers to trade, with the exception of Italy.

As far as the Southern France is concerned, the analysis shows that the PEGS delinks when it is physically separated from PEGN due to LNG supply being diverted, requiring consumption to be met by higher flows from northern France, which in turn congests the interconnecting infrastructure between the two French market zones. As soon as the LNG supply increases in the South of France, which occurred at the end of 2014, the spare transmission capacity between the two adjacent French zones restored price alignment within France. The analysis suggests that the pilot project of coupling the PEG Nord and PEG Sud markets through an implicit allocation scheme, which has been in place since 2011 for a limited amount of the full interconnection capacity, was not enough to solve the bottleneck between PEGS and PEGN in times of LNG scarcity.

Austrian hub de-linkages are also related to physical congestion at Oberkappel (IP between NCG and CEGH), which tends to occur due to heavy exports from Germany to Austria during the summer which saturate the transmission capacity, especially due to physical constraints on the German side (disparity between entry and exit capacity, plus pressure constraints in the MEGAL system). The analysis suggests that in 2014 the offer of interruptible capacity was not enough to solve the bottleneck between NCG and CEGH. Moreover the request to flow gas from Germany to Austria was supported by the higher request for gas to be shipped towards Ukraine in 2014, or possibly to other European markets as a consequence of Russian gas supplies not meeting nominations in the summer of 2014.

The trigger factors which created physical bottlenecks were related to the inevitable changes in supply patterns to Europe: LNG being diverted from Europe in response to demand in the Asian market ${ }^{103}$ and the start of the reverse flow to Ukraine, after Russia stopped flowing gas to Ukraine in March 2014104 .

The analysis shows that the PSV story is somewhat different from the other cases of price delinkages which occurred in 2014. Although the PSV premium increased significantly in the second half of 2014, most of the time the route from the lower-priced NW European hubs to the Italian hub was not physically congested. In 2014 the PSV-NCG price spread stayed at an amount roughly equal to double the transmission tariff at a time when more than $10 \%$ of the capacity connecting NCG to PSV was unused.

The persistence of the price differential and the under-utilization of cross border transmission capacity on the NCG-PSV pipeline system suggests that neither re-sales of pre-booked capacity on an

\footnotetext{
${ }^{103}$ Global gas scenarios and consequence for the European gas market have been presented in Rogers (2015).

${ }^{104}$ Stern at al. (2014).
} 

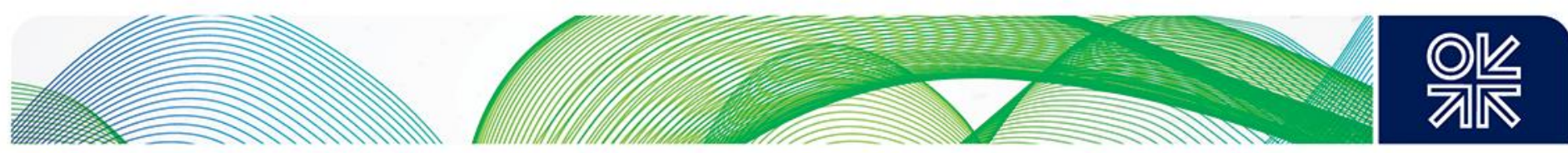

interruptible basis carried out by TSOs nor the release of long term booked capacity undertaken by ENI through periodical auctions were enough to fully exploit arbitrage opportunities between the Italian market and other North West European markets.

The analysis also suggests that traders may not be in a position to procure transmission capacity from NCG/TTF to PSV on time to exploit the price differential, possibly because allocation procedures for transmission capacity on the Swiss side are not harmonized or not transparent.

The analysis finally argues that these periodic price de-linkages come at non-negligible costs. This is due to the fact that above $60 \%$ of consumption in the countries with the less aligned hubs (France, Italy and Austria) is priced based on gas-on-gas competition (as reported by IGU/Nexant). Physical congestion between Germany and Austria resulted in an additional gas procurement cost in 2014 of about $€ 60$ million, most of which was accounted for by CEGH prices being higher than NCG in September and October 2014.

Although the total volume of gas sold at hub-based prices at PEGS is similar to CEGH, the wider delinkage of prices in the South of France compared to those at the adjacent PEGN translated into a cost of $€ 240$ million in 2014. The size of the Italian market meant that, in 2014, barriers to flow gas into PSV resulted in an estimated increase in purchase costs of $€ 330$ million incurred mostly in the September-December period, when the average premium over NCG exceeded $2 € / M W h$ but most of the time the cross border capacity was not fully utilized.

The findings in this work have relevant policy implications as different measures need to be undertaken depending on the nature of the de-linkage drivers, assuming that the policy maker is interested in avoiding price misalignments and the corresponding estimated cost for the gas consumers. Physical barriers (so called "physical congestion") can be removed by additional investment in the infrastructure, non-physical ones instead need to be addressed by rules which optimize the use of existing infrastructures.

This work indicates that the price disconnection still occurring in the South of France and Austria is due to physical barriers and therefore should be addressed by investing in infrastructure. The policy recommendation would then be to build new transmission capacity in France, where substantial investment has already been undertaken aiming at a single French gas market by 2018 . Similarly, for Austria, the indication would be to reinforce the existing pipeline system, possibly solving the pressure constraints in the MEGAL system: more spare capacity should be made available on the German exit side in the direction from NCG to CEGH, in order to strengthen the price alignment between CEGH and NCG.

The analysis also suggests that in the Italian case the policy makers' attention should be on enforcing the rules that optimise the use of existing capacity. If the barrier to trade between NCG and PSV is actually contractual congestion, regulators may consider the enforcement of mandatory resale of either systematically unused or non-nominated capacity on the TENP-Transit pipeline system by means of use-it-or-lose-it provisions, or other CMPs. This said, infrastructural investment could also play a significant role in further integrating the Italian market with the other more liquid European markets: turning the the capacity at Northern Italy border bi-directional will likely make it more attractive from a trader's perspective, fostering more intense cross border trading activity.

Summing up, the work concludes that the main gas hubs in Europe are already well integrated but some bottlenecks are still not solved. In order to alleviate such bottlenecks and the related price misalignment, in some parts of Europe investment and new rules on capacity optimization are needed so that transmission capacity is sufficient to allow for the free flow of gas in response to price signals. From a policy maker's point of view, the paper provides a methodology to determine where in the European gas grid debottlenecking initiatives are requested, and a methodology to determine the costs of price de-linkages, which is relevant in the assessment of the costs and the benefits of debottlenecking initiatives. 

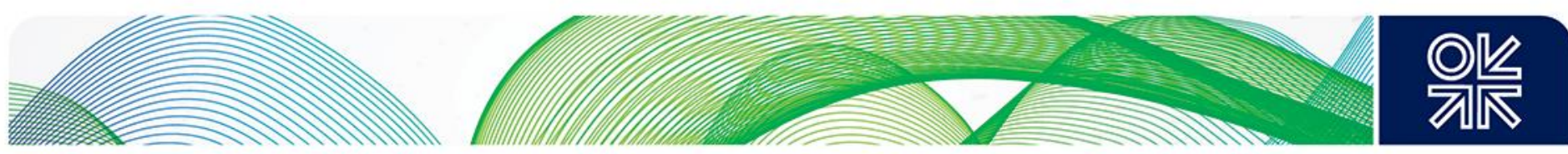

With the increase of hub trading liquidity and the move towards market based prices across Europe, the scope of the present analysis may be extended, both "geographically" - to include more market zones - and "temporarily" - in particular analysing the alignment in prices for gas delivered more distantly in the future or for gas delivered within-day. The within day dimension is particularly relevant in the light of the new gas balancing regime envisaged by European regulation ${ }^{105}$.

As far as the geographical dimension is concerned, it needs to be stressed that this work has focussed on North West, Central Europe and Italy. In Spain and South East Europe hub development is still at an early stage or absent, so that market prices have not developed yet and gas prices in these markets may be not be in line with those where gas hubs have already been developed. Once again however, new infrastructure, and especially planned interconnections with markets further north, accompanied by rules for the optimization of the transmission capacity use, can be expected to align these markets with hub prices over the next several years.

The geographical scope of the analysis could even be enlarged to assess the factors leading to increasing or reducing price integration between Europe and other gas consuming regions.

Finally the work suggests that, even in a mature and well integrated European gas market, it may happen that for some periods, as a consequence of changes in gas flow patterns across Europe, a hub may split from the others and display a price dynamic which is completely different compared to the others, possibly resulting in higher costs.

A natural follow up for this work would then be simulating future bottlenecks in the European gas grid, as well as the corresponding price de-linkages, in the possible scenarios for key global gas fundamentals post 2015, as identified by recent OIES research ${ }^{106}$. Anticipating the future bottlenecks would then help to assess whether there is a case for developing suitable frameworks/incentives aimed at mitigating the potential future factors reducing price integration in the European gas market.

\section{Appendix 1. Methodological notes on data creation}

\section{Price and volume data creation}

Raw data from brokers (specifically the Tankard Parties) and exchange websites were assembled and sampled to obtain streams of daily historical price data and related total daily traded volumes for the selected traded contracts, building up a database of prices and volumes prevailing at the main European gas trading hubs.

The data set has separate daily price series for exchange traded and OTC traded products, to check for any difference when comparing broadly equivalent contracts.

Note that exchange cleared OTC transactions were excluded (so called "given up for clearing" OTC trades or "OTC broker give up") from OTC trades, as although they are recorded by brokers these trades effectively occurred via exchanges.

\section{Computation of daily average prices}

The daily price was computed as the volume-weighted average of the prices of the transactions occurring in a day. However, this average may be computed averaging over either:

(1) prices of trades executed within a restricted time period (the so called "settlement window") at the end of the trading day (obtaining an End of Day Price also known as Settlement Price) or

\footnotetext{
${ }^{105}$ EU Regulation 312/2014 on a European Network Code on Gas Balancing, which should start to be applied from October 2015.

${ }^{106}$ Rogers (2015)
} 

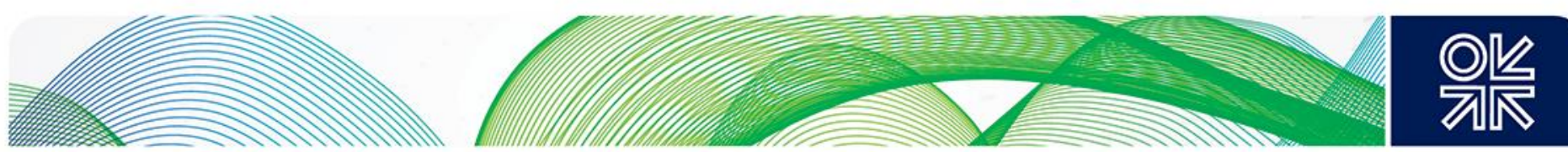

(2) all the orders executed within the whole trading day (obtaining a Daily Average Price).

We chose a Daily Weighted Average Price rather than a Settlement Price. It is worth noticing that the latter is usually considered as a price reference by Price Reporting Agencies and Settlement Prices are published by exchanges (EEX for instance).

\section{Traded volume}

Total traded volume for a single trade is the daily flow rate volume multiplied by the number of days in the corresponding contract. For instance if two parties conclude a Calendar Year 2014 contract and commit to the delivery of a daily lot size of $240 \mathrm{MWh} / \mathrm{d}$, we count the corresponding total traded volume as $240 * 365 \mathrm{MWh}$.

Unit of measurement and conversion factor

All price data is in $€ / M W h$ and volumes are in MWh. NBP and ZEE prices, originally expressed in pence/therm, were converted to $€ / M W h$ assuming a conversion factor of $29.3071 \mathrm{MWh} / 1000$ therms.

We converted pence/therm prices into $€ / M W h$ prices using the daily average euro/GB sterling exchange rate as published by OANDA ${ }^{107}$. The relevant exchange rate is the daily average euro/GB sterling exchange rate of the day of the trade for all products.

\section{Exchange price data}

The sources are the following.

Table 1: Sources for exchange prices used in this study

\begin{tabular}{|l|l|}
\hline Contract & Source \\
\hline PEGN DA & Powernext \\
\hline PEGS DA & Powernext \\
\hline
\end{tabular}

PEGN and PEGS DA exchange price data are based on Powernext exchange data (prices quoted in $€ / M W h$, volumes in $M W h)^{108}$. The Powernext website provides Powernext Gas Spot Daily Prices (Daily Average Price) and historical data on all the trades executed each day on Powernext.

\footnotetext{
${ }^{107}$ http://www.oanda.com/currency/historical-rates/

${ }_{108}$ Powernext data, including the comprehensive record of all the trades concluded on the spot and future market, are free to download on the website 


\section{Appendix 2. Methodology to compute firm technical capacity and capacity utilization rate from NCG to PSV}

Gas can flow from NCG to the PSV exiting Germany at Wallbach IP, then passing through Switzerland and finally entering the Italian gas system at Gries Pass IP on the IT-CH border.

\section{Transmission capacity at Wallbach IP (direction from Germany to Switzerland)}

A simplified representation of Wallbach IP is presented below.

$\begin{array}{ll}\text { IP side 1 } & \text { IP side 2 } \\ \text { (DE to } & \text { (DE to } \\ \mathrm{CH}) & \mathrm{CH} \text { ) }\end{array}$
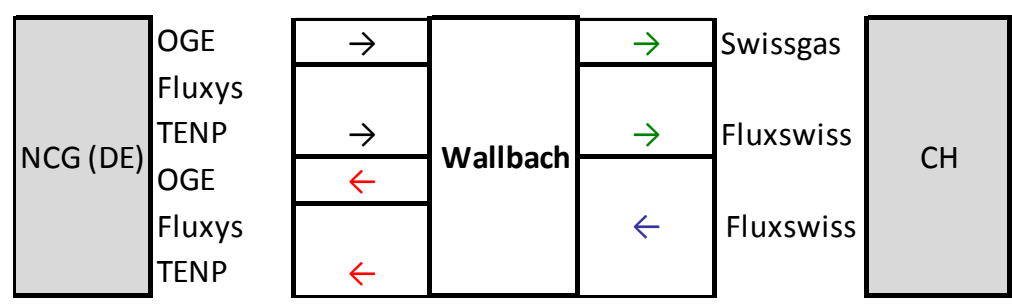

$\begin{array}{ll}\text { IP side 2 } & \text { IP side 1 } \\ \text { (CH to } & \text { (CH to } \\ \text { DE) } & \text { DE) }\end{array}$

Capacity made available by OGE and Fluxys TENP to exit NCG (black arrows in the scheme) ranged between 582 and $524 \mathrm{GWh} / \mathrm{d}$ in 2014.

Firm Technical Capacity data for Wallbach IP, from DE to $\mathrm{CH}$, exit side (GWh/d)

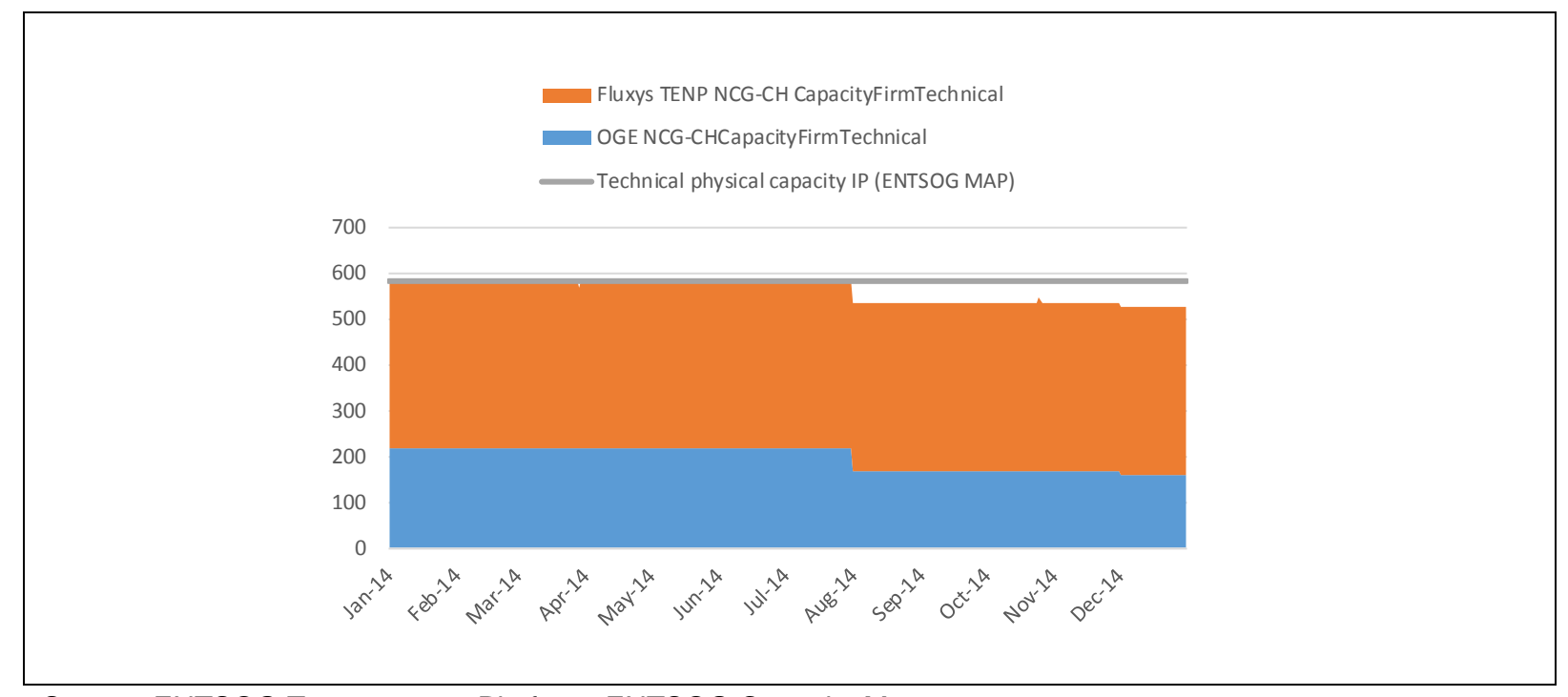

Source: ENTSOG Transparency Platform, ENTSOG Capacity Map 

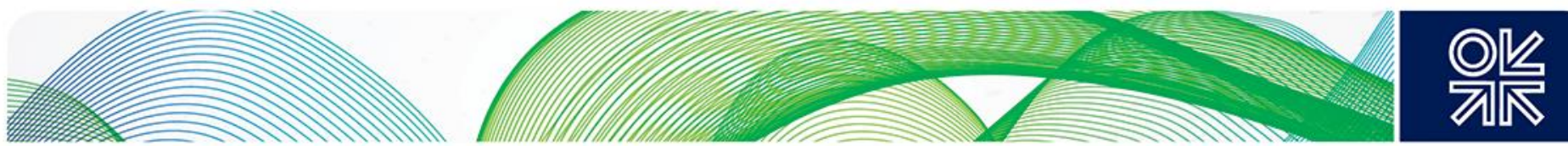

The data for capacity made available at Wallbach by Swissgas and Fluxswiss to enter Switzerland (green arrows in the scheme) is not available on data provided by ENTSOG Transparency Platform.

However, we can limit our analysis to the exit side from Germany to Switzerland because we assume there is no disparity between the capacities available at the two sides of the Wallbach IP, contrary to what occurs at Oberkappel. In fact the technical capacity on the German side is not greater than that published on the ENTSOG Capacity Map, which is calculated according to the "lesser-of-rule" (587 $\mathrm{GWh} / \mathrm{d}$ ). In other words, capacity on the Swiss side cannot be smaller than that on the German side, as, otherwise, Wallbach IP capacity (in the Germany to Switzerland direction) calculated according to the "lesser-of-rule" would be lower.

In order to compute utilization rates we assume that physical flows data reported by Fluxys TENP represents total physical flows for Wallbach IP, in the direction from Germany to Switzerland.

\section{Physical Flows and Technical Firm Capacity data for Wallbach IP, exit side, direction from DE to $\mathrm{CH}(\mathrm{GWh} / \mathrm{d})$}

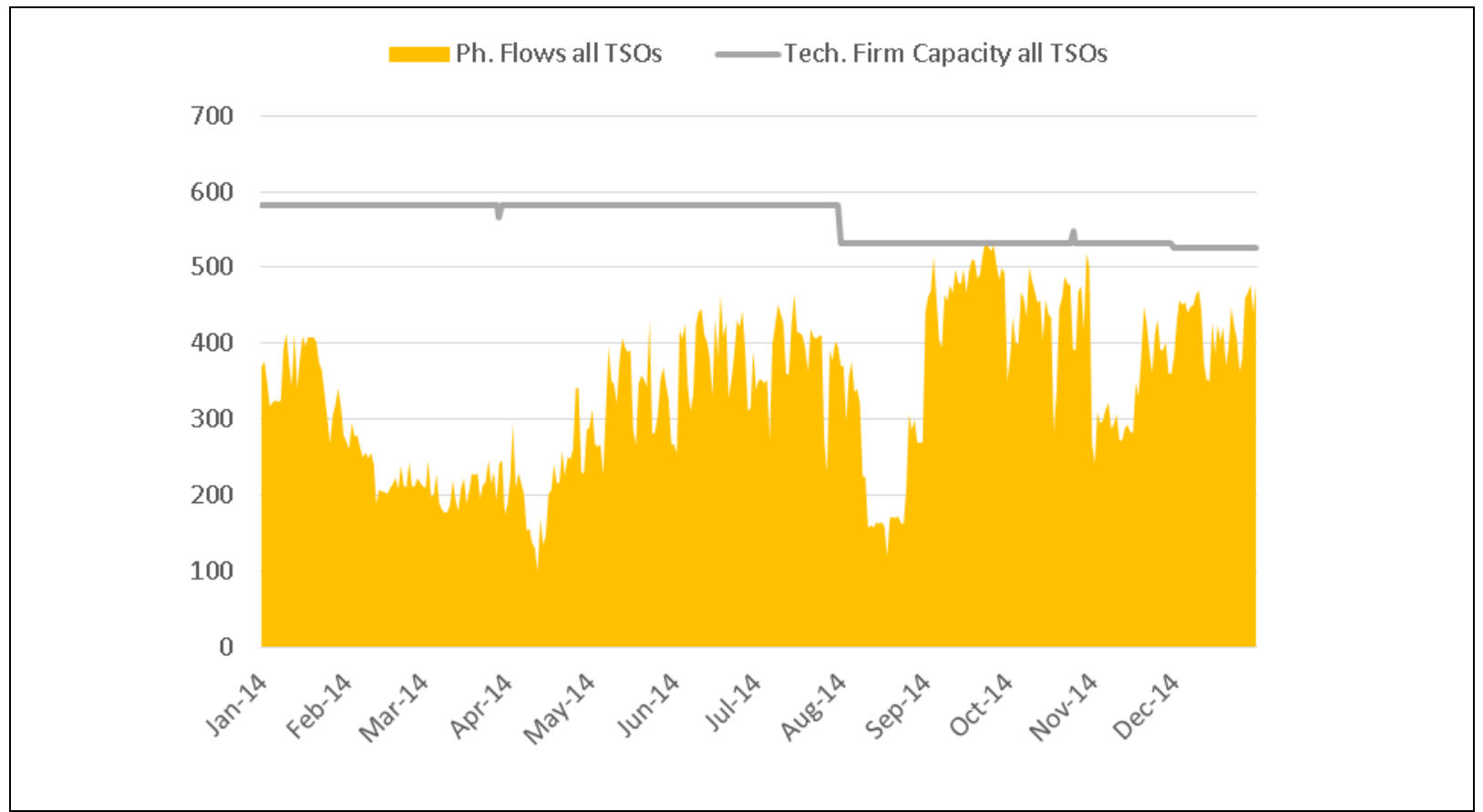

Source: ENTSOG Transparency Platform

Monthly flow data published by IEA confirm that flows from Germany to Switzerland stayed below the maximum technical capacity in 2014. 

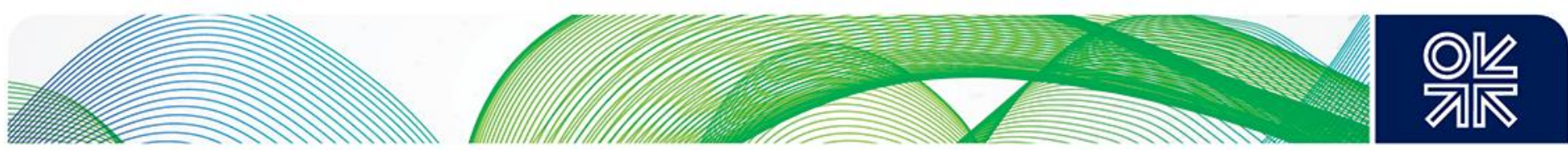

Monthly Flows and Maximum Technical Capacity data for Wallbach IP (direction from DE to CH) (GWh/month)

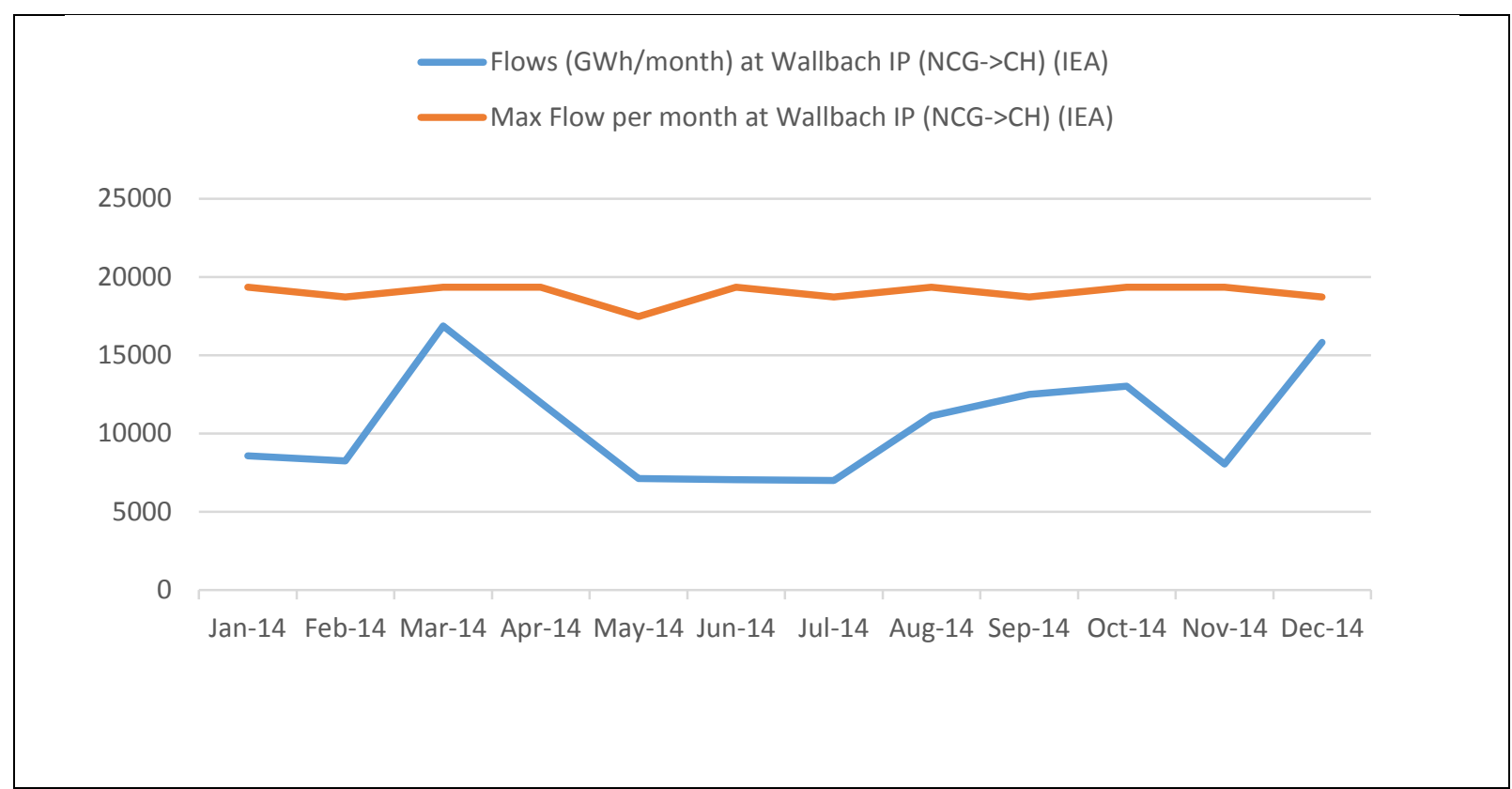

Source: IEA

Transmission capacity at Gries Pass IP (direction from Switzerland to Italy)

A simplified representation of Gries Pass IP is presented below.

IP side 1

IP side 2

$(\mathrm{CH}$ to

$(\mathrm{CH}$ to

IT)

$\mathrm{IT})$

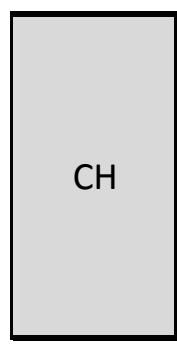
Swissgas
FluxSwiss
Swissgas
FluxSwiss
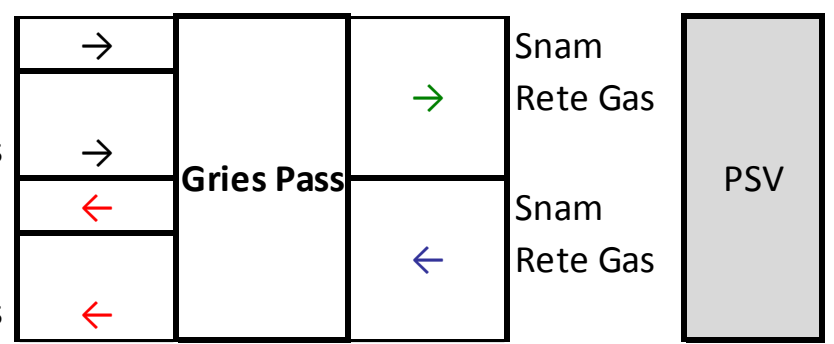

$\begin{array}{ll}\text { IP side 2 } & \text { IP side 1 } \\ \text { (IT to } & \text { (IT to } \\ \text { CH) } & \text { CH) }\end{array}$

Firm capacity made available at Gries Pass IP by Snam Rete Gas to enter the Italian gas system ranged between 624 and $682 \mathrm{GWh} / \mathrm{d}$ in 2014. Data for capacity made available on the Swiss side by Swissgas and FluxSwiss is not available in ENTSOG Transparency Platform data, however we can assume that less capacity is available on the Swiss side than on the Italian side as the capacity 

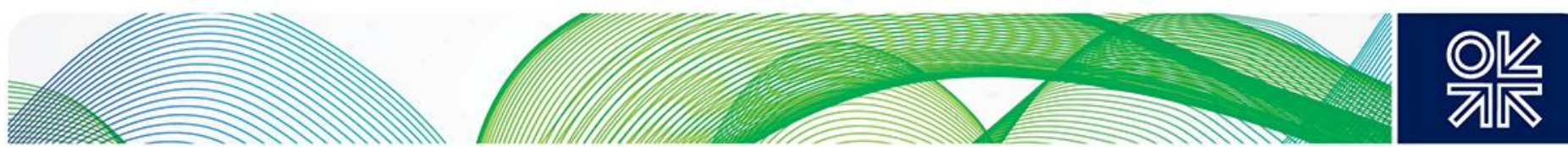

published on the ENTSOG Capacity Map is lower than that on the Italian side (627.2 GWh/d). In order to compute utilization rate at Gries Pass IP we therefore consider the capacity published on the ENTSOG Capacity Map.

\section{Firm Technical Capacity data for Gries Pass from CH to IT (GWh/d)}

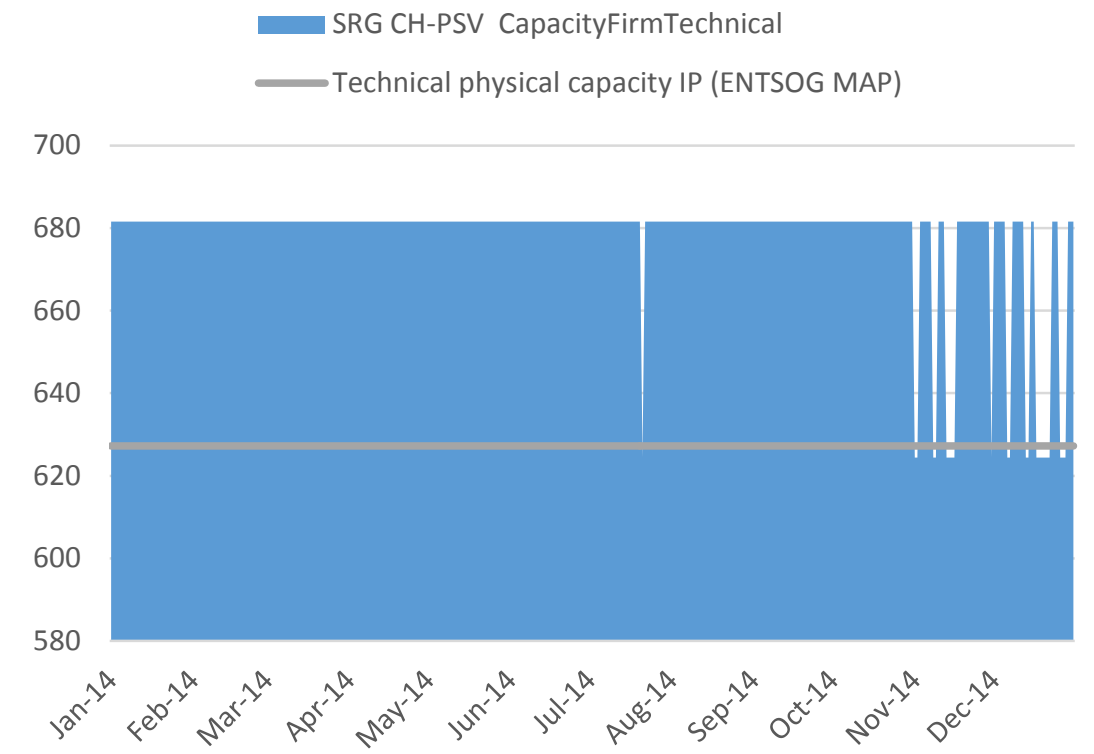

Source. ENTSOG Transparency Platform, ENTSOG Capacity Map

In order to compute utilization rates we assume that physical flows data reported by Snam Rete Gas represents total physical flows for Gries Pass IP, in the direction from Switzerland to Italy.

Flows and Capacity data for Gries Pass IP, entry side, direction from CH to PSV (GWh/d)

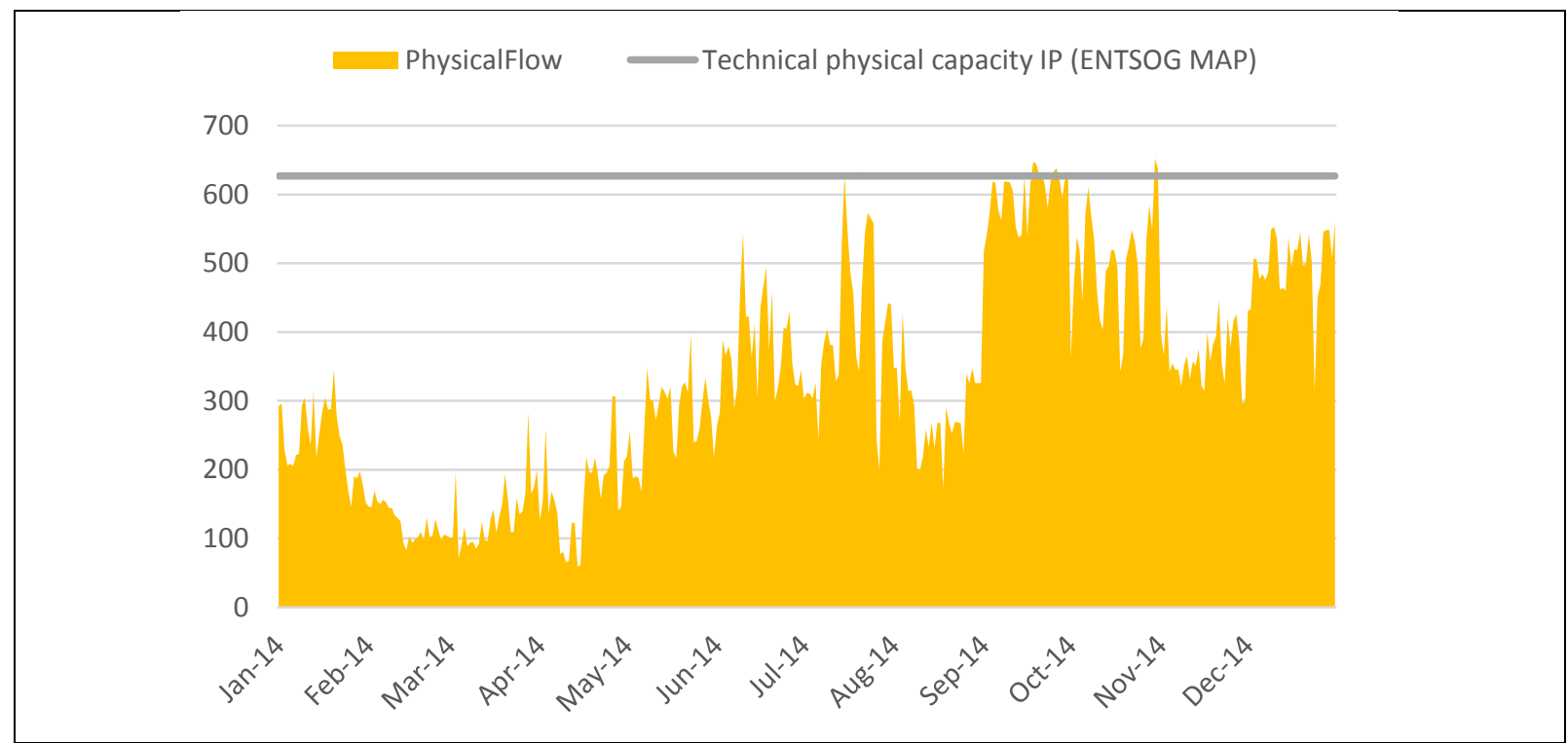

Source: ENTSOG Transparency Platform, ENTSOG Capacity Map

Monthly flow data published by IEA confirm that flows from Switzerland to Italy stayed below the maximum technical capacity in 2014. 

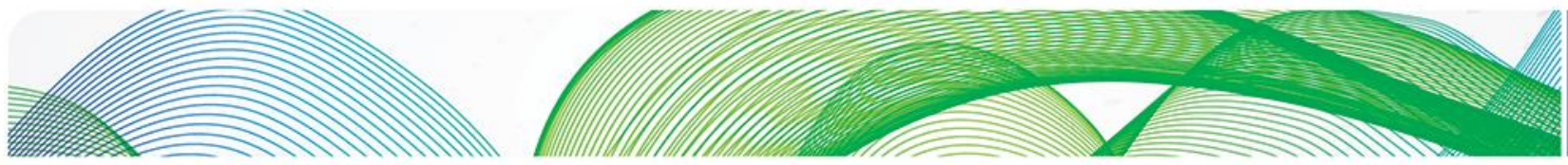

Monthly flows and maximum Technical Capacity data for Gries Pass IP (direction from $\mathrm{CH}$ to IT) (GWh/month)

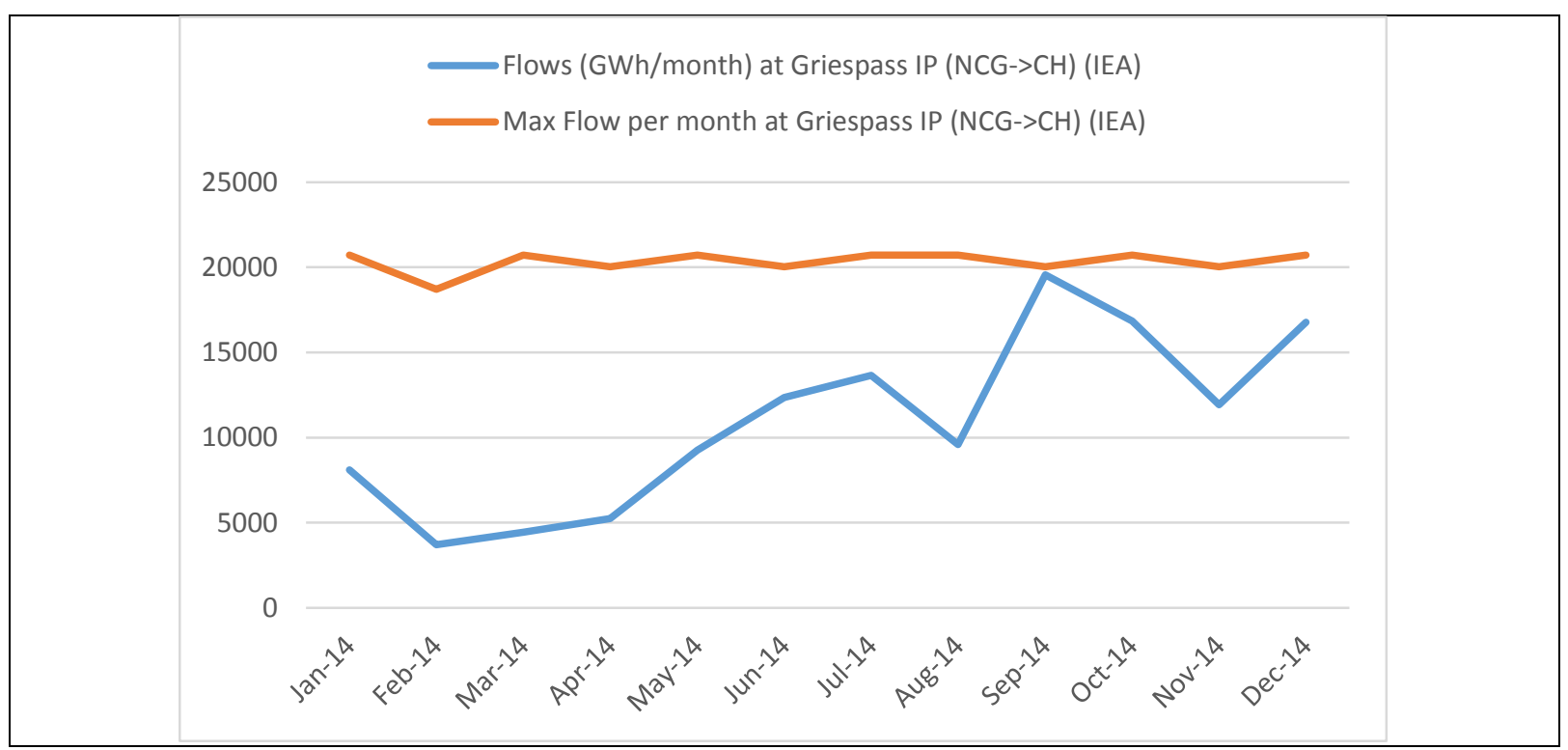

Source: IEA 

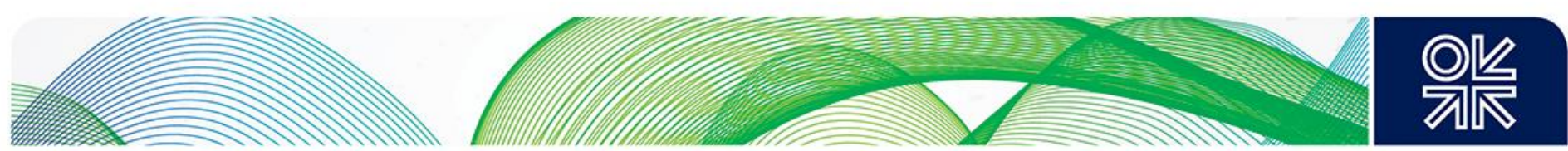

\section{Glossary}

ACER: Agency for the Cooperation of Energy Regulators

Bcm: One billion cubic metres.

Box-plot: A box-plot is a way of summarizing a set of data measured on an interval scale. It is often used in exploratory data analysis. It is a type of graph which is used to show the shape of the distribution, its central value, and variability. Box plots have a main rectangular body (the box itself) and lines extending vertically from the box (so called whiskers). The bottom and top of the box are the first and third quartiles, and the band inside the box is the median; the ends of the whiskers represent the upper and lower adjacent values: the largest value smaller or equal to upper quartile + 1.5 IQR (where IQR is the interquartile range, a measure of statistical dispersion, being equal to the difference between the upper and lower quartiles, IQR $=Q_{3}-Q_{1}$ ) and the smallest value greater or equal to the lower quartile - 1.5 IQR. Any points more extreme then the upper and lower adjacent values are represented as dots. The length of the box represents the IQR and helps indicate the degree of dispersion (volatility) in the data: the more stretched the box is, the more variable prices are within the year. The length of the whiskers is another measure of dispersion; while dots identify outliers, i.e. isolated price peaks or troughs that do not fit the general trend.

Broker: a party who intermediates and facilitates bilateral contracts to be concluded between a buyer and a seller.

CAM: Capacity allocation mechanisms. Rules on CAM are contained in EU Regulation 384/2013.

Capacity hoarding: an action aiming to prevent access to capacity available on the transport network, deemed as an abuse of dominant position.

CEGH: Central European Gas Hub. For the sake of easy comparison to previous papers by this Author we simply name the Austrian gas hub CEGH. However it should be noted that strictly speaking CEGH is only the name of the exchange operator now, not the name of the trading hub/point, which is VTP. More specifically, with the launch of the new Austrian Gas Act in January 2013, trading within the Austrian market changed from a flange-based system to an Entry/Exit regime and trading activities began to be centralized at the Virtual Trading Point (VTP), which is operated by CEGH.

CMP: Congestion management procedures

Coefficient of variation (CV): Normalized measure of dispersion of a frequency distribution: the ratio of the standard deviation to the mean. The actual value of the $\mathrm{CV}$ is independent of the unit in which the measurement has been taken, so it is a dimensionless number and, for comparison between data sets with different units or widely different means, the coefficient of variation is preferred to the standard deviation.

Co-integration analysis: Econometric technique developed for the analysis of time series.

Congestion Management Procedures (CMP) Guidelines: Commission Decision of 24 August 2012 on amending Annex I to Regulation (EC) No 715/2009 of the European

Parliament and of the Council on conditions for access to the natural gas transmission networks (2012/490/EU), OJL 213/16, 28.8.2012

Contract settlement: Resolution of a contract at its expiry. A contract may be settled through physical delivery, by cash settlement or by settling the payment and "giving up the volume" to an exchange, that is by tendering the quantity of gas on an exchange platform for whatever price it can be sold for. 

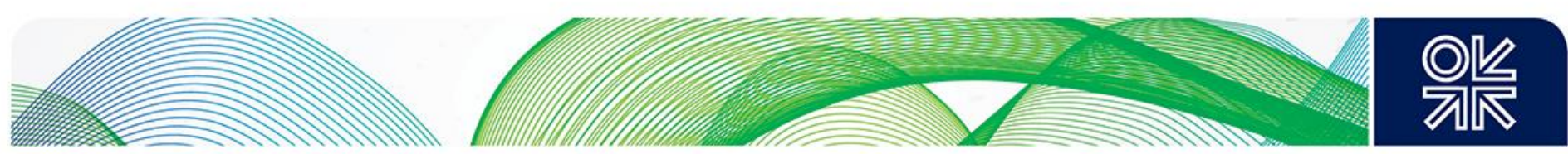

Correlation: (see Pearson Product-Moment Correlation coefficient)

Day ahead (DA) contract/product: Contract for the purchase or sale of gas to be delivered the day after the trading date.

Delivery/net physical delivery: The moment when a player makes a nomination to the system operator, who in turn uses this input to compute the total volume to be injected/withdrawn into the grid. Nomination is made before gas has to be injected/withdrawn into the grid. In the UK nomination has to be made for gas to be injected/withdrawn into the grid the following day (day $d$ ). A player nomination is computed by netting off all the traded volumes relating to the day ahead.

Entry-exit system A system where gas can be traded independently of its location in the pipeline system, with the possibility for network users to book entry and exit capacity independently, creating gas transport through zones instead of along contractual paths.

Exchange trade: Anonymous and regulated trade whereby the buyer and the seller of gas have the exchange operator as a central counterparty operating as a clearing house.

Financial trade: Trade which is settled without the actual delivery of gas but rather through a cash payment, normally of the difference between the agreed price and the outturn spot price.

Firm Day ahead Use it or Lose it: see Use it or Lose it

Forward gas contract: Contract for the purchase or sale of gas to be delivered on a future agreed date (delivery date).

Gross traded volumes (traded volumes): The total gas amounts that are traded on each hub which are usually a multiple of the physical quantity that is actually delivered on the grid. Traded volumes can exceed consumed physical volumes in a commodity market as quantities can be bought and sold many times prior to delivery.

GSL: Gaspool, gas hub based in Germany.

GTM (Gas Target Model): Conceptual model for the single European gas markets originally developed by CEER in 2011, and updated in 2015.

H-gas: High-calorific gas (also called H-gas or high gas) is the highest quality natural gas due to its high methane content (between $87 \%$ and $99 \%$ ).

HHV: The higher heating value (HHV: also known as the gross calorific value or gross energy) of a fuel is defined as the amount of heat released by a specified quantity (initially at $25^{\circ} \mathrm{C}$ ) once it is combusted and the products have returned to a temperature of $25^{\circ} \mathrm{C}$. It thus includes the latent heat of condensation of water in the combustion products.

Hub (gas hub): A virtual or physical location within the grid where the exchange of gas volumes takes place. In fact a gas hub is a market for gas, where the commodity is traded on a standardized basis between market participants. In this paper each hub represents a different price area.

Interconnection Point: Means a location, whether it is physical or virtual, between two or more EU Member States as well as between two adjacent entry-exit-systems within the same Member State, where the pipeline systems of the two adjacent Member States or entry exit systems join.

Interconnector (IUK): The bi-directional pipeline allowing the flow of gas from Britain to Belgium and vice versa.

Interquartile range (IQR): A measure of statistical dispersion, used also for non parametric data, being equal to the difference between the upper and the lower quartiles: Q3-Q1. It measures volatility in absolute terms. 

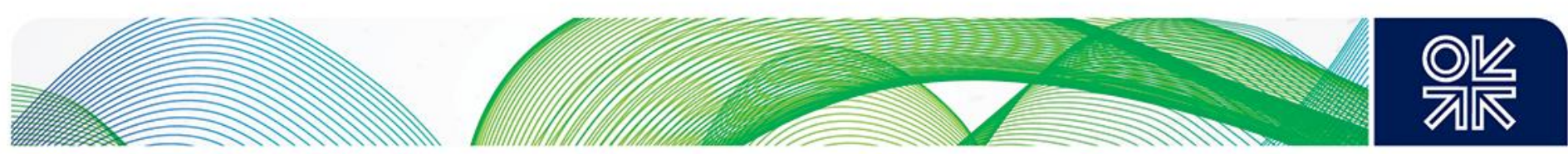

JTS: Joint Transport Storage: Capacity at the North-South link available thanks to the joint optimisation of GRTgaz's system and Storengy's storage facilities, sold by GRTgaz on a day-ahead basis

kWh: A unit of energy equivalent to a Kilowatt of power for the duration of one hour.

LEBA volume report: Regular monthly volume report covering the main gas, power, coal and emission markets, published by LEBA. LEBA volume data are available from January 2011.

LEBA: The London Energy Brokers' Association, is the industry association representing the FSA regulated wholesale market brokers in the over the counter (OTC) and the exchange traded UK and liberalised European energy markets. The major products that they deal in include crude oil and refined petroleum products, gas, electricity and emissions.

L-gas: Low-calorific gas (L-gas or low gas) is natural gas with a lower methane content of between $80 \%$ and $87 \%$.

LTC: Long term contract for the sale and purchase of natural gas.

Long Term Use it or Lose it: see Use it or Lose it

mcm: One million cubic metres.

Month ahead (MA) or front month contract/product: Contract for the purchase or sale of gas to be delivered in the month after the trading date.

MWh: A unit of energy equivalent to a Megawatt of power for the duration of one hour.

NBP: National Balancing Point, gas hub based in Great Britain.

NCG: Net Connect Germany, gas hub based in Germany.

OTC (over the counter) trades: Bilateral non-regulated trade however involving standardized physical and financial deals. Such trades are based on standard agreements defining the point of delivery for gas along with other technical and legal terms. They can be for standard volumes of clip sizes of gas and multiples thereof.

Pearson Product-Moment Correlation coefficient (Pearson coefficient, $r$ ): Statistical metric which measures the strength of the linear relationship (linear correlation) between two data series. The correlation coefficient always takes a value between -1 and 1 , with 1 or -1 indicating perfect correlation (all points would lie along a straight line in this case). A positive correlation indicates a positive association between the variables (increasing values in one variable correspond to increasing values in the other variable), while a negative correlation indicates a negative association between the variables (increasing values in one variable correspond to decreasing values in the other variable). A correlation value close to 0 indicates no association between the variables.

PEGN: Point d'Echange de Gaz Nord (Peg North), gas hub based in the North of France, coinciding with GRTgaz network.

PEGS: Point d'Echange de Gaz Sud (Peg South), gas hub based in the South of France. On April 1, 2015, the PEG TIGF and PEG Sud hubs merged to form a single gas hub to be named Trading Region South (TRS).

PEGT: Point d'Echange de Gaz TIGF (Peg South), gas hub based in the South of France. On April 1, 2015, the PEG TIGF and PEG Sud hubs merged to form a single gas hub to be named Trading Region South (TRS).

Physical trade: Trade which is settled at expiry by the actual delivery of gas.

Price correlation: When prices move closely in parallel over time.

Price de-linkage: Period of low price correlation. 

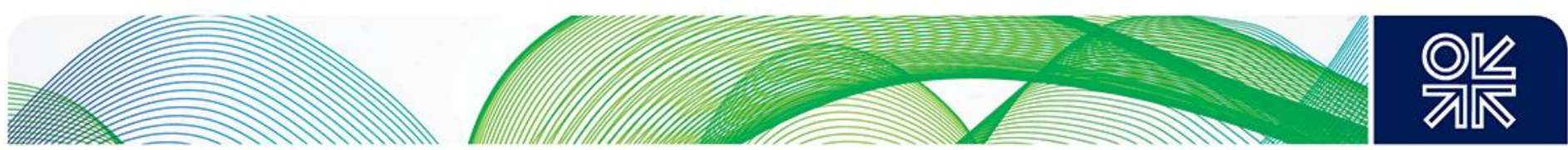

PSV: Punto di Scambio Virtuale, the Italian gas hub.

Relative law of one price: In a competitive market the price of a homogeneous good should tend towards uniformity, allowances being made for transportation and other transaction costs.

Scatter plot: Useful summary of a set of bivariate data (two variables), usually drawn before working out a linear correlation coefficient or fitting a regression line. It is a mathematical diagram using Cartesian coordinates plotting one variable against the other. It gives a good visual picture of the relationship between the two variables, and aids the interpretation of the correlation coefficient or regression model. Each unit contributes one point to the scatterplot, on which points are plotted but not joined. The resulting pattern indicates the type and strength of the relationship between the two variables.

Significance level: In statistics and probability theory, is the low probability of obtaining at least as extreme results given that the null hypothesis is true

Standard deviation: In statistics and probability theory, the standard deviation (SD) (represented by the Greek letter sigma, $\sigma$ ) measures the amount of variation or dispersion from the average. A low standard deviation indicates that the data points tend to be very close to the mean (also called expected value); a high standard deviation indicates that the data points are spread out over a large range of values.

Tankard Parties: Tankard is an industry initiative created and developed by ICAP Energy Limited (ICAP), Marex Spectron Group (Marex Spectron) and Tullett Prebon Group Limited (Tullett Prebon).

TENP: The gas pipeline that runs across German territory from Bocholtz, at the Dutch border, to the Swiss border, close to Wallbach, where it joins Transitgas.

Transitgas: The gas pipeline that crosses Switzerland from Wallbach at the German border to Passo Gries (Gries Pass) at the Italian border. At Wallbach Transitgas joins the Trans Europa Naturgas Pipeline (TENP), at Passo Gries it joins the Italian network.

Transmission System Operator (TSO): The company responsible for transmission system operation. Some countries have one gas TSO, others have several TSOs.

TRS: Trading Region South, French hub located in the South of France. On April 1, 2015, the PEG TIGF and PEG Sud hubs merged to form a single gas hub to be named Trading Region South (TRS).

TTF: Title Transfer Facility, gas hub based in the Netherlands.

Use-it-or-lose-it (UIOLI): Congestion management provision whereby the transmission capacity which is not nominated (used) by the original owner is made available (lost by the original owner) to other shippers. European rules foresee a "long term" UIOLI and a "day ahead" UIOLI.

WAG: Bidirectional pipeline running from Oberkappel to Baumgarten, Austria. Oberkappel is the IP located at the extreme of WAG located on the Germany-Austria border, Baumgerten is the IP located at the extreme of WAG located on the Austria-Slovakia border. WAG can be used in a flexible way for arbitrage flows. Through WAG Austria can import gas directly from NCG, and gas coming mostly from Russia can also flow through this pipeline in the opposite direction.

WAP: Weighted average price.

ZEE: Zeebrugge, gas hub based in Belgium. 

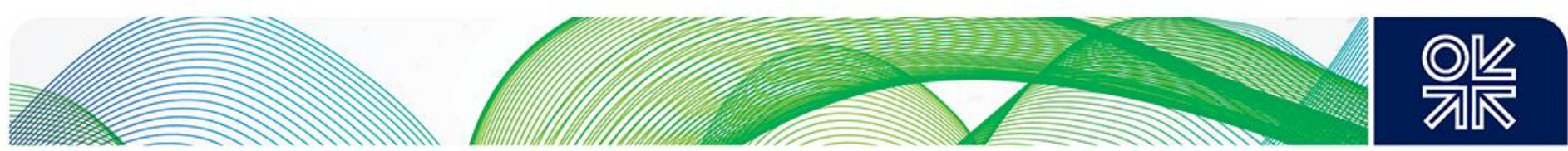

\section{Bibliography}

ACER (2013): ACER Annual Market Monitoring Report 2013

http://www.acer.europa.eu/Official documents/Acts of the Agency/Publication/ACER\%20Market\%2 0Monitoring\%20Report\%202013.pdf

ACER (2014a): ACER Annual Market Monitoring Report 2014,

http://www.acer.europa.eu/Official_documents/Acts_of_the_Agency/Publication/ACER_Market_Monit oring_Report_2014.pdf

ACER (2014b): ACER Annual report on congestion at interconnection points in Q4/2013,

http://www.acer.europa.eu/Official documents/Acts of the Agency/Publication/ACER\%20Gas\%20C ontractual\%20Congestion\%20Report\%202014.pdf

ACER (2015a): ACER, European Gas Target Model -review and update, http://www.acer.europa.eu/Events/Presentation-of-ACER-Gas-Target-Model-

/Documents/European\%20Gas\%20Target\%20Model\%20Review\%20and\%20Update.pdf

ACER (2015b): ACER, Congestion Management Procedures Implementation Monitoring Report 2014, http://www.acer.europa.eu/Official_documents/Acts_of_the_Agency/Publication/ACER\%20CMP\%20I mplementation\%20Monitoring\%20Report\%202014.pdf

ACER (2015c): ACER Annual report on congestion at interconnection points in 2014, http://www.acer.europa.eu/Official_documents/Acts_of_the_Agency/Publication/20150529_ACER\%2 02015\%20Report\%20on\%20Congestion\%20at\%20IPs\%20in\%202014.pdf

Boisseleau (2004): Boisseleau, F. The role of power exchanges for the creation of a single European electricity market: market design and market regulation, Phd Dissertation Thesis, Université Paris IX Dauphine, France, http://repository.tudelft.nl/view/ir/uuid\%3Aadaa3685-ff74-4ad6-b765-

$752 \mathrm{f} 1 \mathrm{a} 673 \mathrm{c} 4 \mathrm{c} /$

CEER (2011): CEER Vision for a European Gas Target Model. Conclusions Paper, Ref: C11-GWG82-03, 1 December 2011. Available at http://www.energy-

regulators.eu/portal/page/portal/EER HOME/EER PUBLICATIONS/CEER PAPERS/Gas/Tab/C11GWG-82-03 GTM\%20vision Final.pdf

CRE (2014): CRE, Electricity and Gas Market Observatory 3Q 2014 available at:

http://www.cre.fr/en/markets/electricity-and-gas-market-observatory

Doane and Spulber (1994): Doane, J. M. and Spulber D. F. (1994). 'Open access and the evolution of the U.S. spot market for natural gas' Journal of Law and Economics, Vol. 37, No. 2, pp. 477-517.

EFET (2014): EFET, Position Paper: Towards efficient and effective congestion management of the European gas transmission network: Difficulties with the current implementation approaches and possible solutions, October 2014 , http://www.efet.org/Cms Data/Contents/EFET/Folders/Documents/EnergyMarkets/GasPosPprs/2005 Today/ contents/9V62KSAY8JWZ977M/EFET PP CMP 01102014.pdf 

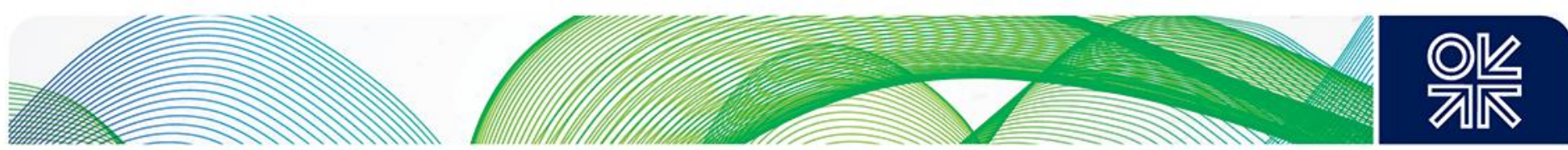

Heather (2012): Heather, Patrick, Continental European Gas Hubs: are they fit for purpose?, NG 63, OIES, June 2012. http://www.oxfordenergy.org/2012/06/continental-european-gas-hubs-are-they-fitfor-purpose/

Petrovich (2013): Petrovich, Beatrice, European gas hubs: how strong is price correlation? NG79, OIES, October 2013. http://www.oxfordenergy.org/2013/10/european-gas-hubs-how-strong-is-pricecorrelation-2/

Petrovich (2014): Petrovich, Beatrice, European gas hubs price correlation: barriers to convergence? NG91, OIES, September 2014. http://www.oxfordenergy.org/2014/09/european-gas-hubs-pricecorrelation-barriers-to-convergence/

Stern et al. (2014): Stern J. at al., Reducing Dependence on Russian Gas: distinguishing natural gas security from geopolitics, NG92, OIES, http://www.oxfordenergy.org/2014/10/reducing-europeandependence-on russian-

gas-distinguishing-natural-gas-security-from-geopolitics/

Stern and Rogers (2011): Stern, J. and Rogers, H. The Transition to Hub-Based Gas Pricing in Continental Europe, NG49, OIES, March 2011, http://www.oxfordenergy.org/wpcms/wpcontent/uploads/2011/03/NG49.pdf

Rogers, H. (2015): Rogers, Howard, The Impact of Lower Gas and Oil Prices on Global Gas and LNG Markets', NG 99, OIES, July 2015, http://www.oxfordenergy.org/2015/07/the-impact-of-lower-gas-andoil-prices-on-global-gas-and-Ing-markets/ 